PNNL-15353

Pacific Northwest National Laboratory

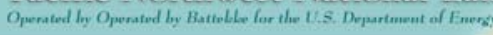

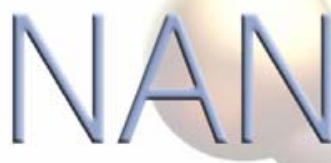

Science, Engineering, and Technology

\title{
Joint Institute for Nanoscience Annual Report, 2004
}




\title{
DISCLAIMER
}

This report was prepared as an account of work sponsored by an agency of the United States Government. Neither the United States Government nor any agency thereof, nor Battelle Memorial Institute, nor any of their employees, makes any warranty, express or implied, or assumes any legal liability or responsibility for the accuracy, completeness, or usefulness of any information, apparatus, product, or process disclosed, or represents that its use would not infringe privately owned rights. Reference herein to any specific commercial product, process, or service by trade name, trademark, manufacturer, or otherwise does not necessarily constitute or imply its endorsement, recommendation, or favoring by the United States Government or any agency thereof, or Battelle Memorial Institute. The views and opinions of authors expressed herein do not necessarily state or reflect those of the United States Government or any agency thereof.

\author{
PACIFIC NORTHWEST NATIONAL LABORATORY \\ operated by \\ BATTELLE \\ for the \\ UNITED STATES DEPARTMENT OF ENERGY
}

under Contract DE-AC06-76RL01830

Printed in the United States of America

Available to DOE and DOE contractors from the

Office of Scientific and Technical Information,

P.O. Box 62, Oak Ridge, TN 37831-0062;

ph: (865) 576-8401

fax: (865) 576-5728

email: reports@adonis.osti.gov

\begin{abstract}
Available to the public from the National Technical Information Service, U.S. Department of Commerce, 5285 Port Royal Rd., Springfield, VA 22161 ph: (800) 553-6847 fax: (703) 605-6900

email: orders@ntis.fedworld.gov

online ordering: http://www.ntis.gov/ordering.htm
\end{abstract}

This document was printed on recycled paper.

$(8 / 00)$ 
PNNL-15353

Joint Institute for Nanoscience Annual Report, 2004

Donald R. Baer

Charles T. Campbell

Co-Directors of the Joint Institute for Nanoscience

July 2005 


\section{Summary}

Due to the inherently interdisciplinary nature of nanoscience and nanotechnology, research in this arena is often significantly enhanced through creative cooperative activities. The Joint Institute for Nanoscience (JIN) is a venture of the University of Washington (UW) and Pacific Northwest National Laboratory (PNNL) to encourage and enhance high impact and high quality nanoscience and nanotechnology research that leverages the strengths and capabilities of both institutions, and to facilitate education in these areas. This report summarizes JIN award activities that took place during fiscal year 2004 and provides a historical list of JIN awardees, their resulting publications, and JIN-related meetings. Major portions of the JIN efforts and resources are dedicated to funding graduate students and postdoctoral research associates to perform research in collaborations jointly directed by PNNL staff scientists and UW professors. JIN fellowships are awarded on the basis of applications that include research proposals. They have been very successful in expanding collaborations between PNNL and UW, which have led to many excellent joint publications and presentations and enhanced the competitiveness of both institutions for external grant funding. JIN-based interactions are playing a significant role in creating new research directions and reshaping existing research programs at both the UW and PNNL. The JIN also co-sponsors workshops on Nanoscale Science and Technology, four of which have been held in Seattle and one in Richland. In addition to involving PNNL staff in various UW nanoscience courses and seminars, a National Science Foundation grant, Development of UW-PNL Collaborative Curriculums in Nano-Science and Technology, has allowed the development of three intensive short courses that are taught by UW faculty, PNNL staff, and faculty from other institutions, including Washington State University, the University of Idaho, Stanford University, and the University of Alaska. The JIN agreement recognizes that cooperation beyond UW and PNNL is highly valuable. Starting in early 2003, efforts were initiated to form a regional communication link called the Northwest Nanoscience and Nanotechnology Network $\left(\mathrm{N}^{4}\right)$. In concept, $\mathrm{N}^{4}$ is a tool to encourage communication and help identify regional resources and nanoscience and technology activities.

In addition to an overview of JIN activities, this report includes summaries of individual JIN Award Projects, an assessment of the impact of the JIN, and a list of publications, presentations and external funding that can be linked to JIN activities. 


\section{Contents}

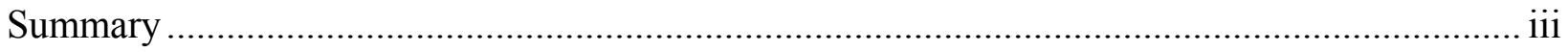

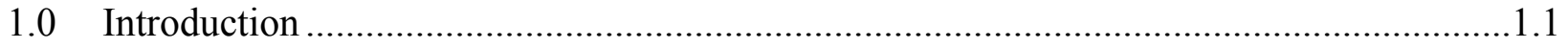

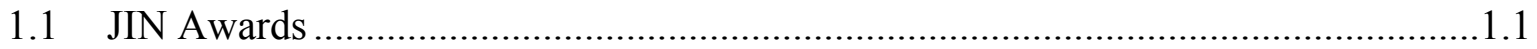

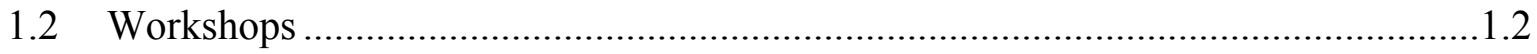

1.3 JIN Related Education Programs ...........................................................................1.3

1.4 Northwest Nanoscience and Nanotechnology Network ………................................1.3

1.5 JIN Organization..........................................................................................

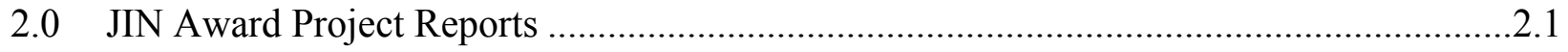

$2.1 \quad$ Awards Authorized, February 2003 …………………........................................2.1

2.2 Awards Authorized, June 2003 ...........................................................................2.24

2.3 Awards Authorized September 2003 ………………...........................................2.45

2.4 Awards Authorized February 2004 ....................................................................2.61

Conference presentations ..........................................................................................2.66

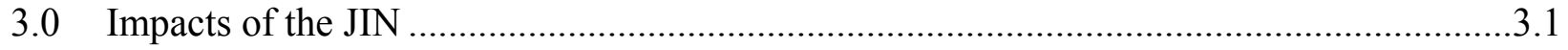

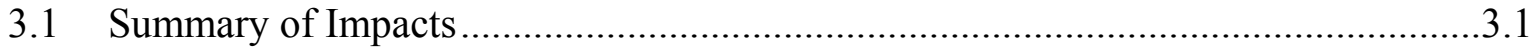

3.2 Papers Related to JIN Awards …………...............................................................

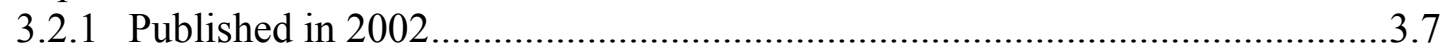

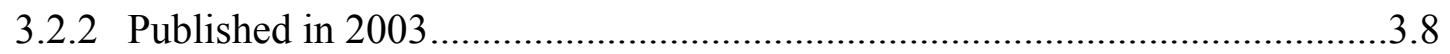

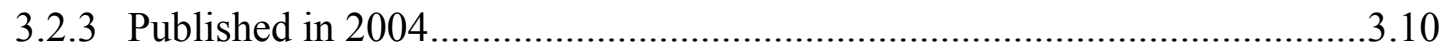

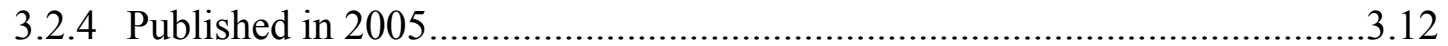

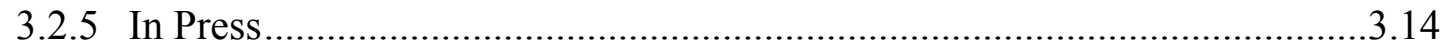

3.2.6 Submitted (as of January 2005) …………………...........................................

3.2.7 In Preparation (as of January 2005) ...............................................................16

3.3 JIN Related Presentations in FY04 ......................................................................18

Appendix A: List of JIN Awards by Award Dates .................................................................. 
Appendix B: JIN Related Award Winners.

Appendix C: Programs from five Nanotech Workshops: Aug. 2001, Feb. 2002, Sept. 2002, Sept.

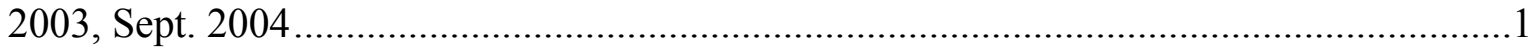

First Annual Seattle Nanotechnology Workshop, Aug. 2001 ……................................................................2

Richland Nanotechnology Workshop: Relating Nanoscience to Problems, .....................................................

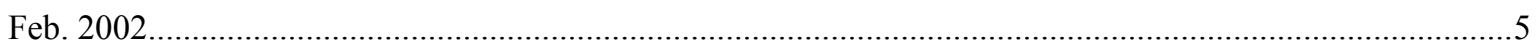

Business Forum Previous to Second Annual Seattle Nanoscale Science and Technology Workshop, Sept. 2002 ....8

Second Annual Seattle Nanotechnology Workshop, Sept. 2002 …..............................................................

Third Annual Seattle Nanotechnology Workshop, Sept. 2003 ...................................................................13

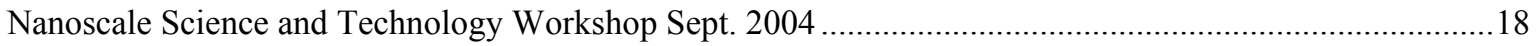

Center for Nanotechnology and UW/PNNL Joint Institute for Nanoscience ................................................18

Appendix D: Syllabi for the Three Intensive Nanoscience Courses ........................................1

D.1 Nanoclusters, Nanomaterials, and Nanotechnologies - May 2003 ............................................................1

D.2 Fabrication and Characterization of Nanomaterials - January 2004 ……............................................6

D.3 Theory and Modeling of Nanoscale Material Systems - Sept. 2003 ....................................................12

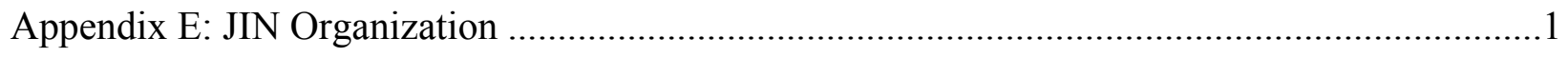

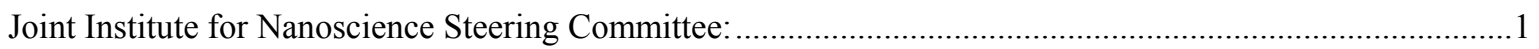

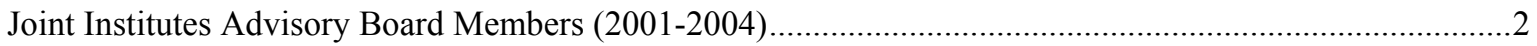




\subsection{Introduction}

The Joint Institute for Nanoscience (JIN) was established by the University of Washington (UW) and Battelle Memorial Institute, which operates Pacific Northwest National Laboratory (PNNL), in April 2001 as recognition of the inherently cross disciplinary nature of nanoscience and related nanotechnologies and the extremely wide range of science and technologies that are being impacted by the concepts and approaches that are now labeled "nano". Each institution offers substantial technical capability and personnel with high levels of skill and expertise in this area. By combining institutional strengths, nanoscience and nanotechnology research progress has been expanded into new areas (and technologies) and new educational opportunities have been created. Activities undertaken include: collaborative research and development (R\&D) projects, sharing facilities, conducting workshops and symposia to enhance communication and staff interactions, and working together to secure external R\&D contracts for research and education. Both UW and PNNL provide resources to support JIN activities.

Although the JIN was established in 2001, full operation did not begin until early calendar year 2002. This report summarizes projects supported in fiscal year 2004. As would be expected, the activities of the JIN have expanded, and the intensity of collaborations in nanoscience and nanotechnology R\&D and their related educational activities have increased. We have cooperated strongly in a variety of efforts to:

- Increase the number of PNNL/UW collaborative projects

- Coordinate education and training opportunities

- Develop multi-disciplinary programs

- Offer short-courses and conferences

- Jointly host visiting scientists

- Secure private and public sector funding for research and education activities.

Those involved with the JIN have seen a dramatic increase in the level of interactions between the two institutions in the past year which have resulted directly from JIN activities. JIN activities are playing a significant role both by creating new research directions and reshaping existing research programs at the UW and PNNL. A separate section of this report examines the impact of JIN activities.

\subsection{JIN Awards}

A major basis of JIN activities involves students or postdoctoral fellows performing research in collaborations jointly directed by PNNL staff scientists and UW professors. JIN fellowships are awarded on the basis of applications which include research proposals. The JIN Steering Committee scores these proposals on the following basis: 
A. Quality of proposed research and (for renewals) performance to date.

B. Expected enhancement of collaborations between PNNL and UW.

C. Contribution toward chances for external funding of collaboration between PNNL and UW, and/or impact on other Joint Institute missions (e.g., quick publications).

D. Relevance to nanoscience and nanotechnology.

E. Previous academic and/or research performance of individual to be funded and/or collaborator from PNNL and UW (new applications ONLY).

F. Performance in first funded period (renewals ONLY).

JIN fellowships include graduate student or postdoc salary, tuition costs for grad students, and travel and housing expenses for time spent at PNNL. Appendix A lists JIN fellowships awarded through October 2004. The main body of the report is a summary from each JIN award project that was active during FY 2004 and outlines the research progress and publications or external grant proposals that have so far resulted from this funding. The reports can also be found at http://www.pnl.gov/nano/institute/index.html.

The JIN seeks to encourage and enhance high-impact and high-quality nanoscience and nanotechnology of all types. However, it is also clear to the JIN Steering Committee that the maximum impact will be best achieved if we focus efforts and attention in specific areas where complementary strengths of the two institutions match scientific, technological, and funding opportunities. One of the first areas of significant overlap was associated with nano-scale magnetic materials and diluted magnetic semiconductors. Many of the early JIN awards were linked to this area; new programs were developed, and new outside funding has been obtained at both UW and PNNL in this area. In January 2003, the JIN Steering Committee formally recognized that the areas of Nano-Structured Reactive Materials Systems and Nanobiological Nano-Materials Based Functional Systems impact a wide variety of technologies (including medical, environmental, national security, and energy) and will strongly benefit from differing scientific skills and technology needs of the two institutions. These represent two areas of major importance that are under-represented in many Nanoscience and Technology efforts. The impact summary in section 3 outlines the several areas where these two focus areas are having an impact.

\subsection{Workshops}

The JIN co-sponsors at least one Nanoscale Science and Technology Workshop annually. These workshops were started in 2001 and the fifth workshop was held on the UW campus in Sept. 2004. Participants include UW students, especially those with JIN awards, UW faculty and PNNL staff and participation throughout the northwest is encouraged. The programs for all workshops can be found in Appendix C. The level of presentations has been superb. Also notable is the attendance of scientists from across the 
country just to listen to the presentations. These have included scientists from WrightPatterson Air Force Base and Lawrence Livermore National Laboratory. The workshops include invited presentations from world leading experts. Starting in 2003 Outstanding Student Presentation Awards were given for the best poster or oral presentations by a student. To facilitate student attendance, many of the Seattle workshops have been held in Seattle. A special workshop focused on relating nanoscience to needs and technologies important to DOE was held in Richland, Washington, in February 2002.

\subsection{JIN Related Education Programs}

In addition to involving PNNL staff in various UW nanoscience courses and seminars, an NSF grant, Development of UW-PNL Collaborative Curriculums in Nano-Science and Technology, has allowed the development of three intensive short courses that are taught by UW faculty, PNNL staff, and faculty from other institutions, including Washington State University, the University of Idaho, Stanford University, and the University of Alaska. The three courses are: 1) An introduction to nanoscience and nanotechnology: 2) Theory and Modeling of Nanoscale Material Systems: and 3) Fabrication and Characterization of Nano-materials. Various versions of these courses have been taught in Richland at PNNL and in Seattle. The introductory course was taught in Seattle during the winter quarter 2003 and in Richland the last two weeks in May of 2003, 2004 and 2005. The Modeling and Theory course was first offered in September 2003 in Seattle. The Fabrication and Characterization course was given in January 2004 and January 2005 in Richland. (http://www.nano.washington.edu/pnnl/courses.html). Syllabi for these courses are listed in Appendix D.

\subsection{Northwest Nanoscience and Nanotechnology Network}

The initial JIN agreement recognized that expansion of cooperation beyond UW and PNNL would be highly valuable. Starting in early 2003, efforts were initiated to form a regional communication link called the Northwest Nanoscience and Nanotechnology

Network $\left(\mathrm{N}^{4}\right) . \mathrm{N}^{4}$ is a tool to encourage communication and help identify regional resources and nanoscience and technology activities. There is a public website offering a variety of information, including contacts and participating institutions as well as a calendar and information about research, education, and business activities. In addition to the public site, there is a secure member area where reports can be processed; members can post information or work, in a secure fashion, on proposals and publications. The public site started preliminary operation in the fall of 2003. The site can be found at www.pnl.gov/nwnano. Many Northwest universities and research organizations were asked to become founding $\mathrm{N}^{4}$ members, each with an institutional representative who helps chart the future of the network. Initial participants have suggested that, in addition to webbased communication, $\mathrm{N}^{4}$ participants may want to be involved in an annual meeting, and the possibility of live internet of video seminars should be explored. A current list of organizations associated with $\mathrm{N}^{4}$ can be found on the website. As of December 2004 there are participants from 17 different institutions. 


\subsection{JIN Organization}

The organization of the UW and PNNL agreement for the JIN gave much of the responsibility for JIN operation to a Steering Committee made up of five researchers each from the two institutions. It is the responsibility of the Committee to work out criteria, develop and implement policy (with approval of an advisory board), and evaluate the fellowship applications. Much of the success of the JIN builds on the hard work of the Steering Committee members (see Appendix $\mathrm{C}$ for participants). The JIN is part of a more general Joint Institutes agreement between the UW and PNNL. All JIN activities have been undertaken under the guidance of a Joint Institutes Advisory Board and a Council of Fellows whose members are listed in Appendix E. 


\subsection{JIN Award Project Reports}

This section contains short reports describing JIN awards that received funding in fiscal year 2004. These reports are arranged in four groups based on when the awards were initiated or renewed.

\subsection{Awards Authorized, February 2003}

"Activating Ferromagnetism in Dilute Magnetic Semiconductor $\mathrm{Co}^{2+}: \mathrm{TiO}_{2}$ and $\mathrm{Cr}^{3+}: \mathrm{TiO}_{2}$ Nanorods"

Awardee: J. Daniel Bryan, Ph.D.

Mentors: Daniel R. Gamelin - UW, Scott Chambers and Chongmin Wang - PNNL

Page 2.2

"Study of Various Titania Nanostructures for the Exploration of Charge Transport in DyeSensitized Solar Cells"

Awardee: Tammy P Chou - UW

Mentors: Guozhong Cao - UW, Glen E Fryxell - PNNL

Page 2.6

"Nondestructive Carbon Nanotube Modification for Tailored Functionality"

Awardee: Leonard S. Fifield

Mentor: Christopher L. Aardahl

Page 2.11

"Fundamental Studies of Monolayer-Protected Nanoparticles by Gas Chromatography" Awardee: Gwen M. Gross

Mentors: Jay W. Grate - PNNL, Robert E. Synovec - UW

Page 2.13

"Redox Reactions of Colloidal Metal Oxides"

Awardee: Mira Kazenlberger

Mentors: James M. Mayer - UW, James A. Franz - PNNL

Page 2.18

"Bioaerosol Detection via Nanoparticle Surface Enhanced Raman Spectroscopy"

Awardee: Mary Laucks

Mentors: E. James Davis - UW, Cindy Bruckner-Lea (for Mark Kingsley)- PNNL, Richard Zheng - PNNL

Page 2.19

"Epitaxial Growth and Properties of Nanoscale Oxides for Spintronics"

Awardee: Diedrich Schmidt

Mentors: Marjorie Olmstead - UW, Scott Chambers - PNNL

Page 2.22 


\section{Activating Ferromagnetism in Dilute Magnetic Semiconductor $\mathrm{Co}^{2+}: \mathrm{TiO}_{2}$ and $\mathrm{Cr}^{3+}: \mathrm{TiO}_{2}$ Nanorods}

Awardee: J. Daniel Bryan, Ph.D.

Mentors: Daniel R. Gamelin - UW, Scott Chambers and Chongmin Wang - PNNL

\section{Project Summary}

The discovery of high- $\mathrm{T}_{\mathrm{c}}$ ferromagnetism in $2 \% \mathrm{Co}^{2+}: \mathrm{TiO}_{2}$ anatase thin films by Matsumoto et $\mathrm{al}^{1}$ has sparked a tremendous experimental and theoretical research effort focused on understanding the intrinsic magnetic exchange mechanism in these doped metal oxides. Recently, defects created at aggregated nanocrystalline $\mathrm{Ni}^{2+}: \mathrm{ZnO}$ (ref 2) interfaces or $\mathrm{TM}: \mathrm{SnO}_{2}$ $(\mathrm{TM}=\mathrm{Mn}, \mathrm{Co}, \mathrm{Fe})$ (ref 3) thin film/substrate interfaces have been suggested to be critical for the existence of ferromagnetism in these dilute magnetic oxides. Since nanocrystals possess large surface-area-to-volume ratios, ${ }^{4}$ colloidal DMS nanocrystals provide a unique opportunity to control nanocrystalline interfacial defect formation through the introduction or removal of surface passivating organic molecules from nanocrystalline surfaces. We have performed a series of experiments to investigate the mechanism by which the paramagnetic to ferromagnetic phase transition in colloidal doped $\mathrm{TiO}_{2}$ nanorods occurs. In parallel with these studies of nanostructured materials, we have examined thin films of related diluted magnetic semiconductors grown by MOCVD and by OPA-MBE vacuum deposition techniques, and the results from these two forms of the same class of material have been compared.

Figure 1 shows the transmission electron microscopy images along with XRD data for doped $\mathrm{Co}^{2+}$ - and $\mathrm{Cr}^{3+}$-doped $\mathrm{TiO}_{2}$ nanorods. A pronounced shape anisotropy is observed from the TEM as well as a narrow [004] reflection by XRD, both indicating preferential growth along the $c$-axis direction of the anatase lattice. Figure 2 shows $300 \mathrm{~K}$ electronic absorption and $5 \mathrm{~K}$ MCD spectra along with energy level calculations for $\mathrm{Cr}^{3+}$ in various coordination environments. The data in Figure 2 are all consistent with $\mathrm{Cr}^{3+}$ occupying the $D_{2 d} \mathrm{Ti}^{4+}$ cation site of the anatase host lattice.

These colloidal $\mathrm{Co}^{2+}: \mathrm{TiO}_{2}$ and $\mathrm{Cr}^{3+}: \mathrm{TiO}_{2}$ nanorods show paramagnetism in both surfacepassivated powder and colloidal forms. The nanorods could be activated to a ferromagnetic state by room temperature aggregation in the absence of passivating ligands or by spin coat processing at $350{ }^{\circ} \mathrm{C}$, as shown in Figure 3. These results are consistent with the generation of oxygen vacancies, $\mathrm{O}_{\mathrm{v}}$, at interfacial fusion sites. Time dependent annealing experiments of $\mathrm{Cr}^{3+}: \mathrm{TiO}_{2}$ nanorods thin films under aerobic conditions support this hypothesis. These results provide mechanistic insight into the structural/electronic factors necessary for dilute magnetic semiconductor ferromagnetism in doped metal oxides.

\section{References}

(1) Matsumoto, Y.; Murakami, M.; Shono, T.; Hasegawa, T.; Fukumura, T.; Kawasaki, M.; Ahmet, P.; Chikyow, T.; Koshihara, S.; Koinuma, H. Science 2001, 291, 854-856.

(2) Radovanovic, P. V.; Gamelin, D. R. Phys. Rev. Lett. 2003, 91, 157202/1-4.

(3) Coey, J. M. D.; Venkatesan, M.; Fitzgerald, C. B. Nature Materials 2005, 4, 173-179.

(4) Bryan, J. D.; Gamelin, D. R. Prog. Inorg. Chem. 2005, 54, 47-126. 

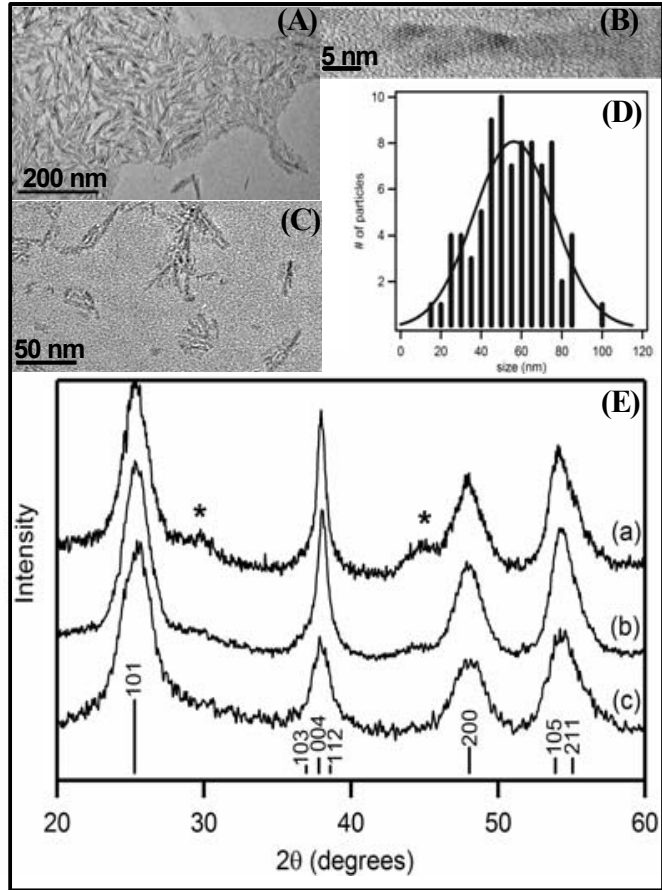

Figure 1. Low resolution TEM image of (A) $\mathrm{Co}^{2+}: \mathrm{TiO}_{2}$ and (C) $\mathrm{Cr}^{3+}: \mathrm{TiO}_{2}$. (B) High resolution image of $\mathrm{Co}^{2+}: \mathrm{TiO}_{2}$ nanorods. (D) Histogram showing distribution of nanorod lengths (E) Xray powder diffraction of (a) oleic acid capped $1.4 \% \mathrm{Cr}^{3+}: \mathrm{TiO}_{2}$ nanorods, (b) oleic acid capped $4.0 \% \mathrm{Co}^{2+}: \mathrm{TiO}_{2}$ nanorods, (c) $3.0 \% \mathrm{Co}^{2+}: \mathrm{TiO}_{2}$ TOPO capped nanocrystals. The reference reflections for bulk $\mathrm{TiO}_{2}$ anatase are also shown. * indicates reflections from close packed capping ligands.

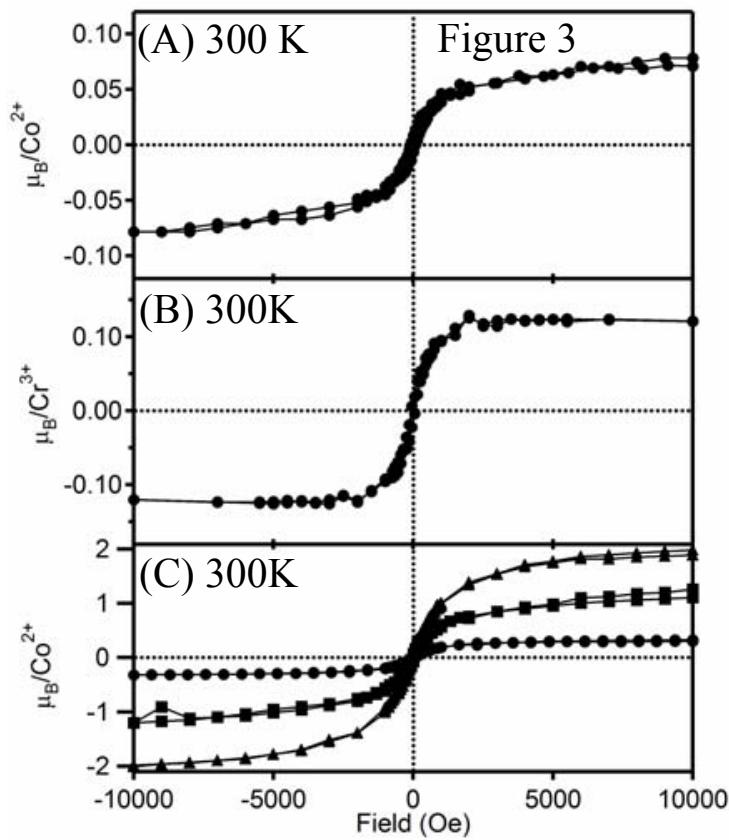

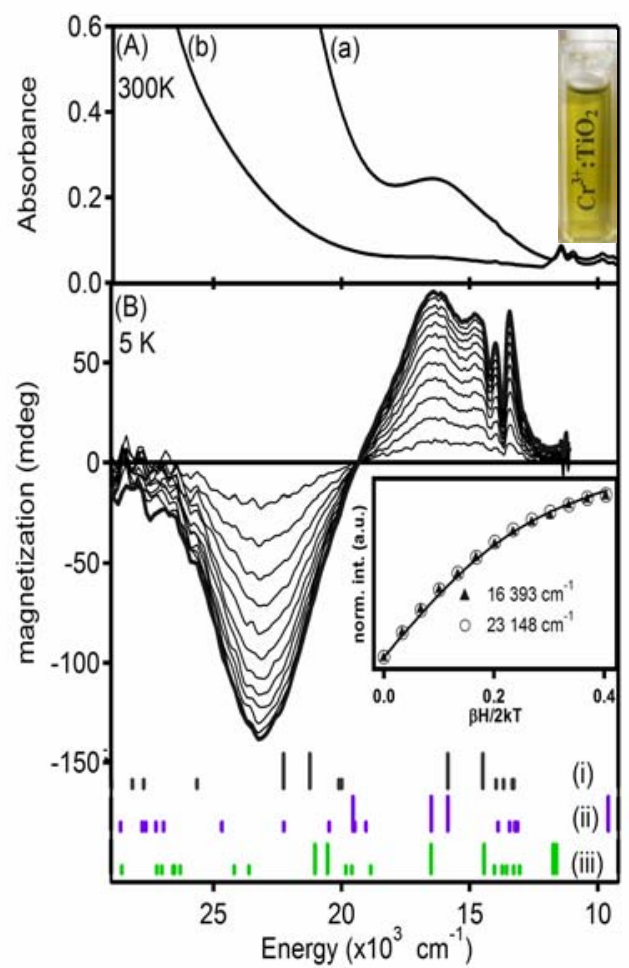

Figure 2. (A) $300 \mathrm{~K}$ absorbance of $1.4 \%$ $\mathrm{Cr}^{3+}: \mathrm{TiO}_{2}$ colloidal nanorods (a) and $10 \mathrm{x}$ diluted sample (b) suspended in toluene. (B) $5 \mathrm{~K} \mathrm{0-6} \mathrm{T} \mathrm{MCD} \mathrm{spectra} \mathrm{collected} \mathrm{on}$ a frozen solution of $1.4 \% \mathrm{Cr}^{3+}: \mathrm{TiO}_{2}$ nanorods. Inset shows $5 \mathrm{~K}$ variable field saturation magnetization for the 16393 $\mathrm{cm}^{-1}$ and $23148 \mathrm{~cm}^{-1}$ band along with a fit to equation 1 (solid line). Predicted energies of the ligand field spin-allowed transitions (full intensity) and spinforbidden transitions (one quarter intensity) of the $\mathrm{Cr}^{3+}$ in the $D_{2 d}$ anatase cation symmetry with (i) 6 coordinate, (hexaaquo) $\mathrm{e}_{\sigma}=5767 \mathrm{~cm}^{-1}, \mathrm{~B}=695 \mathrm{~cm}^{-1}$ $\mathrm{c}=4 \mathrm{~B}$, (ii) hexaquo values, 5 coordinate, axial vacancy, (iii) hexaaquo values, 5 coordinate, equatorial vacancy.

Figure 3. 300K magnetization data collected on spin coated films of (A) $3.0 \% \quad \mathrm{Co}^{2+}: \mathrm{TiO}_{2}$ nanorods, (B) $1.4 \%$ $\mathrm{Cr}^{3+}: \mathrm{TiO}_{2}$ nanorods, and (C) $3.0 \%$ $\mathrm{Co}^{2+}: \mathrm{TiO}_{2}$ spherical nanocrystals (C). 


\section{Publications:}

"Negligible Magnetism in Structurally Excellent $\mathrm{Cr}_{\mathrm{x}} \mathrm{Ti}_{1-\mathrm{x}} \mathrm{O}_{2}$ Anatase Contrasts High- $\mathrm{T}_{\mathrm{C}}$ Ferromagnetism in Structurally Defective $\mathrm{Cr}_{\mathrm{x}} \mathrm{Ti}_{1-\mathrm{x}} \mathrm{O}_{2}$ " T. C. Kaspar, L. Ye, C. M. Wang, J. D. Bryan, J.E. Jaffe, T. Droubay, V. Shutthandandan, S. Thevuthasan, D.E. McCready, D.R. Gamelin, A.J. Freeman, S.A. Chambers, in preparation.

“Activating Ferromagnetism in $\mathrm{Cr}^{3+}: \mathrm{TiO}_{2}$ and $\mathrm{Co}^{2+}: \mathrm{TiO}_{2}$ nanorods" J. D. Bryan, S.Santangelo, S. Keveren, D. R. Gamelin, 2005, submitted to Chemistry of Materials.

"Strong Room-Temperature Ferromagnetism in $\mathrm{Co}_{2}+$ doped $\mathrm{TiO}_{2} \mathrm{Made}$ from Colloidal Nanocrystals", J. D. Bryan, S. M. Heald, S. A. Chambers, D. R. Gamelin, Journal of the American Chemical Society, 2004, 126, 11640-11647.

"The Influence of Dopants on the Nucleation ofSemiconductor Nanocrystals from Homogeneous Solution" J. D. Bryan, D.S.Schwartz, D.R. Gamelin, Journal of Nanoscience and Nanotechnology (invited), 2005, in press.

"Doped Semiconductor Nanocrystals: Synthesis, Characterization, Physical Properties and Applications", J. D. Bryan, D.R. Gamelin, Progress in Inorganic Chemistry (invited review) 2005, 54, 47-126.

"Epitaxial Growth and Properties of Cobalt-doped $\mathrm{ZnO}$ on $\left\langle-\mathrm{Al}_{2} \mathrm{O}_{3}\right.$ Single-crystal Substrates." Tuan, A. C.; Bryan, J. D.; Pakhomov, A. B.; Shutthanandan, V.; Thevuthasan, S.; McCready, D. E.; Gaspar, D.; Engelhard, M. H.; Rogers, J. W., Jr.; Krishnan, K.; Gamelin, D. R.; Chambers, S. A., Physical Review B: Condensed Matter and Materials Physics, 2004, 70, 054424.

\section{Funding Resulting from This Research}

- Acquisition of a Scanning Probe Microscope System for Research and Education in Nanomagnetism and Spinelectronics, Co-PI: Daniel R. Gamelin with Marjorie Olmstead and Kannan Krishnan; NSF-IMR grant for $\$ 160 \mathrm{~K}$ awarded for acquisition of the proposed instrumentation

- An Integrated Laboratory for Physical Property Measurements of Advanced Materials and Novel Devices, Co-PI:- Daniel R. Gamelin, Murdoch Foundation grant for $\$ 499 \mathrm{~K}$ for period 3/01/05 to 2/28/06. Pending.

- Chemical Manipulation of High Temperature Spin Ordering in Oxide Semiconductors, PI: Daniel R. Gamelin; DOE grant for $\$ 590 \mathrm{~K}$ for period 6/15/05 to 6/14/08. Pending.

- Integrating Magnetic Oxide Nanostructures in Silicon Based Spintronics, Co-PI: Daniel

R. Gamelin; NSF-ECS grant for $\$ 840 \mathrm{~K}$ for period 8/01/05 to 7/31/08. Pending.

- Spectroscopy of Photovoltaic and Photoconductive Doped Oxide Electrodes Related to Photocatalysis and Solar Energy Conversion. P.I.: D. R. Gamelin, 1/1/06 -1/1/09 120K.

Pending.

- Preparation, Spectroscopy, and Photochemistry of Colloidal Nanocrystalline Water-Splitting Semiconductor Photocatalysts. P.I.: D. R. Gamelin 7/1/03-8/1/05 100K. 


\title{
Study of Various Titania Nanostructures for the Exploration of Charge Transport in Dye-Sensitized Solar Cells
}

\author{
Awardee: Tammy P Chou - UW \\ Mentors: Guozhong Cao - UW, Glen E Fryxell - PNNL
}

\section{Project Summary}

This project fabricated and studied various titania nanostructures for improving charge transport properties and light conversion efficiencies in dye-sensitized solar cells. The nanostructures investigated include: 1) nanoparticle films, 2) nanorod films, and 3) nanoparticle and nanorod composite films. In addition, the influences of different annealing atmospheres and the introduction of indium doped tin oxide (ITO) to titania films on the electrical transport and light energy conversion efficiency have been studied. Some of the results are briefly summarized below.

As shown in Figure 1, nanorod films demonstrated the lowest light conversion efficiency due to low open circuit voltage and short circuit current, while the nanoparticle films possessed the best efficiency of light energy conversion with both high open circuit voltage and short circuit current. Although the detailed explanation is still under investigation, the smaller short circuit current is likely attributable to smaller amounts of nanorods than nanoparticles in the films, leading to thinner films and smaller surface area for light absorption and conversion. The lower open circuit voltage may be attributable to the less favorable surface chemistry. Specifically, titania nanorods are made by template-based sol electrophoretic deposition. The PC templates used to form nanorods are typically removed by pyrolyzing at elevated temperatures $\left(480^{\circ} \mathrm{C}\right)$ in air. The local reduction gaseous environment may create a lot of surface oxygen vacancies and/or low valence state titanium ions, which in turn promoted surface charge recombination.

The influence of the annealing condition on the light conversion efficiency is presented in Figure 2. The open circuit voltage increased from $350 \mathrm{mV}$ when sintered in air to $580 \mathrm{mV}$ when subjected to $\mathrm{O}_{2}$ annealing at the same temperature for the same period of time. Although more evidence is needed to further verify our above hypothesis, Figure 2 does show a plausible indication that $\mathrm{O}_{2}$ annealing modifies the surface chemistry of titania, leading to enhanced open circuit voltage, possibly due to reduced surface charge recombination.

From Figure 1, one can see that the light conversion efficiency is seriously compromised by the relative internal charge transport resistance. One possible improvement is to incorporate optically transparent conductive materials into titania films. Figure 3 compares the I-V curves of titania films with and without the incorporation of ITO. The choice of ITO is straightforward, since there are very limited candidate materials that possess both good electrical conductivity and optical transparency. Figure 3 clearly demonstrated that the incorporation of ITO significantly improved the internal charge transport property in the resultant solar cells, as evidenced with little decrease of current as the voltage increased. It should also be noted that the open circuit voltage of $\mathrm{TiO}_{2}$-ITO films remains the same or slightly higher than $\mathrm{TiO}_{2}$ films, indicating there is no negative impact on the surface chemistry. However, there is a noticeable 
decrease in the short circuit current, which is currently under investigation.

Our current work continues to achieve a better fundamental understanding of the influences of nanostructures and annealing conditions on the light conversion efficiency. However, our focus is on the $\mathrm{ITO}^{-} \mathrm{TiO}_{2}$ core shell nanocable arrays for significantly improved light conversion efficiency.

\section{Publications, Presentations, and Proposals:}

\section{Publications:}

1. T.P. Chou, G.Z. Cao, and G.E. Fryxell, "Development of Titania Nanostructures for the Exploration of Electron Transport in Dye-Sensitized Solar Cells, in Nanophotonic Materials, Proceedings of SPIE 5510, eds., D.L. Andrews, G.Z. Cao, and Z. Gaburro, p.129-137, 2004.

2. T.P. Chou, S.J. Limmer, and G.Z. Cao, "Functionalized, Hierarchically Structured Mesoporous Silica by Sol Electrophoresis and Self Assembly," Nanoscale Optics and Applications, Proceedings of SPIE 4809, ed. G.Z. Cao and W.P. Kirk, p.239-248, 2002.

3. T.P. Chou, C.M. Chung, and G.Z. Cao, "Ordered Dye-Functionalized Titania Nanorods and Their Applications as Sensors," in Nanomaterials and Their Optical Applications, Proceedings of SPIE 5224, eds. G.Z. Cao, Y.N. Xia, and P. Braun, p. 53-61, 2003.

4. T.P. Chou, C. Chandrasekaran, and G.Z. Cao, "Sol-Gel-Derived Hybrid Coatings for Corrosion Protection," Journal of Sol-Gel Science and Technology 26, 321-327 (2003).

5. T.P. Chou and G.Z. Cao, "Adhesion of Sol-Gel-Derived Organic-Inorganic Hybrid Coatings on Polyester," (Invited, special issue on ceramic coatings on polymer), Journal of Sol-Gel Science and Technology 27, 31-41 (2003).

6. S.J. Limmer, T.P. Chou, and G.Z. Cao, "Formation and Optical Properties of Gold-Coated Oxide Nanorods," Journal of Physical Chemistry B107, 13313 -13318 (2003).

7. S.J. Limmer, T.P. Chou, and G.Z. Cao, "A Study on the Growth of Titania Nanorods by Sol Electrophoresis," Journal of Materials Science 39, 895-901(2004).

8. T.L. Wen, J. Zhang, T.P. Chou, S.J. Limmer, and G.Z. Cao, "Template-Based Growth of Oxide Nanorods by Centrifugation," Journal of Sol-Gel Science and Technology 33, 193200 (2005).

9. S.J. Limmer, T.P. Chou, and G.Z. Cao, "Influences of Processing Parameters on Templatebased Growth of Oxide Nanorod Arrays by Sol Electrophoretic Deposition," Journal of Sol-Gel Science and Technology, in press.

10. C.M. Chung, T.P. Chou, and G.Z. Cao, "Porous Organic-Inorganic Hybrids for Removal of Amines via Donor-Acceptor Interaction," submitted to Materials Chemistry and Physics.

11. T.P. Chou, G. Fryxell, and G.Z. Cao, "Fabrication and Characterization of $\mathrm{ITO}^{-\mathrm{TiO}_{2}}$ Core-Shell Nanocable Arrays in Dye-Sensitized Solar Cells," in preparation.

12. T.P. Chou, G. Fryxell, and G.Z. Cao, "Enhanced Transport Properties in Dye-Sensitized Solar Cells with the Incorporation of $\mathrm{TiO}_{2}$ Nanorods," in preparation.

13. T.P. Chou, G. Fryxell, and G.Z. Cao, "Direct Fabrication of Porous $\mathrm{TiO}_{2}$ Films through a Combination of Hydrothermal and Electrophoretic Deposition for Enhanced Light Energy Conversion," in preparation. 


\section{Presentations:}

1. "Development of Titania Nanostructures for the Exploration of Electron Transport in Dye-Sensitized Solar Cells," (Oral), T.P. Chou, G.Z. Cao, and G.E. Fryxell, 2004 SPIE Annual Meeting, Denver, CO, August 2, 2004.

2. "Development of Titania Nanostructures for the Exploration of Electron Transport in Dye-Sensitized Solar Cells," (Oral), T.P. Chou, G.Z. Cao, and G.E. Fryxell, 56 ${ }^{\text {th }}$ Pacific Coast Regional Meeting and Basic Science Division Meeting of the American Ceramic Society, Seattle, WA, September 15, 2004.

3. "Functionalized, Hierarchically Structured Mesoporous Silica by Sol Electrophoresis and Self Assembly," (Poster), T.P. Chou, S.J. Limmer, and G.Z. Cao, Conference on Nanoscale Optics and Applications, 2002 SPIE Annual Meeting, Seattle, WA, July 7-11, 2002.

4. "Growth of Nanorods Of Various Oxides And Hierarchically-Structured Mesoporous Silica

By Sol Electrophoresis," (Poster), T. P. Chou, S.J. Limmer, and G.Z. Cao, Gordon Research Conference: Solid State Studies in Ceramics, Meriden, NH, August 11-16, 2002.

5. "Functionalized, Hierarchically Structured Mesoporous Silica by Sol Electrophoresis and Self Assembly," (Oral), T.P. Chou, S.J. Limmer, and G.Z. Cao, 54 ${ }^{\text {th }}$ Pacific Coast Regional Meeting and Basic Science Division Meeting of the American Ceramic Society, Seattle, WA, Oct. 1, 2002.

6. "Ordered Dye-Functionalized Titania Nanorods and Their Applications as Sensors," (Oral), T.P. Chou, C.M. Chung, and G.Z. Cao, 2003 SPIE Annual Meeting, San Diego, CA, Aug. 3-8, 2003.

\section{Proposals:}

1. Hierarchical Assemblies of Nanofibers for Photovoltaic Devices (NIRT, PI: Younan Xia) Submitted 11/12/04, NSF/ $\$ 400,000$, not funded. 


\section{Figures:}

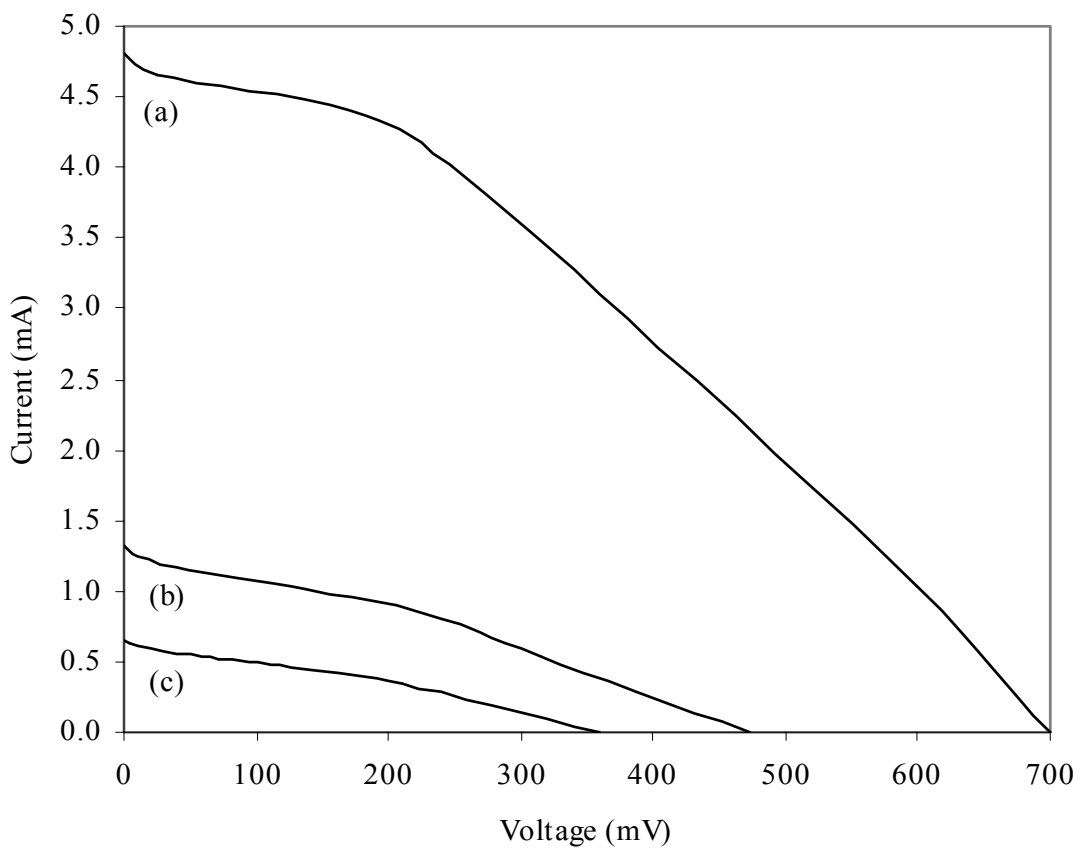

Figure 1. I-V behavior of dye-sensitized solar cells consisting of electrode films with (a) $\mathrm{TiO}_{2}$ nanoparticles, (b) a mixture of $\mathrm{TiO}_{2}$ nanoparticles and $\mathrm{TiO}_{2}$ nanorods, and (c) $\mathrm{TiO}_{2}$ nanorods.

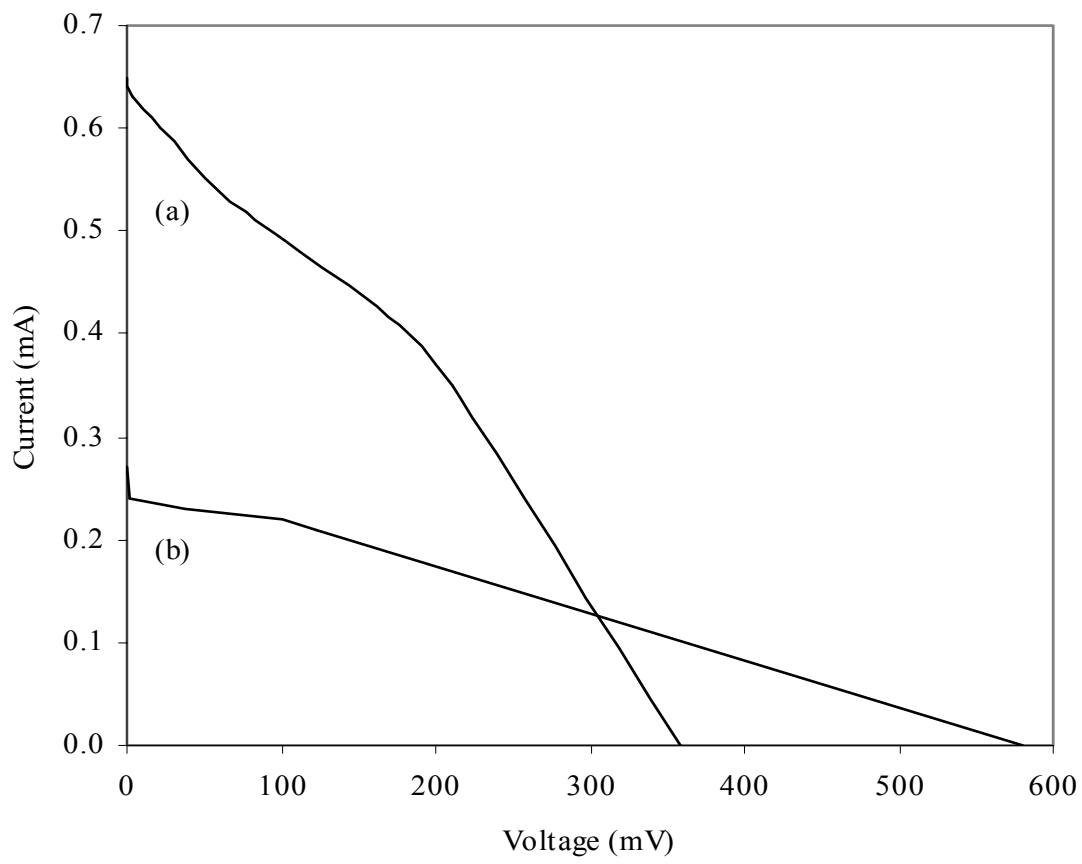

Figure 2. I-V behavior of dye-sensitized solar cells consisting of electrode films with $\mathrm{TiO}_{2}$ nanorods obtained by sintering at $500^{\circ} \mathrm{C}$ in (a) air and (b) $\mathrm{O}_{2}$. 


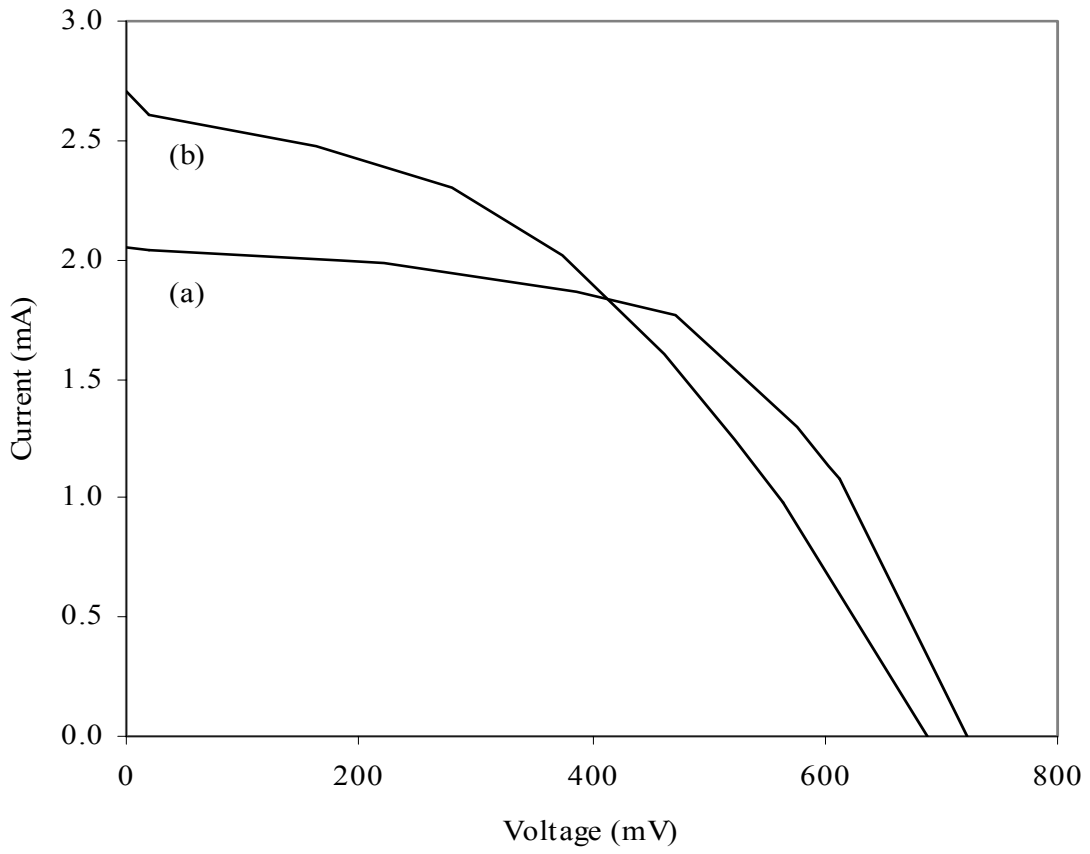

Figure 3. I-V behavior of dye-sensitized solar cells consisting of electrode films with $\mathrm{TiO}_{2}$ nanoparticles (a) with and (b) without the incorporation of an ITO layer. 


\section{Nondestructive Carbon Nanotube Modification for Tailored Functionality}

Awardee: Leonard S. Fifield

Mentor: Christopher L. Aardahl

Project Summary

Controlled chemical modification of carbon nanotubes and other graphitic structures is highly desirable for the processing and use of these materials in practical devices. Chemical means for modifying nanotubes have existed for some time, but most involve pre-treating the tubes in strong acids to induce oxidized defects in the tube surfaces and ends at which to perform chemistry. Sidewall functionalization methods, such as those employed by James Tour and his group at Rice University, have been developed to attach desired chemical groups to nanotubes without first damaging the tubes by oxidation. This approach, however, also results in an interruption of the conjugated backbone of the carbon nanotube with a corresponding loss in mechanical and electronic properties. One strategy to limit this drawback is the use of such chemistry on multi-wall carbon nanotubes. In the case of multiwall nanotubes, only the outer wall might be damaged in the process, leaving the inner walls intact. Unfortunately for this strategy, the larger diameter of multi-wall carbon nanotubes leads to a lower strain in the carboncarbon bonds of the tubes and a much lower reactivity compared to single wall carbon nanotubes. Chemical modification of multi-wall nanotubes is thus difficult to accomplish without cutting, opening, and oxidatively damaging the tubes to provide reaction sites. The utilization of noncovalent means for carbon nanotube modification is preferable for applications in which the properties resulting from the conjugated backbone of the nanotubes need to be maintained. In addition, noncovalent approaches, such as the use of molecular anchors for chemical functionalization, are generally applicable to all types of graphitic surfaces. The use of organic molecular anchors is a viable way to chemically modify multi wall carbon nanotubes, which are less difficult to synthesize and less expensive to purchase than single wall nanotubes, while keeping attractive carbon nanotube properties intact. We have developed a facile and effective method for depositing molecular anchors onto multi-wall carbon nanotubes using supercritical fluids. Characterization of the degree of loading in these nanotube-anchor structures is achieved with the use of thermal gravimetric analysis (TGA) and differential scanning calorimetry (DSC). It is our contention that employment of the described method will facilitate the use of carbon nanotubes in a variety of applications, including chemical separations and chemical sensors.

\section{Publications, Presentations, and Proposals}

"Noncovalent Functionalization of Carbon Nanotubes with Molecular Anchors using Supercritical Fluids." Leonard S. Fifield, R. Shane Addleman, Glen E. Fryxell, Christopher L. Aardahl. 2005. American Chemical Society Meeting, San Diego, March 13-17, 2005.

"Homogeneous Catalysts Tethered to Carbon Nanotubes." Leonard S. Fifield, John C. Linehan, R. Shane Addleman, Christopher L. Aardahl, J. David Newell, and Thomas E. Bitterwolf. 
Materials Research Society Spring 2005, San Francisco, CA

"Noncovalent Functionalization of Carbon Nanotubes with Molecular Anchors Using Supercritical Fluids" Leonard S. Fifield, Larry R. Dalton, R. Shane Addleman, Rosemary A. Galhotra, Mark H. Engelhard, Glen E. Fryxell, and Christopher L. Aardahl. Phys. Chem. B (2004), 108, 8737-8741

"Nanostructured materials for efficient carbon dioxide separation " Leonard S. Fifield, Glen E. Fryxell, Thomas S. Zemanian, R. Shane Addleman, Feng Zheng, Larry R. Dalton, and Christopher L. Aardahl. 225th ACS National Meeting, New Orleans, LA, March 23, 2003.

"Development of Active Nanomaterials based on Carbon Nanotubes" Leonard S. Fifield, Larry R. Dalton, Rosemary A. Golhotra, R. Shane Addleman, Glen E. Fryxell, and Christopher L. Aardahl. JINN Nano Workshop, University of Washington, Seattle, WA, September, 2003.

Proposals Submitted as a Result of this Work

"CO2 Capture from Submarine Atmospheres" NAVSEA Philadelphia—in process "Signature Collection" Coastal Security, United States Navy—in process

\section{Selected Figures}

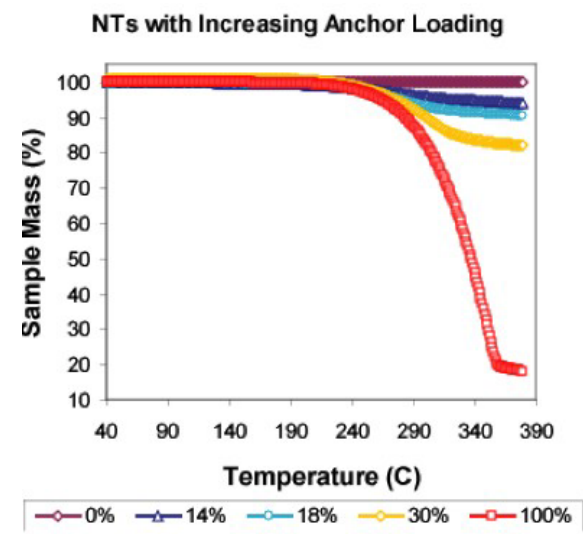

Figure 1. Plot of TGA data for anchor compound reacted with MWNTs. Control over loading is achieved by controlling the reaction ratio of anchor to nanotubes.

Work resulting from this JIN proposal has also recently received some media attention:

http://www.voyle.net/Nano\%20Research-05/research-05-0058. htm http://www.eurekalert.org/features/doe/2004-08/dnnl-fcn082404.php http://www.innovations-report.com/html/reports/materials science/report41985.html 


\section{Fundamental Studies of Monolayer-Protected Nanoparticles by Gas Chromatography}

Awardee: Gwen M. Gross

Mentors: Robert E. Synovec - UW, Jay W. Grate - PNNL

\section{Project Summary}

This has been a successful project with excellent results. Synthesis and characterization of three gold-centered monolayer protected nanoparticle (MPN) stationary phases has been completed, in close collaboration with personnel from PNNL and UW. This research included utilization of EMSL technology for characterization of the MPN materials produced. The purity of the MPN products were tested and deemed satisfactory to address the project goals using thin layer chromatography (TLC) stained with iodine to test for residual thiols. Characterization of the MPNs was done using thermal gravimetric analysis (TGA), UV-vis absorbance spectroscopy, as well as transmission electron microscopy (TEM) to determine the size of the MPNs. The awardee has determined that utilizing the MPN materials as a thin coat stationary phase in open tubular gas chromatography (GC) is an ideal platform to study the mass transfer and thermodynamic properties of these MPN materials, thus addressing the goals of the proposed research. Furthermore, the MPN-based GC columns have proven to be a very successful application of MPNs in the design of state-of-the-art chemical analysis instrumentation such as GC, as described below. Overall, this project gained considerable visibility as indicated by the large number of presentations and publications (7), including an invited book chapter (reference 5) and an invited manuscript (reference 7). The project should maintain high visibility and productivity as the collaboration continues.

The following is a brief review of the highlights of the project. The methodology for production of a dodecanethiol MPN-based stationary phase for GC capillary columns has been established with considerable chromatographic results published (eg., Figure 1, reference 3). Based upon the separation efficiencies and reduced plate height studies as a function of linear flow velocity, we concluded that a dodecanethiol MPN stationary phase operated at nearly the optimum possible performance level when compared to commercially available polymer stationary phases. The robustness of the MPN phase has also been studied with consistent performance observed over several months (reference 7). Using the same methodology, the production of multiple columns has been achieved with acceptable levels of reproducibility. This is promising for successful future studies and applications of MPN phases.

One such application explored was the possible implementation of the dodecanethiol MPN stationary phase within micro-fabricated GC channels. A 100 - $\square$ m square capillary was used as a model for a microfabricated-GC system (Figure 2). The potential application of the MPN material for the emerging area of microfabricated analytical measurements is shown by the efficiency of the separations obtained using the square capillary column (Figure 3, reference 4).

Very recent studies using smaller capillaries, a novel high-speed injection design (reference 6), and application of the dodecanethiol MPN within a two-dimensional separation (GC $\mathrm{x}$ GC) format (Figure 4, reference 7) have been very fruitful. Ongoing work on the application of other 
MPN materials, specifically chlorobenzenethiol MPNs and tri-flouromethylthiolphenol MPNs, is also progressing well. Successful application of these materials involves modification of previous column production methods and initial steps. This project is a very successful application of nanoparticle technology. Actual instrumental devices have been developed and the establishment of an efficient thin film stationary phase now allows for the thermodynamic studies of various chemical functional groups with the MPN nanoparticle materials. Continued development of MPN stationary phases is ongoing between the Grate and Synovec Laboratories. This collaboration will ensure accurate and successful characterization of the sorptive and mass transfer properties of the current MPNs and novel MPNs. In turn, the implementation of MPNs in cutting edge analytical instrumentation and measurement science should continue.

\section{Publications, Presentations and Proposals Resulting From this Work:}

"Open Tubular Gas Chromatography using Monolayer Protected Gold Nanoparticles as the Stationary Phase." G. M. Gross, D. A. Nelson, J. W. Grate, R. E. Synovec, 26th International Symposium on Capillary Chromatography and Electrophoresis in May 2003, Las Vegas NV, poster presentation. (invited)

"Fundamental Studies of Monolayer-Protected Nanoparticles by Gas Chromatography." G.M. Gross, D.A. Nelson, J.W. Grate, R.E. Synovec, Nanoscience Workshop for the PNNL/UW Joint Institute of Nanoscience, Seattle, WA, September 2002 \& 2003, two poster presentations.

G.M. Gross, D.A. Nelson, J.W. Grate, R.E. Synovec "Monolayer Protected Gold Nanoparticles as a Stationary Phase for Open Tubular Gas Chromatography”, Anal. Chem., 75, 2003, 45584564.

G.M. Gross, J.W. Grate, R.E. Synovec, "Monolayer-Protected Gold Nanoparticles as an Efficient Stationary Phase for Open Tubular Gas Chromatography using a Square Capillary: A Model for Chip-Based Gas Chromatography in Square Cornered Microfabricated Channels", J. Chromatogr. A, 1029, 2004, 185-192.

J.W. Grate, D.A. Nelson, R. Skaggs, R.E. Synovec, G.M. Gross, "Metal Nanoparticles Protected with Monolayers: Applications for Chemical Vapor Sensing and Gas Chromatography" chapter for the Encyclopedia of Nanoscience and Nanotechnology, Marcel Dekker, Inc., New York, ISBN:0-8247-4797-6, 2004, pp. 1859-1867. (invited)

G.M. Gross, B.J. Prazen, J.W. Grate, R.E. Synovec, "High-Speed Gas Chromatography using a Synchronized Dual-Valve Injector” Anal. Chem., 76, 2004, 3517-3524.

G.M. Gross, J.W. Grate, R.E. Synovec, "The Development of Novel Gas Chromatographic Stationary Phases Using Monolayer Protected Gold Nanoparticles for Application in High-Speed and Multi-Dimensional Gas Chromatographic Separations", J. Chromatogr. A,1060, 2004, 225236. (invited) 


\section{Funding and Intellectual Property that has resulted from this research:}

Record of Invention for Patent Protection: G. M. Gross, J. W. Grate, R. E. Synovec; "Monolayer Protected Gold Nanoparticles for use as a Gas Chromatographic Stationary Phase in Capillary and Microfabricated Chromatographic Systems". Date received at OTL: 10/17/2003 (31314038DL), 2004.

DARPA micro-Gas Chromatograph Proposal (Funded): R.E. Synovec (University of Washington) - \$420,000 for 4.5 years starting August 2004. 


\section{Figures:}

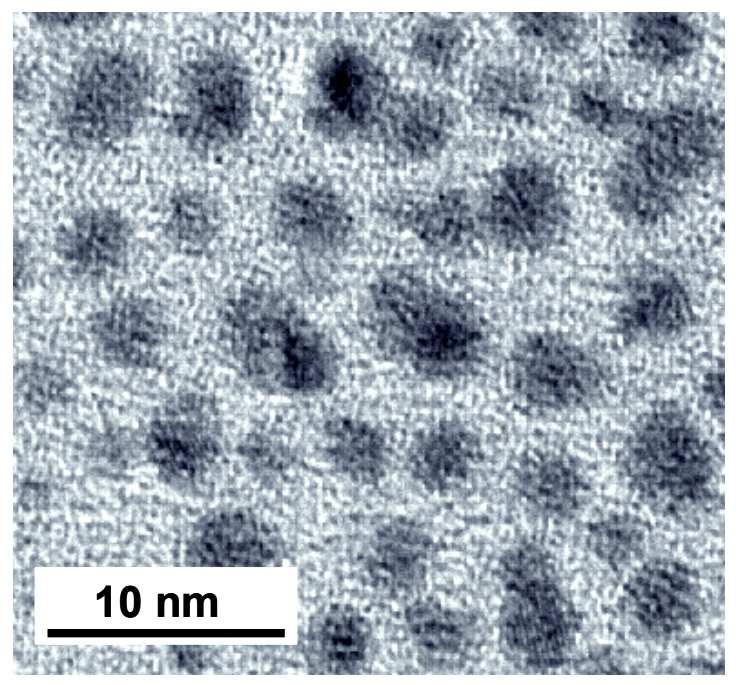

Figure 1. Transmission electron micrograph (TEM) of a thin film of dodecanethiol MPNs. The TEM image indicates the nanoparticle core size was moderately polydisperse with diameters ranging from about 1.5 to $5 \mathrm{~nm}$ with an average of $3.2 \mathrm{~nm}$.
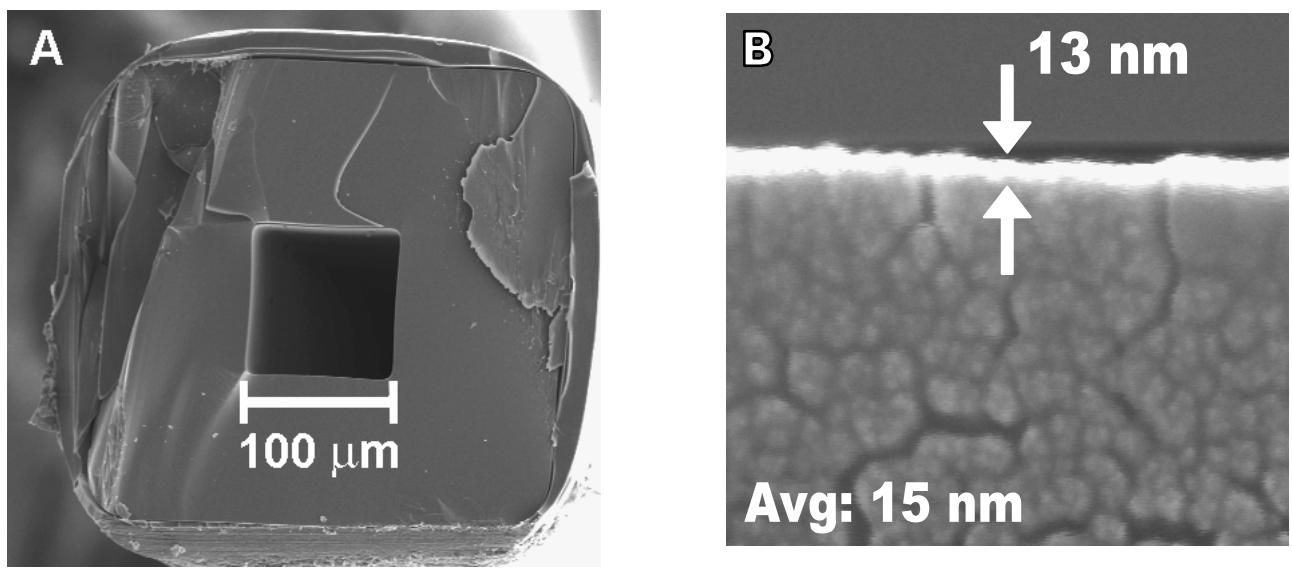

Figure 2. (A) Scanning Electron Microscope (SEM) image of the dodecanethiol MPN stationary phase within the $100 \square$ m square capillary. (B) Representative view of the MPN stationary phase along the capillary wall. Here, the thickness is $13 \mathrm{~nm}$. Fourteen measurements from five locations along the column resulted in an average film thickness of $15 \mathrm{~nm}(+/-4 \mathrm{~nm})$. 


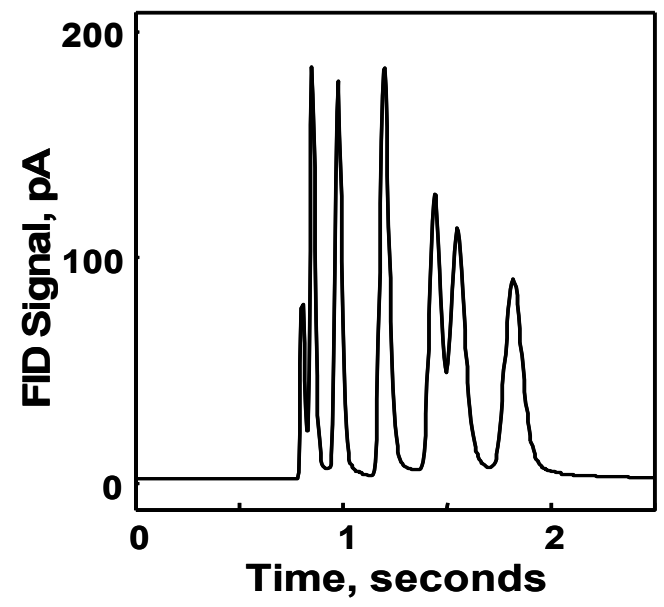

Figure 3. High-speed separation of seven components is shown using the dodecanethiol MPN stationary phase within the $100 \square \mathrm{m}$ square capillary. The following is the retention order: methyl ethyl ketone, benzene, octane, chlorobenzene, anisole, 3-octanone, and decane. The separation was obtained using a $1.3 \mathrm{~m}$ column with the dodecanethiol MPN stationary phase at $75^{\circ} \mathrm{C}$, operated under constant pressure conditions at $170,000 \mathrm{~Pa}(\sim 200 \mathrm{~cm} / \mathrm{s}$ hydrogen gas $)$.

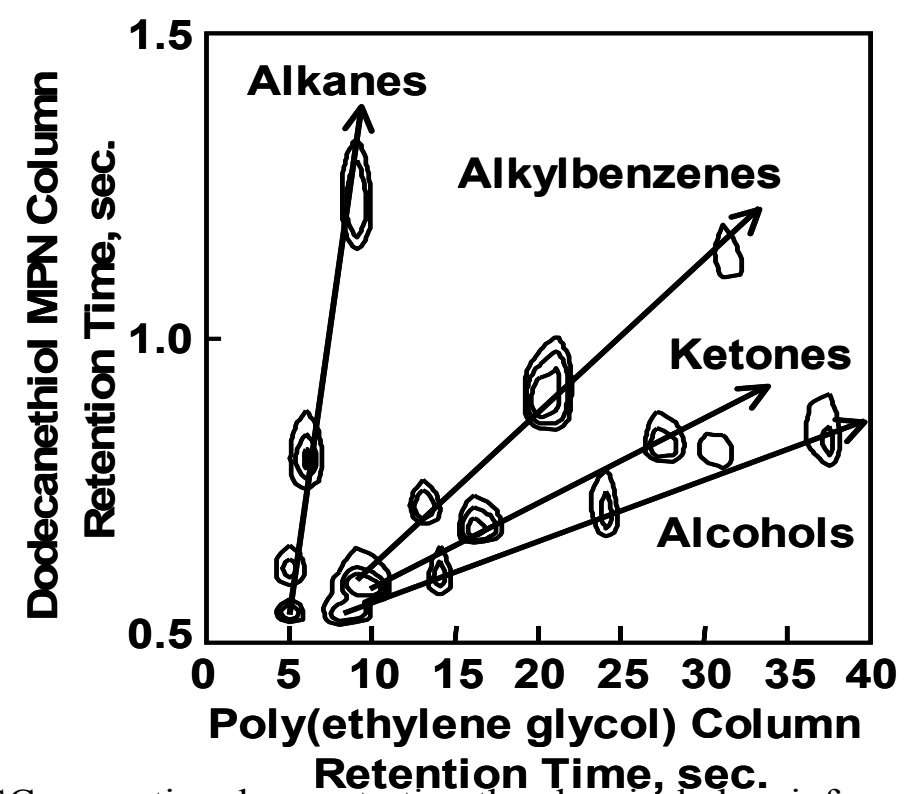

Figure 4. GC x GC separation demonstrating the chemical class information obtained with a multi-dimensional separation. The dodecanethiol MPN stationary phase $(0.100 \mathrm{~mm}$ i.d. capillary) was the second dimension of the separation shown. This separation was obtained using a $4 \mathrm{~m}$ poly(ethylene glycol) column ( $250 \square \mathrm{m}$ i.d., $0.2 \square \mathrm{m}$ film) as the first column at $34,000 \mathrm{~Pa}(\sim 40 \mathrm{~cm} / \mathrm{sec})$ with $1.5 \mathrm{~m}$ of the dodecanethiol MPN $0.100 \mathrm{~mm}$ i.d. capillary column as the second column operated at $240,000 \mathrm{~Pa}(\sim 440 \mathrm{~cm} / \mathrm{sec})$. A temperature ramp of $50{ }^{\circ} \mathrm{C} / \mathrm{min}$ from $40-75{ }^{\circ} \mathrm{C}$ was used with the FID and inlet temperatures at $250{ }^{\circ} \mathrm{C}$. A $0.5 \square 1$ injection was introduced with a 600:1 split on the inlet. The valve injection onto the second column had a 15 ms wide injection pulse width, a $1.3 \square 1$ loop with a one second modulation period. 


\section{Redox Reactions of Colloidal Metal Oxides}

Awardee: Mira Kazenlberger

Mentors: James M. Mayer - UW, James A. Franz - PNNL

\section{Project Summary}

It is proposed to study chemical reactions of colloidal metal oxide particles. An understanding of the chemical reactivity of nanoscale particles is critical to their use and to their behavior in the environment. There are a variety of procedures known to make well-defined colloidal dispersions of metal oxides, both in aqueous and non-aqueous solvents. Our initial studies will focus on colloidal manganese dioxide as a welldefined nanostructured oxide. Extensions to iron oxides (FeOOH, Fe2O3) and photo-activated $\mathrm{TiO} 2$ are planned. These colloidal particles will be reacted with organic substrates such as 9,10-dihydroanthracene, toluenes, phenols, and hydroquinone. Reduction of these particles causes dissolution, which will be monitored optically and by EPR. Because the particles dissolve away completely, the average thermodynamic driving force for reaction $(. \mathrm{G}, \mathrm{H})$ is essentially that of the bulk material. Knowledge of this thermodynamic driving force enables testing of the recently developed Marcus/Polanyi approach to hydrogen atom transfer/proton coupled electron transfer reactions of molecular metaloxide materials. Successful application of this approach would provide new and important understanding of the reactivity of metal oxide particles.

Mira Kanzelberger was supported by this award for six months. Mira prepared colloidal manganese dioxide following a wide variety of different procedures, some reported and some newly developed, and she studied their reactivity in the oxidation of hydrocarbons. We were unable to get reproducible reactivity, in contrast with our own preliminary studies and surprisingly in contrast with the known reactivity of bulk $\mathrm{MnO}_{2}$. Since this reactivity was the prerequisite for the proposed work, the project was terminated after 6 months and the remaining funds returned to JIN.

Publications, Presentations and Proposals: none 


\section{Bioaerosol Detection via Nanoparticle Surface Enhanced Raman Spectroscopy}

Awardee: Mary Laucks

Mentors: E. James Davis - UW, Cindy Bruckner-Lea (for Mark Kingsley)- PNNL, Richard Zheng - PNNL

\section{Project Summary}

Conventional methods of sampling and analyzing bioaerosols do not presently provide rapid identification of potential bio-threats. Time-of-flight mass spectrometers have made possible the rapid detection of inorganic and some organic molecules, but these systems ablate the particles, and the identification of the fragments would be especially difficult for bioaerosol particles. To detect small quantities of biomaterial against a high background of other commonly occurring atmospheric particles, any potential bio-detection system would require both high sensitivity (small quantities of material present) and the ability to separate the signal of interest from the background (much biomaterial is similar). Rapid identification requires that sampling and analysis occur in the same instrument.

The idea of this project is to study the potential of surface enhanced resonance Raman spectroscopy (SERRS) or surface enhanced Raman spectroscopy (SERS) as a method for detecting bioaerosol. We will use the recent advances in nanosurface techniques to produce a surface onto which we can deposit sample bioaerosol and chemically analyze it using SERRS or SERS.

We have made significant progress on the first phase of our research plan, which was to identify a surface preparation that would provide significant enhancement when a known material was adsorbed on it. As a baseline study, we used silver colloid suspensions (50 to 75 $\mathrm{nm}$ ) to demonstrate enhancements of pyridine on the order of $10^{9}$. We were able to detect the $\sim 1050 \mathrm{~cm}^{-1}$ peak in a $10^{-9} \mathrm{M}$ pyridine solution and compare it to the same peak from a nonenhanced (no silver colloid present) $1 \mathrm{M}$ solution of pyridine. For these experiments, we used optical glass Raman cuvettes and the $514.5 \mathrm{~nm}$ line of an Ar ion laser. From this baseline study, we found that our setup was able to detect nanomolar levels of pyridine, demonstrating that we will be able to detect these levels of other materials if we achieve similar enhancements on prepared surfaces.

We have also prepared silver film surfaces by etching them in nitric acid solution and have demonstrated large enhancements of the same pyridine peak on these surfaces. The prepared Ag surface was soaked in a $10^{-4} \mathrm{M}$ solution of pyridine and then washed and air-dried. This enhancement was not measurable because we could not detect the pyridine peak on a non-etched Ag surface, even though we deposited pure pyridine $(\sim 13 \mathrm{M})$ on it. However, we can say that the enhancement was larger than $7 \times 10^{5}$. Figure 1 shows the comparison between pyridine adsorbed on a smooth, non-etched Ag surface and on a prepared (modified) surface. 
In addition to pyridine, we have deposited 100-nm latex nanospheres on the nitric acidetched Ag surface and were able to see some enhancement. Particles smaller than 1 micrometer are very difficult to detect (and have not been detected to our knowledge) with Raman scattering, but Figure 2 provides evidence that nanometer particles may be detectable.

Another aspect of our research to date has been the study of the Raman scattering from common bacteria so as to determine if their spectra are different enough to be "fingerprints" for each type of bacteria. Dr. Cindy Bruckner Lea's group at PNNL has provided us with samples of gram negative (E. Coli), gram positive (Staphylococcus epidermidis), and spore (Bacillus globigii) bacteria as agreed upon in our proposal. We used 785-nm laser radiation to study these samples, but as yet have not been able to see any spectra. We are modifying our optics to allow the collection of more scattered light from the samples in hopes of increasing our signal-to-noise ratio. So far we have only deposited these bacteria on non-prepared surfaces, but we plan to test the enhanced surfaces soon.

We are planning to do a study of the surface characteristics of the etched Ag films using SEM so as to be able to identify which surface preparation is optimal for enhancement. Our collaborator, Dr. Richard Zheng at PNNL, will provide some time on their SEM for this purpose.

We hope to be able to show enhancements of biomaterial on Ag surfaces soon.

\section{Proposals}

A team grant entitled, "Bioaerosol Detection via Nanoparticle Surface Enhanced Raman" was submitted by E. James Davis, Francois Baneyx, and Daniel T. Schwartz to NSF $(\$ 749,711)$ for 36 months funding (denied).

A single investigator grant is in preparation to NSF by E. James Davis for 36 months of funding (not yet submitted).

\section{Presentations}

Center for Nanotechnology, NSF site visit, presented by Atanu Sengupta (graduate student) titled, "Chemical Analysis of Nanogram Quantities of Matter by Raman Enhancement using Nanoscale Surfaces." 


\section{Figures:}

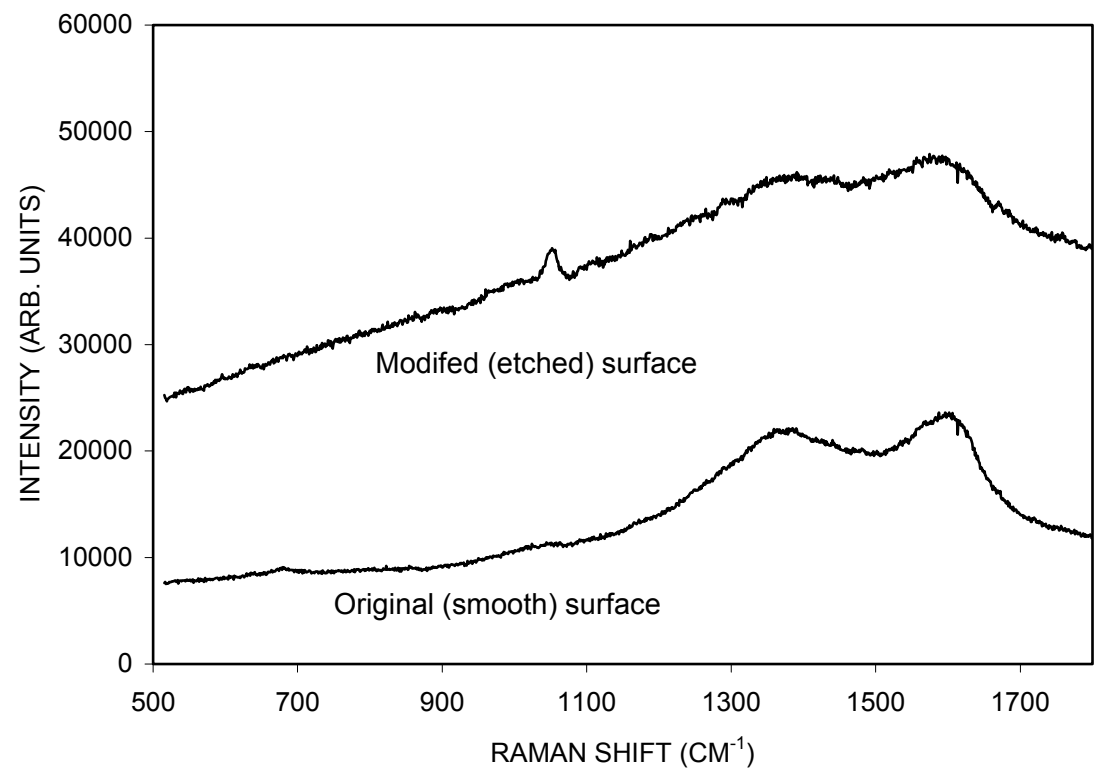

Figure 1. Raman spectra of pyridine on two surfaces. On the modified surface, we adsorbed $10^{-4} \mathrm{M}$ pyridine, and on the original surface, we adsorbed pure pyridine $(\sim 13 \mathrm{M})$. An enhancement of about $10^{5}$ can be seen.

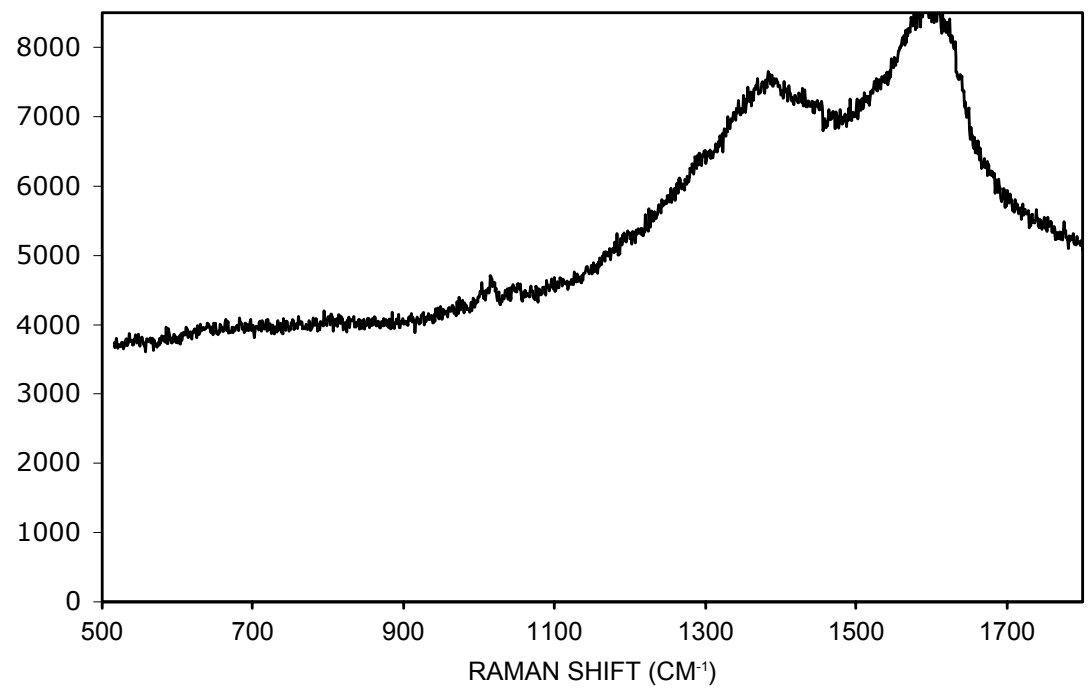

Figure 2. Preliminary data for 100-nm latex spheres deposited on a prepared Ag surface shows a small peak near $1000 \mathrm{~cm}^{-1}$. 


\section{Epitaxial Growth and Properties of Nanoscale Oxides for Spintronics}

Awardee: Diedrich A. Schmidt

Mentors: Marjorie A. Olmstead - UW, Scott A. Chambers - PNNL

\section{Project Summary}

An area of research which has become more important in recent years is oxide heteroepitaxy; in particular, the controlled growth of oxides other than $\mathrm{SiO}_{2}$ on silicon. However, direct oxide heteroepitaxy on silicon is very difficult because of the formation of silicides and/or $\mathrm{SiO}_{2}$. We have successfully utilized the semiconducting chalcogenide, gallium (sesqui-)selenide $\left(\mathrm{Ga}_{2} \mathrm{Se}_{3}\right)$, as a novel means of preventing $\mathrm{SiO}_{\mathrm{x}}$ formation from occurring during controlled oxide growth. The controlled growth of oxides on silicon has many technological impacts ranging from future transistor gate oxides and spintronics (electronics which manipulate the electron's spin) to catalysis and sensors.

A key property of being able to utilize an oxide semiconductor for spintronics is their compatibility with silicon. Anatase $\mathrm{TiO}_{2}$ is well lattice matched to silicon (001) (mismatch $\sim 1.5 \%$ ) and is therefore attractive as a heteroepitaxial oxide semiconductor on silicon. We have developed a means by which oxides can be grown on silicon without unwanted silicon reactions, and demonstrated this for growth of titanium dioxide $\left(\mathrm{TiO}_{2}\right)$ and $\mathrm{Co}$-doped $\mathrm{TiO}_{2}\left(\mathrm{Co}: \mathrm{TiO}_{2} ; 5 \%\right.$ Co-doped). We have also succeeded in growing laminar films of $\mathrm{Co}: \mathrm{TiO}_{2}$ on the chalcogonide buffer layer (see Figs. $1 \& 2$ ). This is a very important step in the implementation of a dilute magnetic semiconductor which is compatible with silicon.

Anatase $\mathrm{TiO}_{2}$ also has an added advantage of being a high- $\mathrm{K}$ dielectric and is therefore attractive as a gate oxide as well. However, there are specific valence band and conduction band offsets which are required for the different applications (spintronics or gate dielectrics). The band offsets between $\mathrm{Si}$ and $\mathrm{TiO}_{2}$ should be tunable with the $\mathrm{Ga}_{2} \mathrm{Se}_{3}$ buffer layer by changing the interface dipoles with doping to achieve the desired band offsets for the appropriate application.

While we have made much progress in the growth properties of $\mathrm{TiO}_{2}$, and $\mathrm{Co}: \mathrm{TiO} 2$ on $\mathrm{Si}(001)$, there are still important steps which must be taken to improve on our techniques. In the future, we plan to explore the temperature dependence of our growth conditions for epitaxial, single-crystal thin-films including Co doped anatase thin films. We will also look into perfecting the growth conditions as well as dopant modification of the chalcogenide buffer layer for different applications of the oxide film (i.e. spin-injector vs. gate oxide). We will continue to study the morphology of these films via SPM techniques as well as photoemission spectroscopy. Both experimental techniques will be carried out at UW.

\section{Publications, Presentations and Proposals:}

"Buffer Layer Enhanced Heteroepitaxy of $\mathrm{TiO}_{2}$ on $\mathrm{Si}(001)$ ", D. A. Schmidt, T. Ohta, Q. Yu, F. S. Ohuchi, and M. A. Olmstead. 2004 Nanotech Worskhop, UW, Seattle, WA; 2004 PNWAVS/Surface Analysis, Richland, WA; 2004 CDO Networking Day (talk), UW, Seattle, WA; 
2004 International Conference on the Physics of Semiconductors, Flagstaff, AZ.

"Novel Chalcogenide Buffer Layer for Oxide Heteroepitaxy on Si(001)", D. A. Schmidt, T. Ohta, Q. Yu, F. S. Ohuchi, and M. A. Olmstead. 2005 UW Science and Technology Showcase, Seattle, WA.

"Buffer Layer Enhanced Oxide Heteroepitaxy on Si(001)", D. A. Schmidt, T. Ohta, C. Lu, Q. Yu, F. S. Ohuchi, and M. A. Olmstead. Article in preparation.

"Initial Stages of Anatase $\mathrm{TiO}_{2}$ Heteroepitaxy on Lanthanum Aluminate (001)", D. A. Schmidt, T. Ohta, Q. yu, and M. A. Olmstead. Article in preparation.

\section{Proposals:}

Investigator Name: Kannan Krishnan, PI; Daniel Gamelin, Marjorie Olmstead, Alec Pakhomov and Scott Chambers, co-PIs); Project/Proposal Title: Magnetic oxide nanostructures in silicon based spintronics; Source of Support: National Science Foundation; Period Covered: 08/01/0507/31/08; Location of Research: University of Washington.

Investigator Name: Marjorie Olmstead, PI (Fumio Ohuchi, co-PI); Project/Proposal Title: Chalcogenide Buffer Layers for Oxide Heteroepitaxy on Silicon; Source of Support: National Science Foundation; Period Covered: 06/01/05 - 05/31/08; Location of Research: University of Washington.

As a result of the work presented here, the investigators at UW have registered this technology with the UW TechTransfer Office which might result in a future patent application.

\section{Selected Figures:}

Figure 1: 500 $\times 500 \mathbf{~ n m}^{2}$ Scanning Tunneling Microscopy Images: a) $\sim 3-4 \mathrm{~nm}$ Co-doped $\mathrm{TiO}_{2}$ deposited on $\sim 0.8 \mathrm{~nm} \mathrm{Ga}_{2} \mathrm{Se}_{3}$ buffer layer, b) $\sim 2.6-3 \mathrm{~nm} \mathrm{TiO}{ }_{2}$ deposited on $\sim 0.8 \mathrm{~nm} \mathrm{Ga}_{2} \mathrm{Se}_{3}$ buffer layer. The RMS surface roughness on $0.5 \mathrm{um}^{2}$ scale is only $0.38 \mathrm{~nm}(1 \mathrm{a})$ and $0.83 \mathrm{~nm}(1 \mathrm{~b})$, i.e. approximately $1 / 2$ and $1 \mathrm{TiO}_{2}$ unit cell, respectively. Z-scales are the same for both images indicating the film in Fig. 1a is much more flat than the film in Fig. $1 b$. 


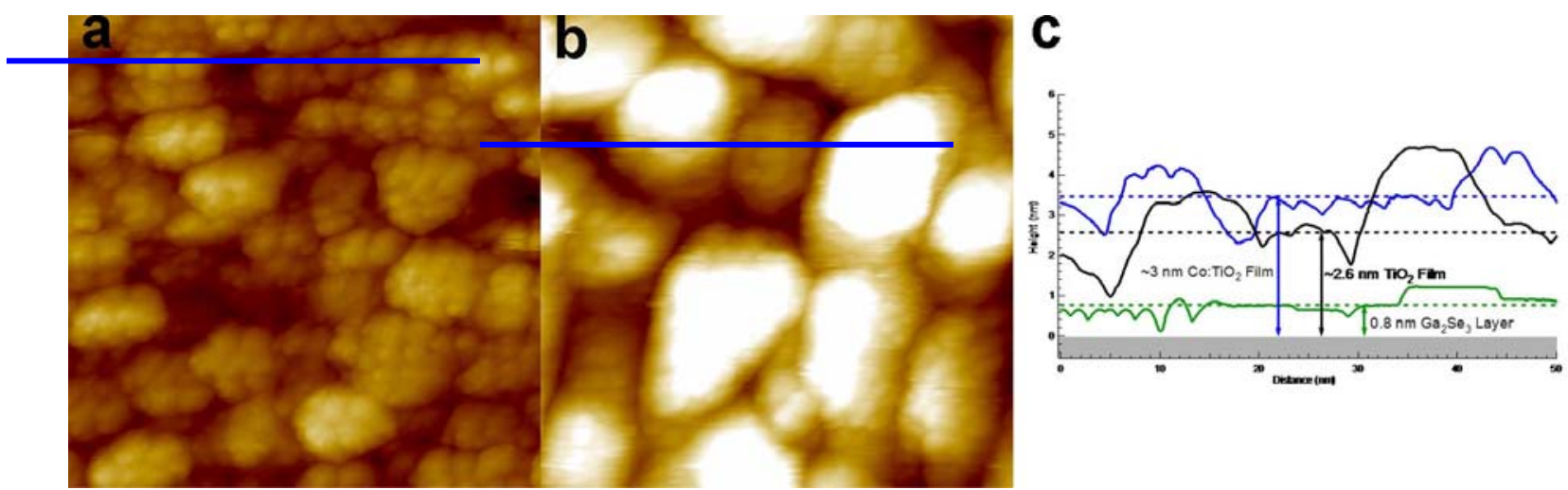

Figure 2: $50 \times 50 \mathbf{~ n m}^{2}$ Scanning Tunneling Microscopy Images and line profiles: a) $\sim 3-4$ nm Co-doped $\mathrm{TiO}_{2}$ deposited on $\sim 0.8 \mathrm{~nm} \mathrm{Ga} \mathrm{Se}_{3}$ buffer layer, b) 2.6-3 nm TiO${ }_{2}$ deposited on $\sim 0.8 \mathrm{~nm} \mathrm{Ga}_{2} \mathrm{Se}_{3}$ buffer layer, c) line profiles of the films (blue lines in $2 \mathrm{a}$ and $2 \mathrm{~b}$ ). The gray represents the $\mathrm{Si}(001)$ substrate while the green line represents the profile of the chalcogenide buffer layer. The blue and black lines are of the films shown in $2 \mathrm{a}$ ) and $2 \mathrm{~b}$ ), respectively. Z-scales are the same for both images indicating the film in Fig. 2a is much more flat than the film in Fig. 2b. The films in $2 \mathrm{a}$ ) and $2 \mathrm{~b}$ ) are likely anatase grown at $300 \mathrm{~K}$ and rutile grown at $613 \mathrm{~K}$, respectively. 


\subsection{Awards Authorized, June 2003}

"Detailed materials, magnetic, and electronic studies of doped transition metal oxides for spintronic applications"

Awardee: Tiffany Kaspar

Mentors: Kannan M. Krishnan - UW, Scott Chambers - PNNL

Page 2.25

"Photochemistry of Colloidal Dilute Magnetic Semiconductor Quantum Dots"

Awardee: Kevin R. Kittilstved

Mentors: Daniel R. Gamelin - UW, Alan G. Joly - PNNL

Page 2.27

"Superparamagnetic Nanoparticles for Biomedical Applications"

Awardee: Nathan Kohler

Mentors: Miqin Zhang - UW; Glen Fryxell - PNNL

Page 2.30

"Molecular Engineering of the Conjugated Polymers for High - Performance LightEmitting Diodes (LEDs)"

Awardee: Michelle Liu- UW

Mentors: Alex K.-Y. Jen - UW, Paul Burrows - PNNL

Page 2.34

"Magnetic Nanocrystals: Synthesis and a Study of ZnO and GaN Diluted Magnetic Semiconductors"

Awardee: Nick Norberg

Mentors: Daniel Gamelin - UW, James Amonette - PNNL

Page 2.37

"Pd Nanoclusters Supported on MgO(100): Effects of Cluster Size on Chemisorption Properties"

Awardee: Steven Tait

Mentors: Charles Campbell and Samuel Fain - UW, Zdenek Dohnalek and Bruce Kay - PNNL

Page 2.42 


\section{Detailed Materials, Magnetic, and Electronic Studies of Doped Transition Metal Oxides for Spintronic Applications}

Awardee: Tiffany Kaspar

Mentors: Krishnan Kannan - UW, Scott Chambers - PNNL

\section{Project Summary}

The emerging field of spintronics (spin transport electronics or spin-based electronics) aims to revolutionize microelectronic devices by utilizing the quantum property of spin for device operation. Since the initial discovery of room temperature ferromagnetism in Co-doped anatase $\mathrm{TiO}_{2}$ in 2001, there has been an explosion of interest in doped transition metal oxides as potential dilute magnetic semiconductors (DMSs), which may find application in future spintronic devices. In the past year, we have initiated a detailed study of $\mathrm{Cr}$-doped $\mathrm{TiO}_{2}$ deposited by oxygen plasma assisted molecular beam epitaxy (OPA-MBE).

At a relatively fast deposition rate $(\sim 0.1 \AA / \mathrm{sec})$, epitaxial Cr-doped anatase films are obtained on $\mathrm{LaAlO}_{3}(\mathrm{LAO})$ substrates. The film surface consists of nanometer-scale roughness. As shown in Figure 1(a), cross-sectional high resolution TEM and EDS indicate that $\mathrm{Cr}$ is distributed uniformly in the film depth, with no segregation to the surface. Spectroscopic analysis by XANES and EXAFS indicate that $\mathrm{Cr}$ (III) substitutes for Ti(IV) without any indication of secondary phases. These samples, which are highly resistive as grown, are ferromagnetic at room temperature with a magnetic moment of $\sim 0.5 \mu_{\mathrm{B}} / \mathrm{Cr}$ and a Curie temperature of $690 \mathrm{~K}$ by VSM. Strong evidence that the ferromagnetic ordering is coupled to the anatase lattice is provided by the observed in-plane magnetocrystalline anisotropy and the strong shape anisotropy.

Films deposited at a slower deposition rate $(\sim 0.015 \AA / \mathrm{s})$ have a higher degree of crystalline order $\left(\mathrm{XRD}\right.$ rocking curve width of $0.095^{\circ}$ ) and a significantly smoother surface, as seen in Figure 1(b). The XANES and EXAFS results are very similar to the fast-grown films, indicating substitution of $\mathrm{Cr}(\mathrm{III})$ for Ti(IV). Contrary to expectations, however, these samples show little or no ferromagnetism.

The lack of strong ferromagnetic ordering in slow-grown $\mathrm{Cr}: \mathrm{TiO}_{2}$ can be understood via density functional theory (DFT) calculations. These calculations show hybridization and ferromagnetic ordering between $\mathrm{Cr}$ dopants occurs only if they each exhibit a formal charge state of +4 . As the dopants are compensated by donor defects to +3 , the hybridization disappears and the dopants do not interact magnetically. Thus, in slow-grown films all the $\mathrm{Cr}$ dopants are fully compensated to $\mathrm{Cr}(\mathrm{III})$, which implies this is the thermodynamically preferred state, and thus no ferromagnetic ordering occurs. $\mathrm{Cr}(\mathrm{IV})$ is also not observed for fast-grown films which do exhibit strong ferromagnetism. In this case, structural or electronic defects in these films appear to mediate ferromagnetic ordering between Cr dopants, although further study is necessary to elucidate the exact mechanism. 
Figure 1. HRTEM images of $\mathrm{Cr}$-doped anatase grown at a fast deposition rate $(5 \% \mathrm{Cr})$ and at a slow deposition rate $(7 \% \mathrm{Cr})$. In both cases, EDS confirms a uniform distribution of $\mathrm{Cr}$ in the film. The highly defective fast-grown films are strongly ferromagnetic at room temperature, while the well-ordered slow-grown films are only weakly ferromagnetic.
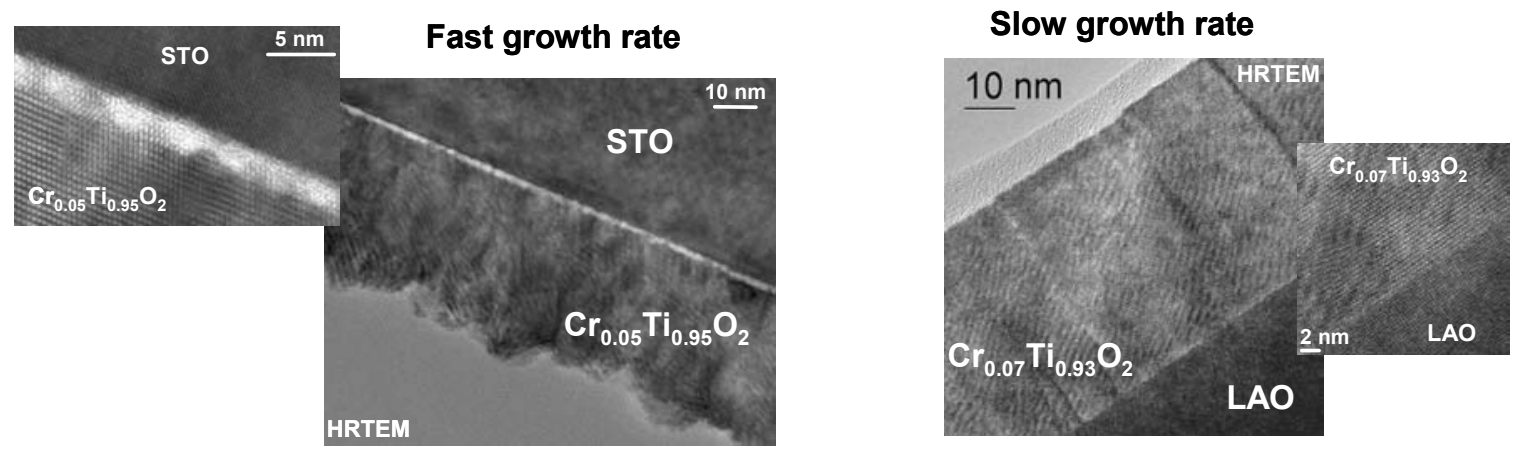

\section{Presentations:}

T.C. Kaspar, T. Droubay, S.M. Heald, C.M. Wang, V. Shutthanandan, S. Thevuthasan, S.A. Chambers. "MBE Growth and Room Temperature Ferromagnetism in Epitaxial Co-doped $\mathrm{SrTiO}_{3}$." AVS $51^{\text {st }}$ International Symposium in Anaheim, California, November 2004.

\section{Publications:}

T.C. Kaspar, L. Ye, S.M. Heald, C.M. Wang, T. Droubay, V. Shutthanandan, S. Thevuthasan, D.E. McCready, A.J. Freeman, S.A. Chambers. "Negligible Magnetism in Structurally Excellent Cr-doped $\mathrm{TiO}_{2}$ Anatase." Physical Review Letters, in preparation (2005).

J. Osterwalder, T. Droubay, T. Kaspar, J. Williams, C.M. Wang, S.A. Chambers. "Growth of Cr-doped $\mathrm{TiO}_{2}$ films in the rutile and anatase structure by oxygen-plasma assisted molecular beam epitaxy." Thin Solid Films 485289 (2005).

S.A. Chambers, T.C. Droubay, T.C. Kaspar. "Epitaxial growth and properties of magnetically doped $\mathrm{TiO}_{2}$." Ch. 7 in Thin Films and Heterostructures for Oxide Electronics. S. Ogale, ed. Kluwer Academic Publishers 2005.

T.C. Kaspar, T. Droubay, C.M. Wang. S.M. Heald, A.S. Lea, S.A. Chambers. "Co-doped anatase $\mathrm{TiO}_{2}$ heteroepitaxy on Si(001)." Journal of Applied Physics 97073511 (2005).

V. Shutthanandan, S. Thevuthasan, S.M. Heald, T. Droubay, M.H. Engelhard, T.C. Kaspar, D.E.McCready, L. Saraf, S.A. Chambers, B.S. Mun, N. Hamdan, P. Nachimuthu, B.Taylor, R.P. Sears, B. Sinkovic. "Room Temperature Ferromagnetism in Ion-implanted Co-doped $\mathrm{TiO}_{2}(110)$ Rutile." Applied Physics Letters 84 (22) 4466 (2004).

S.A. Chambers, T. Droubay, T.C. Kaspar, M. Gutowski. "Accurate Valence Band Maximum Determination for $\mathrm{SrTiO}_{3}(001)$." Surface Science 554 (2-3) 81 (2004).

S.A. Chambers, T. Droubay, T.C. Kaspar, M. Gutowski. "Experimental Determination of Valence Band Maxima for $\mathrm{SrTiO}_{3}, \mathrm{TiO}_{2}$, and $\mathrm{SrO}$ and the Associated Valence Band Offsets with $\mathrm{Si}(001)$." Journal of Vacuum Science and Technology B 22 (4) 2205 (2004). 


\section{Photochemistry of Colloidal Dilute Magnetic Semiconductor Quantum Dots}

Awardee: Kevin Kittilstved

Mentors: Daniel R. Gamelin - UW, Alan G. Joly - PNNL

\section{Project Summary}

The ability to convert visible light into energy required to drive a chemical reaction is an attractive physical process and the subject of intense research. Recent advances in this area have led the Joint Institute to identify heterogeneous catalysis using nanostructured materials as a "Focus Area for JIN Activities and Awards." Some transition metal-doped "wide-gap" semiconductors have been shown to perform these reactions photocatalytically. Our research is focused on the syntheses, spectroscopy, magnetism, and photophysics of these doped semiconductors with nanoscale dimensions. These materials exhibit new interesting magnetic and spectroscopic properties compared to their host semiconductors. Photo-induced charge separation using visible photons in $\mathrm{Ni}^{2+}: \mathrm{ZnS}$ was demonstrated to enhance the photocatalytic evolution of hydrogen gas from aqueous solutions containing sacrificial electron donors compared to pure $\mathrm{ZnS}$. $^{1}$ The focus of this research has shifted to understanding the photophysics of various transition metal doped $\mathrm{ZnO}$ nanocrystals and possibly exploiting these processes towards manipulating the photochemical processes and magnetic properties of these materials.

The synthetic methodologies towards the preparation of high-quality, internally doped $\mathrm{ZnO}$ diluted magnetic semiconductors have been refined and are nicely demonstrated in an article published in the Journal of the American Chemical Society on the synthesis and characterization of $\mathrm{Mn}^{2+}: \mathrm{ZnO}$ nanocrystalline colloids (JIN collaboration). ${ }^{2}$ The ability to produce these highquality, internally-doped diluted magnetic semiconductor nanocrystals in gram quantities has expedited the photocatalytic experiments that have recently been started. In addition to their possibility as materials for photocatalytic applications, these materials are also sought after for their interesting magnetic properties in addition to their semiconducting nature. The results observed towards manipulation of high- $T_{\mathrm{C}}$ ferromagnetism in $\mathrm{Mn}^{2+}: \mathrm{ZnO}^{3,4}$ show great promise for these materials and these perturbations could likewise be used to change the photochemical properties of these materials. The photocatalytic properties of these wide-gap semiconductors are very promising and the high surface area to volume ratios achieved in the nanoscale regime is a reason why these materials are attracting much attention.

The removal of organic solvents and toxins from water is an important environmental process that has been researched for many decades. The reaction that we have selected to follow for the first phase of our photocatalytic experiments is the photodegradation of phenol, a toxic compound used in the production of herbicides and fungicides. The mechanism for phenol photodegradation in aqueous media using $\mathrm{TiO}_{2}$ as a photocatalyst has been shown to follow the generation of hydroxyl radicals adsorbed on the $\mathrm{TiO}_{2}$ surface ${ }^{3}$ formed by trapping photogenerated hole in the valence band. ${ }^{4}$ The hydroxyl radicals can then go on to promote the degradation of phenol. High energy UV photons can produce these hydroxyl radicals on pure $\mathrm{ZnO}$. This is not a very efficient process if one would want to use sunlight, since there is a 
considerable amount of visible photons that are not absorbed in $\mathrm{ZnO}$. Transition metal doping of $\mathrm{ZnO}$ produces acceptor states for the photogenerated electron under visible illumination. The valence band to transition metal is observed in $\mathrm{Co}^{2+}$, and $\mathrm{Ni}^{2+}: \mathrm{ZnO}$ nanocrystalline colloids as broad sub-band gap absorption intensity. ${ }^{5} \mathrm{Mn}^{2+}: \mathrm{ZnO}$ shows the other photoionization process, a transition metal to conduction band transition. ${ }^{2}$ The magnetic circular dichroism spectra for $\mathrm{Co}^{2+}: \mathrm{ZnO}$ DMS quantum dots shows the LMCT transition that is occluded by the band gap absorption of $\mathrm{ZnO}$ in the electronic spectra. ${ }^{5}$ Therefore, this material could possibly promote the photodegradation of phenol under visible light irradiation. The photocatalytic activity of pure $\mathrm{ZnO}$ and $3 \% \mathrm{Co}^{2+}: \mathrm{ZnO}$ is shown in Figure 1. With similar irradiation times the amount of phenol degradation was less than $2 \%$ for pure $\mathrm{ZnO}$ and ca. $60 \%$ for $\mathrm{Co}^{2+}: \mathrm{ZnO}$. This result is very promising and further experiments with $\mathrm{Ni}^{2+}: \mathrm{ZnO}$ and $\mathrm{Mn}^{2+}: \mathrm{ZnO}$ are underway.

\section{Note:}

The Joint Institute was started to establish and strengthen collaborations between research groups at UW and PNNL. The technical expertise that I am receiving through this fellowship in the forms of intense hands-on training and collecting transient absorption decay profiles at PNNL is greatly appreciated. I also extend my knowledge of these experiments to every member of the Gamelin research group; furthering their knowledge of experiments that they would not otherwise have access to. I also have collected TEM images at EMSL for other group members that will be or have been published. The time spent at PNNL also aids in the career decision that I will make after graduate school. I also feel that I have contributed to Dr. Joly's experience through discussion of other areas of my research, such as the interesting magnetic properties of tetrahedral $\mathrm{Ni}^{2+}$, and other aspects of the research aside from the transient absorption measurements. Furthermore, this experience has allowed me the ability to pursue other collaborations at PNNL that will further broaden my experience and strengthen my graduate research.

Figure 1. Change in the electronic absorption spectra of phenol $(0<t<18 \mathrm{~h})$ under visible light irradiation with $3 \% \mathrm{Co}^{2+}: \mathrm{ZnO}$ nanocrystalline powders. Inset: change in the relative phenol

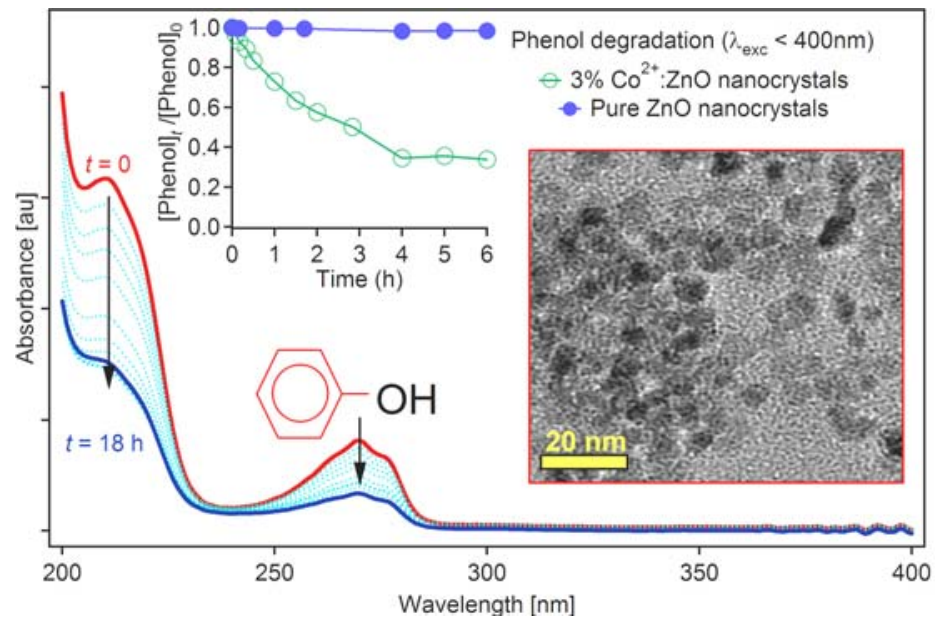

concentration after different irradiation times using $3 \% \mathrm{Co}^{2+}: \mathrm{ZnO}\left(-\odot_{-}\right)$and pure $\mathrm{ZnO}\left({ }^{-}-\right)$. The TEM image is of the $\mathrm{Co}^{2+}: \mathrm{ZnO}$ (ca. 8-9 nm in diameter) nanocrystals collected at EMSL with assistance from Dr. Chongmin Wang. 


\section{References}

1. Kudo, A.; Sekizawa, M., "Photocatalytic $\mathrm{H}_{2}$ Evolution under Visible Light Irradiation on NiDoped ZnS Photocatalyst", Chem. Commun., 2000, 1371-1372.

2. Norberg, N. S.; Kittilstved, K. R.; Amonette, J. E.; Kukkadapu, R. K.; Schwartz, D. A.; Gamelin, D. R., "Synthesis of Colloidal $\mathrm{Mn}^{2+}: \mathrm{ZnO}$ Quantum Dots and High- $T_{\mathrm{C}}$ Ferromagnetic Nanocrystalline Thin Films", J. Am. Chem. Soc., 2004, 126, 9387-9398.

3. Kittilstved, K. R.; Gamelin, D. R., "Activation of High- $T_{\mathrm{C}}$ Ferromagnetism in $\mathrm{Mn}^{2+}: \mathrm{ZnO}$ Using Amines", J. Am. Chem. Soc., 2005, accepted, in press.

4. Kittilstved, K. R.; Norberg, N. S.; Gamelin, D. R., "Chemical Manipulation of High- $T_{\mathrm{C}}$ Ferromagnetism in ZnO Diluted Magnetic Semiconductors", Phys. Rev. Lett., 2005, accepted, in press.

5. Schwartz, D. A.; Norberg, N. S.; Nguyen, Q. P.; Parker, J. M.; Gamelin, D. R., "Magnetic Quantum Dots: Synthesis, Spectroscopy, and Magnetism of $\mathrm{Co}^{2+}$ - and $\mathrm{Ni}^{2+}$-Doped $\mathrm{ZnO}$ Nanocrystals", J. Am. Chem. Soc., 2003, 125, 13205-13218. 


\section{Superparamagnetic Nanoparticles for Biomedical Applications}

Awardee: Nathan Kohler

Mentors: Miqin Zhang - UW, Glen Fryxell - PNNL

\section{Project Summary}

The last few years have seen a growing interest in developing nanoparticle-based targeting agents for tumor diagnostics and therapeutics. It is recognized that with these targeting agents, tumors or other diseased tissues can be detected at the cellular or molecular level. Two major applications associated with these systems are magnetic resonance imaging (MRI) and controlled drug release (CDR). In MRI, nanoparticles with superparamagnetic properties serve as contrast enhancement agents, while in CDR, they function as drug carriers delivering and releasing the drugs into target cells. It is envisioned that the combination of these two technologies will allow simultaneous diagnosis and treatment of the diseased tissues. Whether these nanoparticles are serving as contrast agents or drug carriers, both applications rely on the efficiency of specific targeting by the nanoparticle systems. In addition, the nanoparticle system in CDR is also required to have an effective mechanism of drug release within the target cells. An effective approach to improving the target capability and drug release efficiency is to conjugate nanoparticles with chemical or biological reagents that have strong affinity with target cells and high efficiency of nanoparticle internalization.

In this work, we developed a drug-nanoparticle conjugate by grafting MTX to the iron oxide nanoparticle surface. This design of MTX-nanoparticle system has a number of combined advantages in view of its therapeutic functionality to treat tumors. This new nanoparticle system is capable of real-time monitoring of drug delivery to the target tumor, thus allowing physicians to access the efficacy of their treatment utilizing MRI. Further, by covalently modifying the surface of the nanoparticle via a peptide bond, the MTX is not released from the surface of the nanoparticles under intravenous conditions. Instead, cleavage of the amide bond occurs only under conditions present in the lysosomal compartment, namely, low $\mathrm{pH}$ and in the presence of lysozymes, a typical environment inside the target cells, as shown in Figure 1. This will virtually eliminate toxic effects of free MTX in healthy tissues within the body. Finally, we have demonstrated increased uptake of the MTX conjugated nanoparticles in tumor cells overexpressing the folate receptor. This will lead to greater uptake of the nanoparticles into the targeted tumors cells being treated, as shown in Figure 2.

We have tested the MTX-nanoparticle system in vitro in human breast cancer (MCF-7) and human cervical cancer cells (HeLa). Over a 5 day period, the MTX-nanoparticle system showed a similar reduction in cellular viability compared to the $2 \mathrm{mg} / \mathrm{mL}$ free MTX control system. In addition, we have quantified the uptake of the nanoparticles human primary cardio myocyte cells to access potential toxicity. The HeLa cells demonstrated a 10 fold higher uptake than the primary cells and the MCF-7 cells demonstrated a 30 fold higher uptake than the primary cardio myocyte cells, as shown in Figure 3. 


\section{Publications, Presentations and Proposals:}

"Methotrexate Modified Superparamagnetic Nanoparticles and Their Intracellular Uptake into Human Cancer Cells" N. Kohler, C. Sun., J. Wang, and M. Zhang. Langmuir, (Submitted).

"Methotrexate Modified Superparamagnetic Nanoparticles for Cancer Diagnostics and Therapeutics" N. Kohler, C. Sun, D. Gupta, J. Wang, G. Fryxell, and M. Zhang. Magnetic Microcarriers, Lyon, France, May 2004.

"Novel functional poly(ethylene glycol) self assembled monolayers for ligand grafting to metal oxide nanoparticles" N. Kohler, G. Fryxell, and M. Zhang. Magnetic Microcarriers, Lyon, France. May 2004.

"A Bifunctional Poly(ethylene glycol) Silane Immobilized on Metallic Oxide-Based Nanoaprticles for Conjugation with Cell Targeting Agents" Journal of the American Chemical Society, 2004, 126, 7206-7211.

N. Kohler, G. Fryxell and M. Zhang, "Superparamagnetic nanoparticles for imaging," Nanoscale Science and Technology Workshop, Seattle, WA, Sept. 2003.

Funding obtained that related to this research:

Molecular imaging diagnosis and treatment of medulloblastoma sponsoring agency/organization: $\mathrm{NIH} / \mathrm{NCI}$

Title: Magnetic nanoparticle-conjugates as contrast agents and drug carriers for cancer diagnostics and therapeutics sponsoring agency/organization: Taiwan-ITRI 


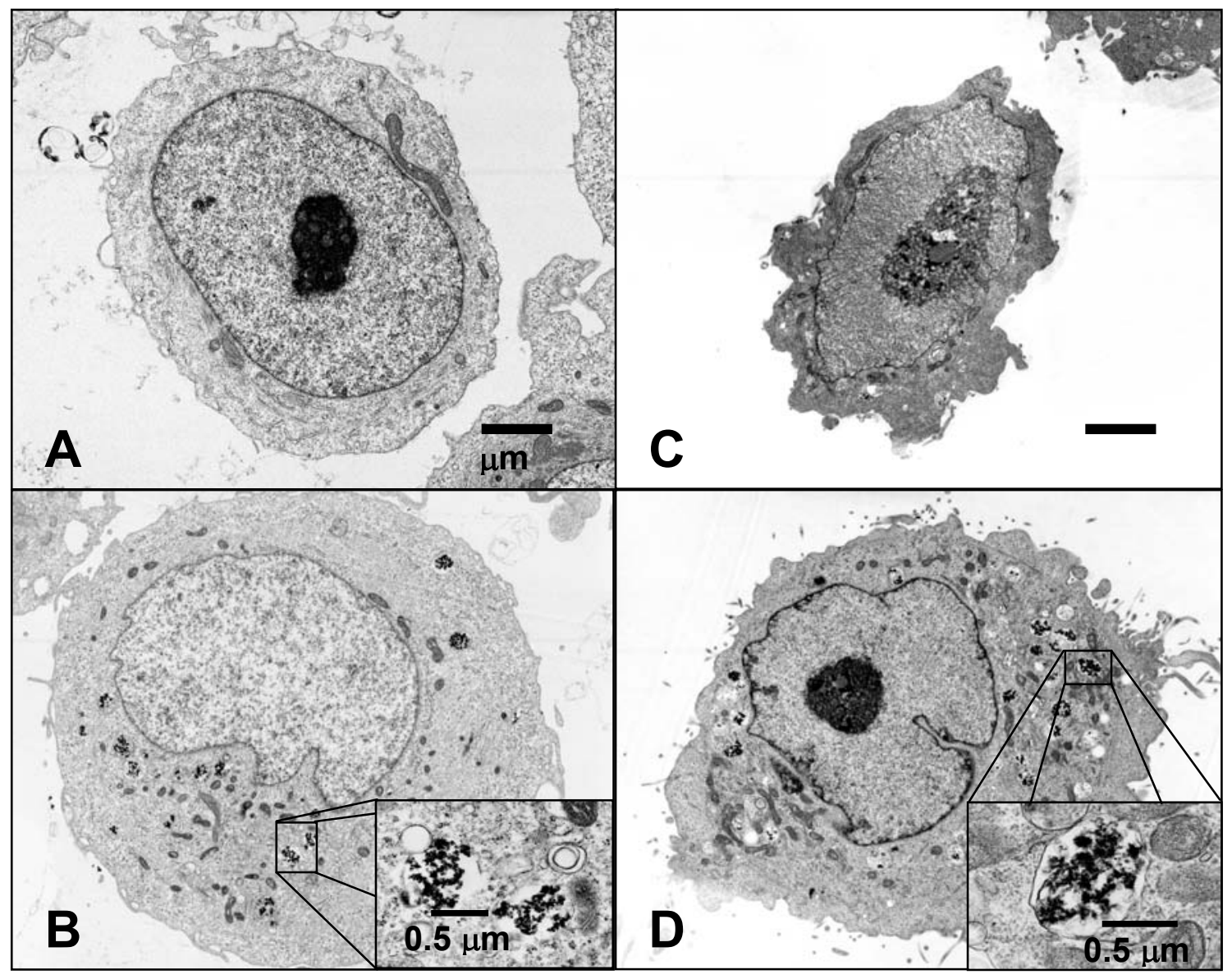

Figure 1. TEM images of MCF-7 control cells (A), MCF-7 cells grown with MTXnanoparticles $(B)$, HeLa control cells $(C)$ and HeLa cells grown with MTX-nanoparticles 


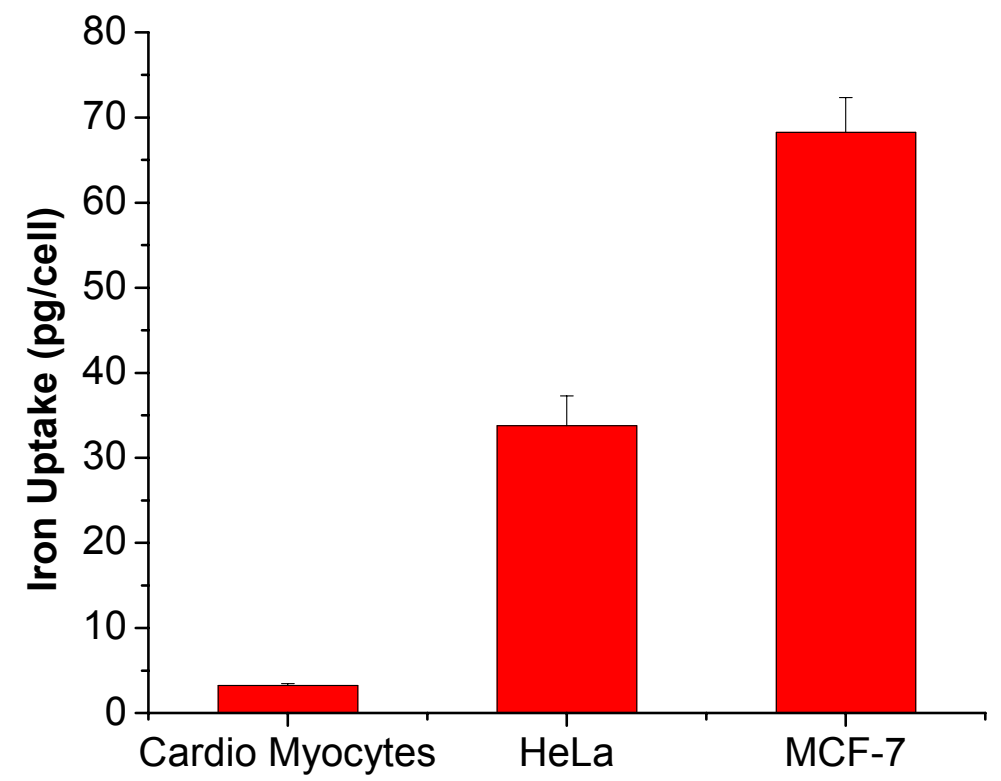

Figure 2. Preferential uptake of nanoparticle-MTX conjugate by breast cancer cells compared to cardiomyocytes. 


\section{Molecular Engineering of the Conjugated Polymers for High - Performance Light-Emitting Diodes (LEDs)}

Awardee: Michelle Liu

Mentors: Alex K.-Y. Jen - UW, Paul Burrows - PNNL

\section{Project Summary}

Hole-electron recombination in organic LEDs Leads to the formation of both singlet and triplet excitons, the efficiency of organic LEDs based on fluorescent conjugated polymers is limited because only $25 \%$ of singlet excitons is emissive. Our approach to improve the device performance is to utilize the phosphorescence emission; the phosphorescent dopants will be incorporated into the polymer matrix to harvest both the singlet and triplet excitons. In order to achieve maximum efficiency in these host-dopant OLEDs, the host for such phosphorescent emitters should fulfill several requirements. First, the triplet energy level of the host has to be higher than that of the guest to prevent back energy transfer from the guest to the host. Second, the emission of the host should have good spectral overlap with the absorption of the guest to ensure efficient energy transfer. Moreover, the host should possess suitable HOMO and LUMO energy levels to facilitate charge injection and transport. The efficiencies of conjugated polymerbased phosphorescence devices usually are much lower than those of the small molecule-based devices, because long effective conjugation length results in lower triplet energy state. The back energy transfer from the phosphor to the polymer host will lead to the phosphorescence quenching and lower device efficiency.

The objective of this project is to develop suitable polymer hosts with high triplet energy levels for highly efficient phosphorescent LEDs. We have developed a series of fluorene-based UV-blue emitting materials with meta-linkage in the polymer back bone (Figure 1). The presence of the meta-linkage will interrupt the conjugation length resulting in the elevated triplet energy levels. The substituting side groups on the phenylene ring, either hole donating carbazoles or electron withdrawing oxadiazoles will facilitate charge injection and transport.

As shown in their photoluminescent spectra (Figure 2), all polymers emit in the purple-blue region. This indicates that the introduction of a meta-phenylene linkage into the polymer backbone effectively interrupts the conjugation and increases the band gap. The oxadiazolecontaining copolymers, PF-mOXDP $(\lambda=398 \mathrm{~nm})$ and PF-mCzP-mOXDP $(\lambda=403 \mathrm{~nm})$ exhibit a slightly red-shifted emission compared to that of PF-mCzP $(\lambda=394 \mathrm{~nm})$, which could be attributed to the weak charge transfer between the electron-rich fluorene and carbazolesubstituted phenylene and electron-deficient oxadiazole-substituted phenylene. This observation suggests that carbazole and oxdiazole substitutions on the phenylene ring only slightly perturb the main chain conjugation.

We have used these UV-blue emitting polymers as host for a red-emitting phosphors. The device with $\mathrm{PF}-\mathrm{mCzP}-\mathrm{mOXDP}$ which possesses bipolar charge-transporting properties shows 
the best electroluminescent performance. The external quantum efficiency can reach $5 \%$, and maximum brightness is around $8230 \mathrm{~cd} / \mathrm{m}^{2}$.

\section{Publications, Presentations and Proposals:}

Development of large band gap host materials for high-energy phosphorescent emitters, M. S. Liu, Y.-H. Niu, A. K.-Y. Jen, PMSE Preprints 92, 2005, 566-567.

Efficient and stable blue light-emitting diodes based on an anthracene derivative doped poly(Nvinylcarbazole), Y.-H. Niu, B. Q. Chen, T.-D. Kim, M. S. Liu, A. K.-Y. Jen, Appl. Phys. Lett. $85,2004,5433-5435$

Material and Interface Engineering for Highly Efficient Polymer Light Emitting Diode, M. S. Liu, Y.-H. Niu, J. D. Luo, B. Q. Chen, T.-D. Kim, A. K.-Y. Jen, J. Macromolecular Chem. (in press)

Multilayer thermally crosslinked hole-transporting polymers for cascade hole-injection and effective electron-blocking/exciton-confinement in polymer hosted phosphorescent lightemitting diodes, Y-H. Niu, M. S. Liu, J-W. Ka, and A K.-Y. Jen, Appl. Phys. Lett. (submitted).

American Chemical Society National Meeting, San Diego, 2005.

Funding from research proposals which was facilitated by these results:

Efficient and Low-cost Lighting Technology Based on Organic White Light-emitting Diodes, PI: A. K.-Y. Jen, UW TGIF fund for $\$ 50 \mathrm{~K}$ for the period $01 / 01 / 05$ to $12 / 31 / 05$.

\section{Figures:}

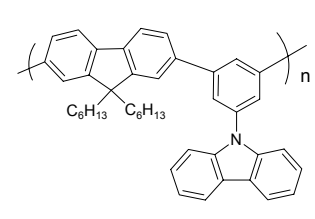

PF-mCzP

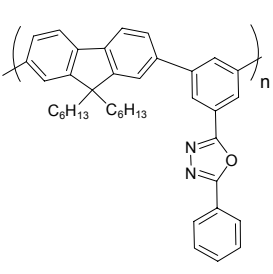

PF-mOXDP

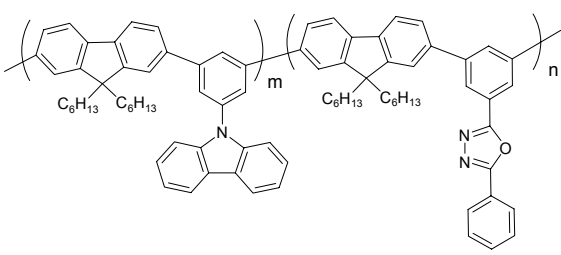

PF-mCz-mOXDP

Figure 1. Chemical structure of the copolymers. 


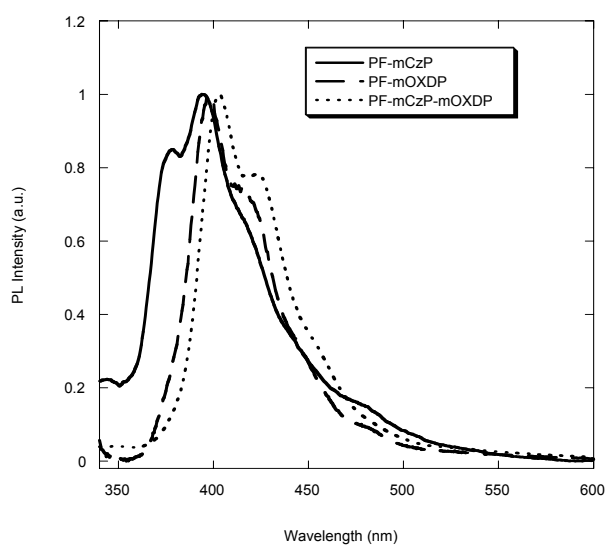

Figure 2. PL spectra of the copolymers. 


\section{Magnetic Nanocrystals: Synthesis and Study of ZnO and GaN Diluted Magnetic Semiconductors}

Awardee: Nick Norberg

Mentors: Daniel Gamelin - UW, James Amonette - PNNL

\section{Project Summary}

Theoreticians have identified $\mathrm{ZnO}$ as an excellent candidate host semiconductor for supporting high- $T_{C}$ ferromagnetism when doped with a variety of $3 \mathrm{~d}$ transition metals. ${ }^{1,2}$ These predictions have been confirmed experimentally, ${ }^{3,4}$ but the difficulty in verifying the source of ferromagnetism arises from the pure diluted magnetic semiconductor (DMS) has aroused doubt on some of these reports, ${ }^{5}$ and remains a challenge in this field. The synthesis of $\mathrm{TM}^{2+}: \mathrm{ZnO}$ nanocrystals through colloidal solution routes provides a convenient way to the synthesis of high quality DMSs, allowing a reliable characterization of their physical properties. This work presents a chemical approach to the synthesis of $\mathrm{Co}^{2+}: \mathrm{ZnO}, \mathrm{Ni}^{2+}: \mathrm{ZnO}$ and $\mathrm{Mn}^{2+}: \mathrm{ZnO}$ nanocrystals, and a study of their magnetic properties.

Our initial synthesis of colloidal $\mathrm{TM}^{2+}: \mathrm{ZnO}$ nanocrystals used ethanol as the primary solvent.[1] We have recently reported a better approach towards the synthesis of high quality $\mathrm{Co}^{2+}$ and $\mathrm{Ni}^{2+}$-doped $\mathrm{ZnO}$ colloidal nanocrystals,[2] where an ethanolic solution of $\mathrm{N}(\mathrm{Me})_{4} \mathrm{OH}$ is added dropwise to a stirring DMSO solution of $\mathrm{Co}(\mathrm{OAc})_{2}$ or $\mathrm{Ni}\left(\mathrm{ClO}_{4}\right)_{2}$, yielding relatively monodisperse, colloidal nanocrystals. This route has now been extended to the synthesis of $\mathrm{Mn}^{2+}: \mathrm{ZnO}$ nanocrystals using $\mathrm{Mn}(\mathrm{OAc})_{2}$ as the precursor dopant.[6]

Homogeneous speciation of the dopant is essential for high quality DMS materials. For $\mathrm{Co}^{2+}: \mathrm{ZnO}$, isotropic doping was confirmed by monitoring the $\mathrm{Co}^{2+}$ ligand-field absorption.[1,2] Homogeneous speciation was achieved for $\mathrm{Co}^{2+}$ and $\mathrm{Ni}^{2+}: \mathrm{ZnO}$ either by growing a $\mathrm{ZnO}$ shell around the $\mathrm{TM}^{2+}: \mathrm{ZnO}$ core (iso-crystalline core/shell method or ICS as previously reported[1]), or by treating the nanocrystals in a $180{ }^{\circ} \mathrm{C}$ solution of technical grade trioctylphosphine oxide (TOPO).[2] The TOPO (and TOPO impurities) strip off the $\mathrm{TM}^{2+}$ from the $\mathrm{ZnO}$ surface, leaving purely internally doped $\mathrm{Co}^{2+}: \mathrm{ZnO}$ or $\mathrm{Ni}^{2+}: \mathrm{ZnO}$ nanocrystals. After either treatment, ligand-field electronic absorption spectroscopy confirmed the homogeneous speciation of the $\mathrm{Ni}^{2+}$ and $\mathrm{Co}^{2+}$ doped nanocrystals (Figure 1).[1,2] Since the weak, spin-forbidden ligand-field transitions of high spin $\mathrm{Mn}^{2+}(\mathrm{S}=5 / 2)$ make electronic absorption unsuitable for determining $\mathrm{Mn}^{2+}$ speciation in $\mathrm{ZnO}$, electron paramagnetic resonance (EPR) was used instead (Figure 1).[6] To remove the $\mathrm{Mn}^{2+}$ surface dopants, we used an improved modification of the previously noted TOPO treatment, where the nanocrystals are heated in dodecylamine (DDA) instead of TOPO. The collaboration with Jim Amonette at PNNL allowed us to collect Q-band EPR spectra of the treated $\mathrm{Mn}^{2+}: \mathrm{ZnO}$ nanocrystals. The combination of X-band and Q-band EPR allows easier distinction between different $\mathrm{Mn}^{2+}$ speciation sites, as their EPR signals will spread out more at the higher Q-band frequency due to differences in g-values. The excellent match between simulations of the X-band and Q-band experimental EPR spectra on the same treated sample of $\mathrm{Mn}^{2+}: \mathrm{ZnO}$ using the EPR parameters of bulk $\mathrm{Mn}^{2+}: \mathrm{ZnO}$ (Figure 1) confirms that the $\mathrm{Mn}^{2+}$ ions only occupy substitutional sites in $\mathrm{ZnO}$ with no other $\mathrm{Mn}^{2+}$ speciation sites present.[6] 
X-ray powder diffraction spectra recorded for $\mathrm{Co}^{2+}-, \mathrm{Ni}^{2+}-$, and $\mathrm{Mn}^{2+}$ - doped $\mathrm{ZnO}$ nanocrystals confirms that wurtzite $\mathrm{ZnO}$ has been made, with no evidence for any other phases. In addition, TEM images collected at PNNL of the same materials $\left(\mathrm{Mn}^{2+}: \mathrm{ZnO}\right.$ in Figure 2)[6] show the nanocrystals are pseudospherical and relatively monodisperse in size. Thus the procedure maintains good control over the size and morphology of the doped $\mathrm{ZnO}$ even when different dopants are used.

The emphasis on speciation of the dopant originates from our objective to correlate magnetic properties of ZnO DMSs to the interactions between substitutionally doped transition metals and the semiconductor bands. The high quality of the samples has also allowed us to confirm intrinsic high- $T_{\mathrm{C}}$ ferromagnetism in $\mathrm{Co}^{2+}: \mathrm{ZnO}$ and $\mathrm{Mn}^{2+}: \mathrm{ZnO}$. When $\mathrm{Co}^{2+}: \mathrm{ZnO}$ nanocrystals were prepared from DMSO, and allowed to slowly aggregate from colloidal solution, we observed room temperature ferromagnetism.[2] We suggest agglomeration is necessary for creating defect sites which may contribute n-type charge carriers, hypothesized to be essential for ferromagnetic ordering in $\mathrm{Co}^{2+}: \mathrm{ZnO}$. Thin films of $\mathrm{Mn}^{2+}: \mathrm{ZnO}$ were prepared by spin-coating and annealing colloidal DDA-capped $\mathrm{Mn}^{2+}: \mathrm{ZnO}$ solutions onto silica substrates. Large, ferromagnetic ordering well above room temperature was observed in these thin films, which we attributed to the incorporation of $\mathrm{N}$ from the DDA capping ligand, producing p-type defects.[6] Opposite to $\mathrm{Co}^{2+}: \mathrm{ZnO}$, p-type defects are proposed to be required for ferromagnetic ordering in $\mathrm{Mn}^{2+}: \mathrm{ZnO}{ }^{1,2}$ The thorough characterization of our ZnO DMS-QDs, produced by a low temperature, chemically controlled synthesis excludes the possibility of impurity formation in the aggregation stage, confirming that the ferromagnetism is intrinsic to $\mathrm{Co}^{2+}: \mathrm{ZnO}$ and $\mathrm{Mn}^{2+}: \mathrm{ZnO}$.

\section{Publications and Presentations:}

[1] "Colloidal Transition-Metal-Doped ZnO Quantum Dots." Radovanovic, Pavle V.; Norberg, Nick S.; McNally, Kathryn E.; Gamelin, Daniel R. J. Am. Chem. Soc., 124, 15192 (2002).

[2] "Magnetic Quantum Dots: Synthesis, Spectroscopy, and Magnetism of $\mathrm{Co}^{2+}$ - and $\mathrm{Ni}^{2+}$-Doped ZnO Nanocrystals." Schwartz, Dana A.; Norberg, Nick S.; Nguyen, Quyen P.; Parker, Jason M.; Gamelin, Daniel R. J. Am. Chem. Soc., 125, 13205 (2003).

[3] "Magneto-optical and Magnetic Studies of Diluted Magnetic Semiconductor Nanocrystals." Norberg, Nick S.; Radovanovic, Pavle V.; Schwartz, Dana A.; Amonette, James E.; Gamelin, Daniel R., Third Annual Nanoscale Science and Technology Workshop, University of Washington, Seattle, Washington, September 2003 (poster).

[4] "Synthesis of Colloidal $\mathrm{Mn}^{2+}: \mathrm{ZnO}$ Quantum Dots and High- $\mathrm{T}_{\mathrm{C}}$ Ferromagnetic Nanocrystalline Thin Films.” Norberg, Nick S.; Kittilstved, Kevin R.; Amonette, James E.; Kukkadapu, Ravi K.; Schwartz, Dana A.; and Gamelin, Daniel R. $41^{\text {st }}$ Annual Meeting of The Clay Minerals Society, CMS2004, Richland, Washington, June 2004. (presentation)

[5] “Colloidal $\mathrm{Mn}^{2+}: \mathrm{ZnO}$ Quantum Dots and High $\mathrm{T}_{\mathrm{C}}$ Ferromagnetic Thin Films.” Norberg, Nick S.; Kittilstved, Kevin R.; Amonette, James E.; Kukkadapu, Ravi K.; Schwartz, Dana A.; and Gamelin, Daniel R., Fourth Annual Nanoscale Science and Technology Workshop, University of Washington, Seattle, Washington, September 2004 (poster). 
[6] "Colloidal Transition-Metal-Doped ZnO Quantum Dots." Norberg, Nick S.; Kittilstved, Kevin; Schwartz, Dana A.; Kukkadapu, Ravi K.; Amonette, James E.; Gamelin, Daniel R. J. Am. Chem. Soc., 126, 9387 (2004).

\section{References:}

(1) Katayama-Yoshida, H.; Sato, K. Physica B: Condensed Matter (Amsterdam, Netherlands) 2003, 327, 337.

(2) Dietl, T.; Ohno, H.; Matsukura, F.; Cibert, J.; Ferrand, D. Science (Washington, D. C.) 2000, 287, 1019.

(3) Ueda, K.; Tabata, H.; Kawai, T. Applied Physics Letters 2001, 79, 988.

(4) Sharma, P.; Gupta, A.; Rao, K. V.; Owens, F. J.; Sharma, R.; Ahuja, R.; Guillen, J. M. O.; Johansson, B.; Gehring, G. A. Nature Materials 2003, 2, 673.

(5) Ando, K. cond-mat/0208010. 


\section{Figures:}

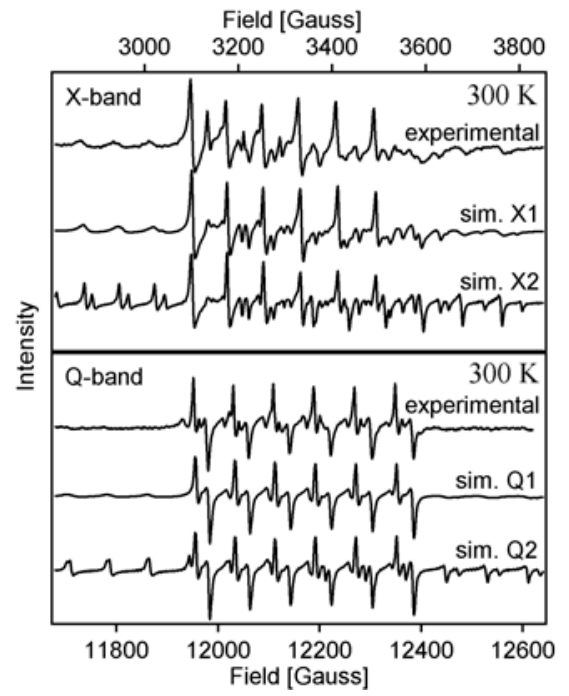

Figure 1. [6] Experimental X-band and Q-band EPR spectra of $0.02 \% \mathrm{Mn}^{2+}: \mathrm{ZnO}$ colloidal nanocrystals with simulations of X-band and Q-band EPR spectra (sim. X1 and Q1). Simulations when D-strain is not included are also shown (sim. X2 and Q2).

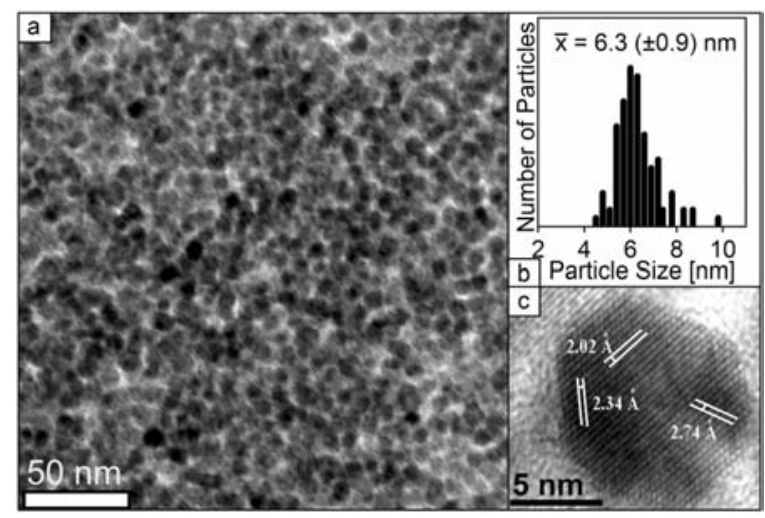

Figure 2. [6] TEM data for $0.2 \% \mathrm{Mn}^{2+}: \mathrm{ZnO}$ nanocrystals: (a) Overview TEM image. (b) Histogram of 100 crystal diameters. (c) High-resolution TEM image of a nanocrystal showing lattice spacings matching those of $\mathrm{ZnO}$. 


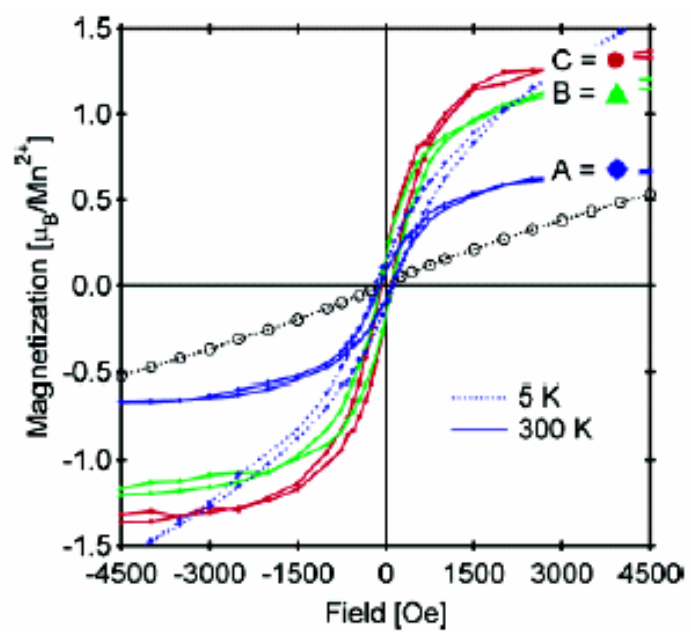

Figure 3. [6] $5 \mathrm{~K}$ (dotted lines) and $300 \mathrm{~K}$ (solid lines) magnetic susceptibilities of $0.20 \%$ $\mathrm{Mn}^{2+}: \mathrm{ZnO}$ nanocrystals (open circles) and thin films (solid symbols). A, B, and C refer to 3 different $\mathrm{Mn}^{2+}: \mathrm{ZnO}$ thin films.

\section{Funding that has resulted from this research:}

- Acquisition of a Scanning Probe Microscope System for Research and Education in Nanomagnetism and Spinelectronics, Co-PI: Daniel R. Gamelin with Marjorie Olmstead and Kannan Krishnan; NSF-IMR grant for $\$ 160 \mathrm{~K}$ awarded for acquisition of the proposed instrumentation

- An Integrated Laboratory for Physical Property Measurements of Advanced Materials and Novel Devices, Co-PI:- Daniel R. Gamelin, Murdoch Foundation grant for $\$ 499 \mathrm{~K}$ for period 3/01/05 to 2/28/06. Submitted, under review.

- Chemical Manipulation of High Temperature Spin Ordering in Oxide Semiconductors, PI: Daniel R. Gamelin; DOE grant for $\$ 590 \mathrm{~K}$ for period 6/15/05 to 6/14/08. Submitted, under review.

- Integrating Magnetic Oxide Nanostructures in Silicon Based Spintronics, Co-PI: Daniel R. Gamelin; NSF-ECS grant for $\$ 840 \mathrm{~K}$ for period 8/01/05 to 7/31/08. Submitted, under review. 


\section{Pd Nanoclusters Supported on MgO(100): Effects of Cluster Size on Chemisorption Properties}

Awardee: Steven Tait

Mentors: Charles Campbell and Sam Fain - UW, Zdenek Dohnálek and Bruce Kay -- PNNL

\section{Project Summary}

Nanometer-size Pd particles supported on oxides are active catalysts for a variety of important reactions involving small alkanes. For example, combustion of methane can be made to go at much lower temperatures using Pd nanoparticles supported on alumina, allowing for cleaner energy production, as this eliminates $\mathrm{NO}_{\mathrm{x}}$ pollution as a side product.

The intent of this project was to study particle size effects on the adsorption and dissociation of methane and small alkanes on model catalysts consisting of size-controlled Pd nanoclusters supported on well-defined surfaces of $\mathrm{MgO}$ and alumina. We have first conducted experiments to measure the interaction of the small alkane molecules with the $\operatorname{MgO}(100)[2,3], \operatorname{Pd}(111)[4]$, $\operatorname{Pt}(111)$ [5] and Graphite(0001) [4] surfaces.

Coverage-dependent desorption kinetics parameters were obtained from high quality temperature programmed desorption (TPD) data for seven small n-alkane molecules on $\mathrm{MgO}(100)[2,3]$. The molecules, $\mathrm{C}_{N} \mathrm{H}_{2 N+2}(N=1-4,6,8,10)$, were each studied for a set of 29 initial coverages at a heating ramp rate of $0.6 \mathrm{~K} / \mathrm{s}$ as well as at a set of nine ramp rates in the range 0.3 to $10.0 \mathrm{~K} / \mathrm{s}$. The inversion analysis method with its least-squares prefactor optimization discussed in [2] is applied to these data. This method allows for accurate determination of prefactors and coverage-dependent desorption energies. The pre-exponential factor for desorption increases dramatically with chain length from $10^{13.1}$ to $10^{19.1} \mathrm{~s}^{-1}$ over the range $N=1$ 10. We show that this increase can be physically justified by considering the increase in rotational entropy available to the molecules in the gas-like transition state for desorption. The desorption energy increases with chain length as $E_{d}(N)=6.5+7.1 \mathrm{~N}$, which implies an incremental increase of $7.1 \pm 0.2 \mathrm{~kJ} / \mathrm{mol}$ per $\mathrm{CH}_{2}$.

We measured the desorption kinetics and dissociative sticking probability of methane on the surfaces of $\mathrm{Pd}(111)$ and $\mathrm{Pd}$ nanoparticles supported on $\mathrm{MgO}(100)$ [4]. A molecular beam system was used to directly probe the fraction of methane molecules that dissociate at the Pd surfaces as a function of the molecular beam energy and incident angle. Measurements on the $\operatorname{Pd}(111)$ surface confirm a "normal energy scaling" of dissociative sticking probability, consistent with an activation barrier normal to the surface. Sticking measurements on supported Pd particles $(\sim 3 \mathrm{~nm}$ wide) with the methane beam directed normal to the $\mathrm{MgO}(100)$ surface results in a large fraction of the methane / Pd collisions occurring on regions of the particles where the beam direction is far from the local particle surface normal, resulting in lower sticking probability. We attempt to decouple this effect from the measured sticking probabilities in order to compare the intrinsic reactivity of the Pd particles with $\mathrm{Pd}(111)$. We find that the sticking probability on $\sim 3 \mathrm{~nm} \mathrm{Pd}$ particle surfaces is at most twice as large as on $\mathrm{Pd}(111)$. This result depends on our assumption that these annealed Pd particles have the known equilibrium particle shape (truncated half 
octahedron). We also discuss the need for detailed structural knowledge of the particles and careful geometric analysis when probing direct collisional activation barrier crossing using molecular beams. Temperature programmed desorption studies of physisorbed (not dissociated) methane reveal that the Pd particles bind methane more strongly than Pd(111). Oxygen adsorbs on the $\mathrm{Pd}$ nanoparticles via a mobile, molecular $\mathrm{O}_{2}$ precursor state which is transiently adsorbed on the $\mathrm{MgO}(100)$ surface. An induction period is observed on Pd nanoparticles for the titration of adsorbed $\mathrm{O}$ by $\mathrm{CO}$ gas to make $\mathrm{CO}_{2}$ which is not observed on $\mathrm{Pd}(111)$. This is attributed to inhibition by adsorbed $\mathrm{O}$, whose saturation coverage on the Pd particles is $41 \%>$ than on $\operatorname{Pd}(111)$.

Complementary non-contact atomic force microscopy (NC-AFM) measurements, which were conducted at the UW, yielded information about the morphology and number density of the Pd nanoclusters as a function of deposition temperature and coverage and time of annealing $[1,6]$. In this way we were able to study the sintering kinetics of Pd catalysts. Together these results allow a greater understanding of the catalytic activity of this important combustion catalyst, and particle size effects in hydrocarbon catalysis in general.

\section{Publications, Presentations and Proposals:}

\section{Publications:}

Growth and Sintering of Pd Clusters on $\alpha-\mathrm{Al}_{2} \mathrm{O}_{3}(0001)$, by L. T. Ngo, S. L. Tait, Q. Yu, S. C. Fain, Jr., and C. T. Campbell, J. Chem. Phys. 122, art. 064712, 2005.

n-Alkanes on $\mathrm{MgO}(100)$ : I. Coverage-dependent Desorption Kinetics of n-Butane, S. L. Tait, Z. Dohnálek, C. T. Campbell, B. D. Kay, J. Chem. Phys. 122, 164707, 2005 (9 pages).

n-Alkanes on $\mathrm{MgO}(100)$ : II. Chain Length-dependence of Kinetic Desorption Parameters for Small n-Alkanes, S. L. Tait, Z. Dohnálek, C. T. Campbell, B. D. Kay, J. Chem. Phys. 122, 164708, 2005 (13 pages).

Methane adsorption and dissociation and oxygen adsorption and reaction with $\mathrm{CO}$ on $\mathrm{Pd}$ nanoparticles on $\mathrm{MgO}(100)$ and on Pd(111), S. L. Tait, Z. Dohnálek, C. T. Campbell, B. D. Kay, Surface Sci. (in press).

n-Alkanes on Pt(111) and Graphite(0001):. Chain Length-dependence of Kinetic Desorption Parameters, S. L. Tait, Z. Dohnálek, C. T. Campbell, B. D. Kay, in preparation

Non-contact Atomic Force Microscopy Studies of Pd Nanoparticles on $\mathrm{Al}_{2} \mathrm{O}_{3}(0001)$, S. L. Tait, L. T. Ngo, C. Polwarth, Q. Yu, S. C. Fain, Jr. and C. T. Campbell, in preparation.

\section{Presentations:}

Steve Tait gave talks about this at several meetings including: three National Symposia of the American Vacuum Society (2002-04), the national meeting of the American Physical Society (2004), the International Symposium on Non-contact Atomic Force Microscopy (2004), and 
several local and regional meetings, including the past three UW/PNNL Nanotechnology Workshops.

CT Campbell spoke about this in invited talks at the National Symposium of the American Vacuum Society and at the National Meeting of the American Chemical Society.

Funding from research proposals which was facilitated by these results:

1. Oxide-supported Metal Nanoparticles: Catalytic Properties and Energetics, PI $=\mathrm{CT}$ Campbell, DOE-BES grant to UW for $\$ 480 \mathrm{~K}$ for the period 3/15/05 to 3/14/08.

\section{Figures:}

Figure 1. Methane sticking probability vs. Pd coverage, from [4]. Circles represent average of

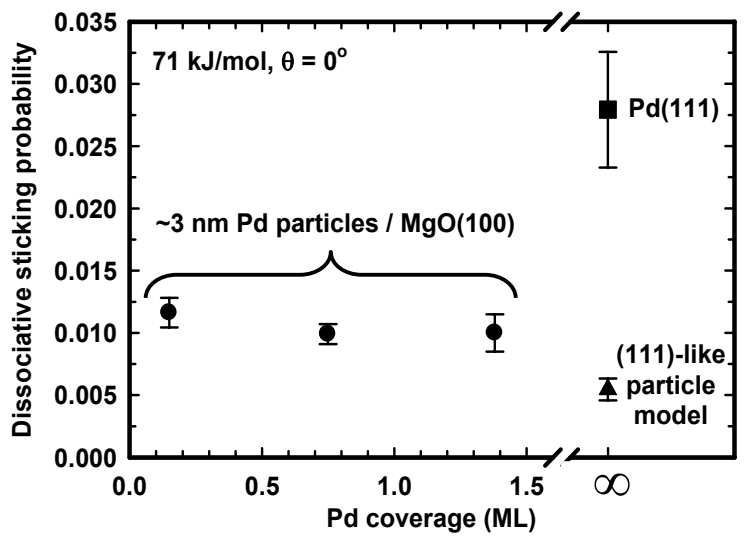

several sticking measurements made on Pd nanoparticles at $T_{S}=500 \mathrm{~K}$. The error bars correspond to one standard deviation of the calculated sticking result. The square point is the measured methane sticking probability on $\operatorname{Pd}(111)$ at $T_{S}=550 \mathrm{~K}$. The triangular point is a calculation of expected sticking on truncated half octahedron (equilibrium) particle shape based on measurement of $S_{0}$ at $\theta=0^{\circ}$ and $56^{\circ}$ on $\operatorname{Pd}(111)$, as described in the [4].

Figure 2.: Histogram of $\mathrm{Pd}$ particle diameter (measured by NC-AFM) at room temperature

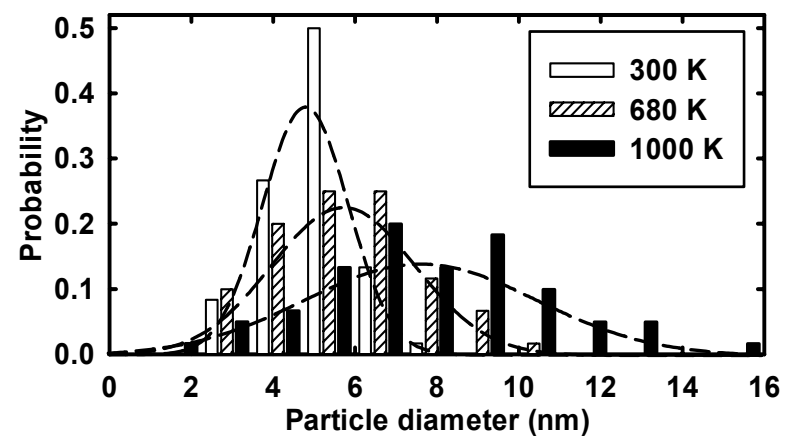

(empty bars) and after annealing to $680 \mathrm{~K}$ (lined bars) and $1000 \mathrm{~K}$ (solid bars) from [1]. The mean and standard deviation of each set were used to calculate the position and width of the three Gaussian curves shown as dashed lines. 


\subsection{Awards Authorized September 2003}

"Growth and Optimization of $\mathrm{TM}_{\mathrm{x}} \mathrm{Ti}_{1-\mathrm{x}} \mathrm{O}_{2}(\mathrm{TM}=\mathrm{Co}, \mathrm{Mn}, \mathrm{Cr})$ Films for Silicon-based Spintronic Devices"

Awardee: Kelli Griffin

Mentors: Kannan Krishnan - UW, Scott Chambers - PNNL

Page 2.46

"Investigation of Macrophage Activation in Response to Nanoscale Biomaterial Surface Features"

Awardee: Allison L. Golden

Mentors: Patrick Stayton - UW, Mary Lipton and Wendy Shaw - PNNL

Page 2.50

Impurities in Thiolated Single-stranded DNA Oligomers and Their Effect on DNA Selfassembly on Gold

Awardee: Chi-Ying Lee

Mentors: David G. Castner - UW, A. Scott Lea - PNNL

Page 2.51

"Development of Cellular Absorptive Tracers (CATs) for a Quantitative Characterization of the Complexity of Nanoscale Biological Systems"

Awardee: Deirdre R. Meldrum

Mentors: Mary Lidstrom and Barry Lutz - UW, Prasad Saripalli - PNNL

Page 2.53

"Nanostructured Cadmium Tungstate Scintillation Films

for Neutron Detection"

Awardee: Mary H. Shang

Mentors: Guozhong Cao - UW, Mary Bliss - PNNL

Page 2.54

"Predicting Catalysis at Oxide Nano-Particles"

Awardee: Kiril Tsemekhman

Mentors: Hannes Jonsson - UW, Eric Bylaska - PNNL

Page 2.58 


\section{Growth and Optimization of $\mathrm{TM}_{\mathrm{x}} \mathrm{Ti}_{1-\mathrm{x}} \mathrm{O}_{2}(\mathrm{TM}=\mathrm{Co}, \mathrm{Mn}, \mathrm{Cr})$ Films for Silicon-based Spintronic Devices}

Awardee: Kelli Griffin

Mentors: Kannan M. Krishnan -UW, Scott Chambers - PNNL

\section{Project summary}

Transition metal (TM) doped $\mathrm{TiO}_{2}$ is of interest for spin-electronic applications as it has shown promising properties as a potential room temperature dilute magnetic semiconductor (DMS). More recently, there has been evidence that TM doped oxides are in fact "dilute magnetic dielectrics" (DMD) from the co-occurrence of ferromagnetism in the dielectric ground state. ${ }^{1-3}$ These results have spurred an interest in these DMD materials for thorough materials characterization both at the atomic and bulk scales to investigate and correlate the structural, chemical, magnetic, and transport properties of these unique materials.

The research on Co doped $\mathrm{TiO}_{2}$ has focused on the experimental investigation of the films as functions of annealing, crystalline quality, and film thickness. Films are grown by rf magnetron sputter deposition, and properties are measured before and after a post-growth annealing method. High angle $\mathrm{x}$-ray diffraction (XRD), high resolution transmission electron microscopy (TEM) imaging, ultra-high resolution scanning TEM (STEM), electron energy loss spectroscopy (EELS), selected area diffraction patterns, and energy dispersive x-ray spectroscopy (EDXS) are used for detailed structural and chemical analysis. A superconducting quantum interference device (SQUID) magnetometer and electrometer are used for magnetic and transport measurements.

Anatase $\mathrm{TiO}_{2}$ films doped with 3.6 at. \% Co are grown by magnetron sputter deposition from a ceramic oxide target on $\mathrm{LaAlO}_{3}(001)$ substrates at $550^{\circ} \mathrm{C}$ at a growth rate of $0.12 \AA / \mathrm{s}$, followed by vacuum annealing at $450^{\circ} \mathrm{C}$ for 1 hour. Previous studies of these films $[1,2]$ show that Co is dispersed in the anatase lattice in the +2 state, with no evidence of secondary phases from x-ray absorption spectroscopy, TEM, and XRD measurements. Films are ferromagnetic and highly insulating at room temperature, and with annealing the moment increases by $0.5 \mu_{\mathrm{B}} / \mathrm{Co}$ atom (for $100 \mathrm{~nm}$ film) and yet still remain highly insulating. Meanwhile, undoped anatase $\mathrm{TiO}_{2}$ films grown under the same conditions become semiconducting upon annealing, with a resistivity of $0.1 \Omega \mathrm{cm}$.

Ultra-high resolution STEM and EELS on an as-deposited and annealed $\mathrm{Co}: \mathrm{TiO}_{2}$ film show high uniformity of $\mathrm{Co}$ concentration in the anatase lattice with an average $\mathrm{Co} / \mathrm{Ti}$ ratio of 0.04

\footnotetext{
${ }^{1}$ T. Droubay, S. M. Heald, V. Shutthanandan, S. Thevuthasan, S. A. Chambers, J. Osterwalder, J. Appl. Phys. 97, $046103(2005)$.

${ }^{2}$ K.A. Griffin, A.B. Pakhomov, C.M. Wang, S.M. Heald, and Kannan M. Krishnan, Phys. Rev. Lett., 94, 157204 (2005).

${ }^{3}$ T. Zhao, S. R. Shinde, S. B. Ogale, H. Zheng, T. Venkatesan, R. Ramesh, S. Das Sarma, Phys. Rev. Lett. 94, 126601 (2005).
} 
throughout the bulk of the film. Fig. 1. includes two high angle annular dark field (HAADF) images from STEM at $50 \mathrm{kx}$ (left) and $100 \mathrm{kx}$ (right) of an annealed $\mathrm{Co}: \mathrm{TiO}_{2}$ sample, with corresponding maps of the low loss Co M edge areal density. These low loss maps demonstrate the Co uniformity over large area within the film. The STEM and EELS analysis confirmed that there were no secondary phases present in the films, and the calculated $\mathrm{Co} \mathrm{L}_{2} / \mathrm{L}_{3}$ ratio confirmed Co to be in the +2 oxidation state.

Room temperature hysteresis measurements reveal that the magnetism of the films is strongly dependent on film thickness (Fig. 2), indicating that even though the Co is dispersed relatively evenly through the bulk of the film, there may be some evidence for a more enhanced ferromagnetic "layer" within the film, possibly near the substrate or surface. The moment/Co is shown to increase from $\sim 0.3$ to $1.6 \mu_{\mathrm{B}} / \mathrm{Co}$ atom upon decreasing film thickness, whereas the moment $/ \mathrm{nm}^{2}$ decreases from 147 to $5 \mu_{\mathrm{B}} / \mathrm{nm}^{2}$ with decreasing film thickness.

The current research is focused on the continued investigation of the origin of the ferromagnetism of this unique material. This study includes the effects of crystalline quality, annealing process, and film thickness on the Co distribution in the anatase $\mathrm{TiO}_{2}$ lattice and the resultant bulk magnetic, transport, and structural properties. Detailed STEM/EELS analysis will allow for atomic-to-micron scale analysis of chemical, electronic, and structural properties, which is necessary to study the role of the TM dopant and other native defects (oxygen vacancies and grain boundaries) in relation to film growth, annealing, and material properties. The combination of room temperature ferromagnetism and highly insulating ground state presents $\mathrm{Co}: \mathrm{TiO}_{2}$ as a potential magnetic tunneling barrier material in spin-filter devices.

\section{Publications:}

"Intrinsic Ferromagnetism in Insulating Cobalt doped Anatase $\mathrm{TiO}_{2}$," K.A. Griffin, A.B. Pakhomov, C.M. Wang, S.M. Heald, and Kannan M. Krishnan, Phys. Rev. Lett., 94, 157204 (2005).

"Cobalt-Doped Anatase $\mathrm{TiO}_{2}$ - a room temperature dilute magnetic dielectric material," K.A. Griffin, A.B. Pakhomov, C.M. Wang, S.M. Heald, and Kannan M. Krishnan, $49^{\text {th }}$ Conference on Magnetism and Magnetic Materials, Jacksonville, FL, J. Appl. Phys., 97, 10D320 (2005).

"Nanomagnetism and spinelectronics: materials, microstructure and novel properties," Kannan M. Krishnan, Alexandre B. Pakhomov, Yuping Bao, Peter Blomqvist, Yoonsoo Chun, Marcela Gonzales, Kelli Griffin, Xiaosong Ji and Brad Roberts, J. Materials Science, (in press 2005).

\section{Presentations:}

"Ferromagnetism in Co doped Anatase $\mathrm{TiO}_{2}$ - for spintronics applications," K. A. Griffin, A. B. Pakhomov, Kannan M. Krishnan, March 9th, 2005 (oral presentation), Department of Physics \& Astronomy, Solid State Physics Colloquium, University of Glasgow, Glasgow, Scotland, U.K. "Cobalt-Doped Anatase $\mathrm{TiO}_{2}$ - a room temperature dilute magnetic dielectric material," K. A. Griffin, A. B. Pakhomov, C. M. Wang, S. M. Heald, Kannan M. Krishnan, November 10, 2004 (oral presentation), 49th Conference on Magnetism and Magnetic Materials, Jacksonville, FA. 
"Cobalt Doped Anatase $\mathrm{TiO}_{2}$ - a room temperature dilute magnetic dielectric material for spinelectronics," K. A. Griffin, A. B. Pakhomov, C. M. Wang, S. M. Heald, V. Shutthanandan, S. A. Chambers, Kannan M. Krishnan, Nanoscale Science and Technology Workshop, September 2004 (poster presentation), Seattle, WA.

"Ferromagnetism in Co doped $\mathrm{TiO}_{2}$ films grown by RF magnetron sputtering," K. A. Griffin, A. B. Pakhomov, C. M. Wang, Kannan M. Krishnan, Annual American Physical Society Meeting, March 2004 (poster presentation), Montreal, Quebec, Canada.

\section{Figures:}
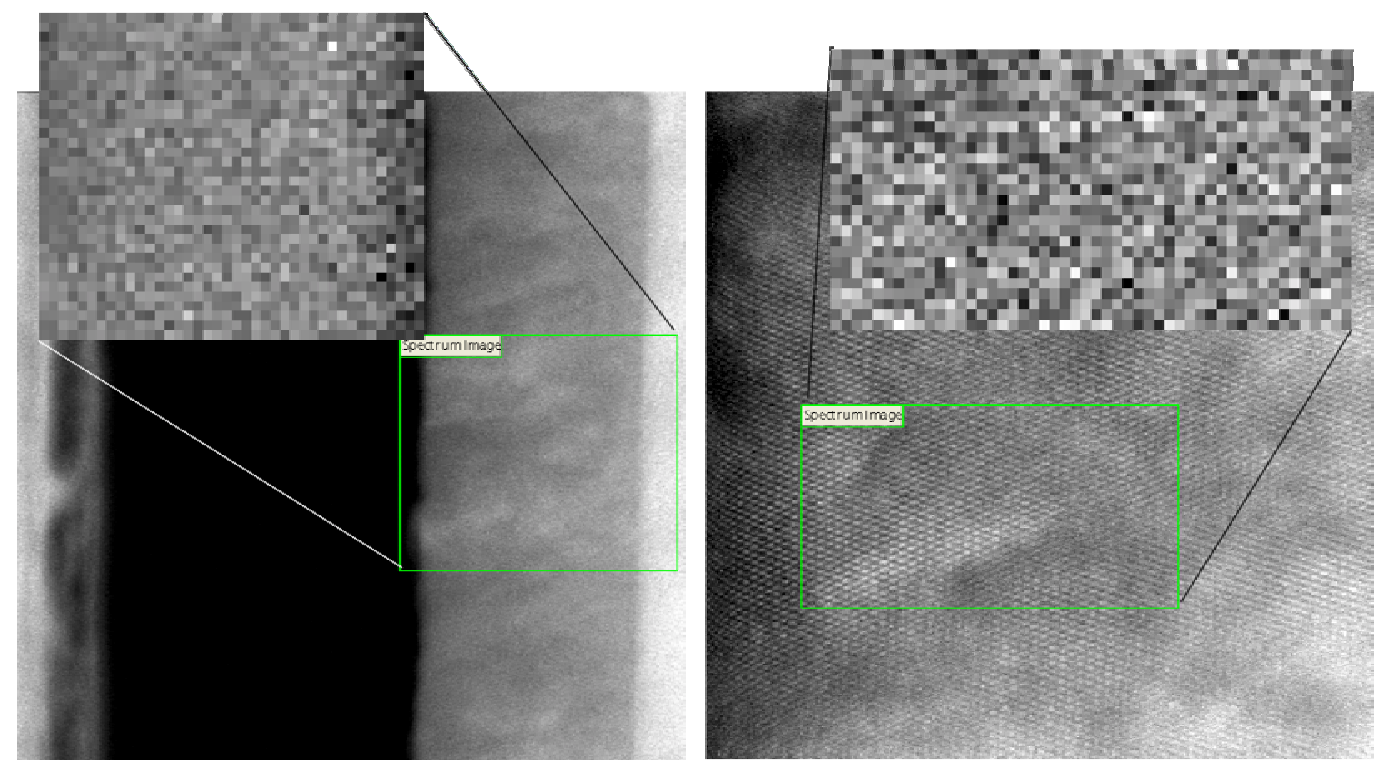

FIG. 1. Low loss spectrum images from STEM EELS measurements of annealed $\mathrm{Co}: \mathrm{TiO}_{2}$ sample: left $(50 \mathrm{kx})$ and right (100kx) HAADF images with insets of Co M edge areal density map normalized by film thickness. 


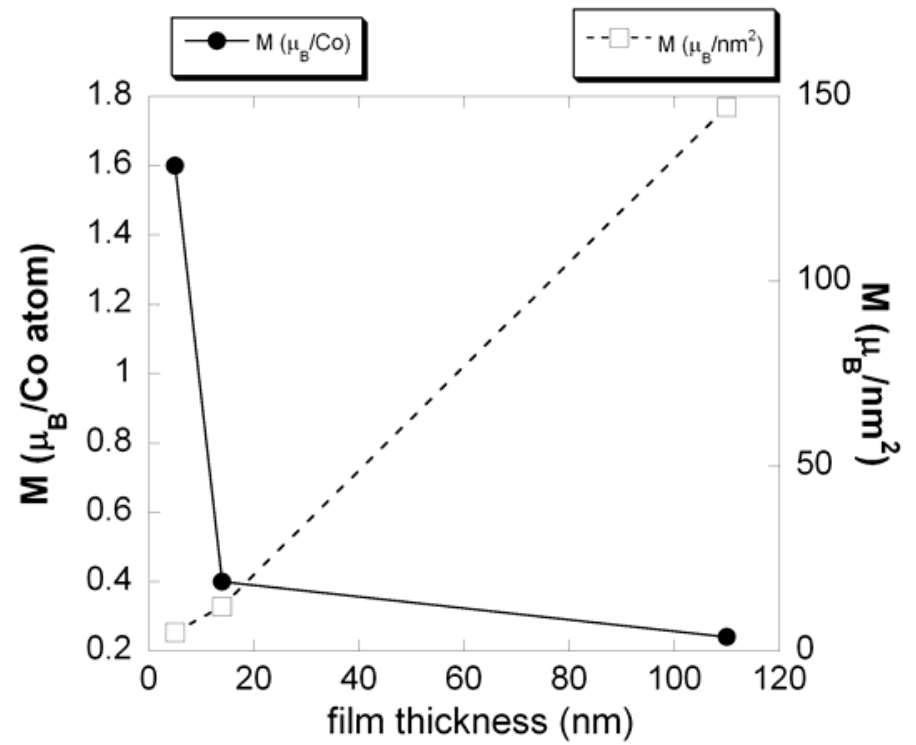

FIG. 2. $M_{\mathrm{S}}$ vs. film thickness of $\mathrm{Co}: \mathrm{TiO}_{2}$ films measured at $300 \mathrm{~K}$ of annealed samples. Plotted in $\mu_{\mathrm{B}} / \mathrm{Co}$ (filled circle) and $\mu_{\mathrm{B}} / \mathrm{nm}^{2}$ (empty square). 


\section{Investigation of Macrophage Activation in Response to Nanoscale Biomaterial Surface Features}

Awardee: Allison Golden

Mentors: Patrick Stayton - UW, Mary Lipton - PNNL, Wendy Shaw - PNNL

Project Summary

The control of the foreign body reaction to implanted biomaterials and tissue engineering scaffolds is a central aspect of biocompatibility. The design of biomaterial coatings that minimize chronic inflammation, yet encourage healing responses, is a key goal in the medical device field. Recent findings in this group and others have shown that materials with nanoscale fibrous features exhibit favorable in vivo biological responses. Underlying this response are differences in macrophage biology that are related to biomaterial architecture. Surface topography at small nano- to meso- scales may thus be a major influence in the biocompatibility of a material[1,2]. With advances in genomic and proteomic technologies, it is now possible to study in unprecedented detail the pro-inflammatory activation of macrophages as a function of the nanoscale features of biomaterials. This new mechanistic detail will identify common architectural properties that can be incorporated into biomaterial surfaces. The identification of the key signaling pathway components associated with the response to nanoscale features will also provide targets for the design of drug delivery coatings from biomaterials that can augment the surface architecture effect. This collaborative proposal will combine the biomaterials and biological expertise at the University of Washington with the proteomics expertise at PNNL to study the pro-inflammatory response of macrophages to materials with nanoscale surface features. The response of human primary macrophages on polytetrafluoroethylene materials that are topographically distinct at under $100 \mathrm{~nm}$ will be studied using advanced techniques mass spectrometry proteomic techniques. Tandem mass spectrometry coupled with Fourier transform ion cyclotron resonance (FITCR) mass spectrometry will be used to study signaling pathway activation as monitored by phosphorylation activation of pro-inflammatory pathway components[3, 4]. The proposed research aims to characterize dynamic signaling pathways in monocyte response to better understand and control the effect of material nanostructure on the inflammatory response. 


\section{Impurities in Thiolated Single-stranded DNA Oligomers and Their Effect on DNA Self-assembly on Gold}

Awardee: Chi-Ying Lee

Mentors: David G. Castner - UW, A. Scott Lea - PNNL

\section{Project Summary}

Commercially synthesized single-stranded DNA oligomers containing a thiol anchor group (SH-ssDNA) are utilized in applications ranging from DNA microarrays to biosensors. The diversity of techniques used in the synthesis, treatment and purification of the oligomers has led to a significant variation in the purity of commercially available SH-ssDNA. The presence of contaminants in SH-ssDNA may change the structure and coverage of the DNA film on the surface. This, in turn, should alter the hybridization efficiency of the immobilized DNA probe with the targets in solution.

For this project, we have used x-ray photoelectron spectroscopy (XPS) and time-of-flight secondary ion mass spectrometry (ToF-SIMS) to study the self-assembly process of SH-ssDNA oligomers onto gold surfaces and determined how the impurities present in commerciallysynthesized SH-ssDNA oligomers affect the structure of the resulting films. Using XPS, quantitative atomic compositions of the individual DNA films prepared from SH-ssDNA oligomers from three vendors were obtained and compared. The molecular fragmentation patterns acquired with ToF-SIMS were used to determine the identity of several contaminants present in some of the DNA films.

XPS results indicate that two of the purchased SH-ssDNA oligomers contain excess carbon and sulfur. The excess sulfur found in these samples suggests that the contamination maybe due to the presence of excess dithiothreitol (DTT), a reductant commonly used to cleave disulfide precursors. The molecular fragmentation patterns obtained with ToF-SIMS were used to determine the identity of several contaminants in the DNA films, including poly(dimethylsiloxane) (PDMS), lipid molecules, and sulfur-containing molecules. In particular, the ToF-SIMS results determined that the excess sulfur detected by XPS was in fact due to the presence of DTT.

Furthermore, we found that the SH-ssDNA self-assembly process is affected by the presence of these contaminants. When relatively pure SH-ssDNA is used to prepare the DNA films, the P, $\mathrm{N}, \mathrm{O}$ and $\mathrm{C}$ atomic percentages were observed by XPS to increase over a 24-hour time period. In contrast, surfaces prepared using SH-ssDNA containing higher levels of contaminants did not follow this trend. XPS result indicates that after the initial SH-ssDNA adsorption, the remaining material incorporated into these films was due to contamination. Results from these experiments underscore the importance of using surface specific techniques to confirm the chemistry of surfaces modified with DNA (such as microarray films) prior to their use in commercial applications. 


\section{Publications and Presentations:}

"X-ray Photoelectron Spectroscopy and Time-of-Flight Secondary Ion Mass Spectrometry Investigation of Commercial Thiolated Single-Stranded DNA Oligomers." C-Y. Lee, H.E. Canavan, L.J. Gamble, D.G. Castner

15th Annual Symposium of the Pacific Northwest Chapter of the American Vacuum Society, PNNL, Washington, June 2004 (poster presentation).

"XPS and ToF-SIMS Characterization of Thiolated Single-stranded DNA Oligomers Selfassembled onto Gold Surfaces." C-Y. Lee, H.E. Canavan, L.J. Gamble, D.G. Castner

$4^{\text {th }}$ Annual Nanoscale Science and Technology Workshop, Seattle, Washington, September 2004 (poster presentation).

"Analysis of Contaminants in Commercial Thiolated Single-stranded DNA Oligomers by XPS and ToF-SIMS" C-Y. Lee, H.E. Canavan, L.J. Gamble, D.G. Castner

AVS $51^{\text {st }}$ International Symposium, Anaheim, California, November 2004 (poster presentation).

"Evidence of Impurities in Thiolated Single-stranded DNA Oligomer and Their Effect on DNA Self-assembly on Gold ." C-Y. Lee, H.E. Canavan, L.J. Gamble, D.G. Castner (paper submitted to Langmuir).

Funding that has resulted from this research: None so far. 


\title{
Development of Cellular Absorptive Tracers (CATs) for a Quantitative Characterization of the Complexity of Nanoscale Biological Systems
}

\begin{abstract}
Awardee: Deirdre Meldrum
Mentors: Mary Lidstrom - UW, Barry Lutz - UW, Eric Ackerman - PNNL, Prasad Saripalli - PNNL

Project Summary

The goal of this project is to develop a new method, entitled Cellular Absorptive Tracers (CATs; PNNL Invention Disclosure; Saripalli, P. 2001). CATs are useful for characterizing the extent, location, and morphology of cell mass in MEMS, by preferentially absorbing into the living or lysed cells or adsorbing at the cell surfaces. We will identify suitable CATs molecule(s), measure their affinity to various cellular phases and test them in larger scale flow experiments. The molecules chosen will be used to demonstrate their utility to quantitatively characterize the biomass, its location and morphology in MEMS. The results will yield first-oftheir-kind datasets relating metabolic parameters to heterogeneity and morphology of cells. The data will be used to obtain quantitative information needed for the characterization of cellular phase masses, their location and morphology in MEMS, and to develop the theory relating the cellular phenomena of interest to cellular heterogeneity and morphology. The proposed research contributes a new set of tools for a rapid, noninvasive characterization of nanoscale biological systems.
\end{abstract}




\section{Nanostructured Cadmium Tungstate Scintillation Films for Neutron Detection}

Awardee: Haumei Shang

Mentors: Guozhong Cao - UW, Mary Bliss - PNNL

\section{Project Summary}

My research has been focused mainly on the fabrication of oxide scintillation films with solgel processing, hydrothermal method, and spontaneous growth, taking $\mathrm{CdWO}_{4}(\mathrm{CWO})$ and $\mathrm{ZnO}: \mathrm{Ga}$ as model systems based on their high light yield, short decay time, and relative simplicity of chemical composition for the proposed investigation. However, the processing strategies established can be readily applied to the fabrication of other oxide scintillation films. CWO nanocrystal films were made through controlled sol-gel processing and pre-designed doping. The sol-gel derived films were typically of $\sim 500 \mathrm{~nm}$ in thickness and the grain size was of $100 \sim 300 \mathrm{~nm}$ in diameter, and the studies revealed that doping with $\mathrm{Li}^{+}, \mathrm{B}^{3+}$ and $\mathrm{Bi}^{3+}$ resulted in appreciably reduced grain size and porosity of sol-gel films, leading to enhanced optical transmittance and relatively high density. Preliminary neutron detection results revealed that boron doped CWO film is a promising candidate for neutron detection. Hydrothermal CWO films on glass substrate were prepared at temperatures ranging from 120 to $180^{\circ} \mathrm{C}$ from cadmium nitride and tungstic acid in hydrogen peroxide solution. Crack free and dense CWO films with textured structure and thickness up to $10 \mu \mathrm{m}$ were formed at $150^{\circ} \mathrm{C}$ and $180^{\circ} \mathrm{C}$. Photoluminescence measurements revealed that highly textured CWO thick films possess better PL property. The growth mechanism and preferred orientation or textured structured as well as the relations between textured structure and PL property have been discussed.

$\mathrm{ZnO}: \mathrm{Ga}$ nanorod arrays were grown on ITO substrate from aqueous solution with electric field assisted nucleation, followed with thermal annealing. The diameter of $\mathrm{ZnO}$ nanorods was $60 \sim 300 \mathrm{~nm}$ and the length was up to $2.5 \mu \mathrm{m}$. The alignment and structure of the nanorod arrays were greatly depended on the doping level of gallium. Photoluminescence spectra showed a broad emission band spreading from 500 to $870 \mathrm{~nm}$, which suggests that nanorods have a high density of oxygen interstitials. The optimization of $\mathrm{ZnO}$ :Ga nanorod arrays with proper doping level and the detection of neutron will be investigated in the future.

Future research will be focused on further optimization of processing parameters for the fabrication of $\mathrm{CWO}$ and $\mathrm{ZnO}: \mathrm{Ga}$ films with particular attention on the nano and microstructure control. However, most of my research will be devoted to the scintillation characterization, particularly neutron detection analyses. We are also looking for possible X-ray scintillation characterization through collaboration with Prof. Gunner at Cornell. Neutron detection and Xray scintillation results will be used to guide my future step in further modify the chemistry and improve the microstructure of both $\mathrm{CWO}$ and $\mathrm{ZnO}: \mathrm{Ga}$ films, and to achieve a better fundamental understanding of the relationship between processing parameters, chemical composition, nanoand microstructure, optical properties, and scintillation performance. 


\section{Publications, Presentations and Proposals:}

\section{Publications:}

H.M. Shang, Y. Wang, M. Bliss and G.Z. Cao, "Hydrothermal Growth and Photoluminescence of Textured $\mathrm{CdWO}_{4}$ Scintillation Films," Applied Physics Letters, in press.

H.M. Shang, Y. Wang, B. Milbrath, M. Bliss, and G.Z. Cao, "Development of Nanostructured Oxide Scintillator Films for Neutron Detection," Nuclear ${ }^{\text {Instr }}$ uments and ${ }^{\text {Methods }}$ in ${ }^{\text {Phys }}$ ics ${ }^{\text {Res }}$ earch A , in press.

H.M. Shang, Y. Wang, B. Milbrath, M. Bliss, and G.Z. Cao, "Doping Effects on Photoluminescent Properties of Sol-Gel Derived Cadmium Tungstate Films," to be submitted to Applied Physics Letters, in preparation.

H.M. Shang, Y. Wang, B. Milbrath, M. Bliss, and G.Z. Cao, "Dependence of Photoluminescent Properties of Sol-Gel Derived Cadmium Tungstate Films on Sintering Conditions," to be submitted to Journal of Luminescence, in preparation.

H.M. Shang, Y. Wang, D. Li, K. Takahashi, Y.N. Xia, and G.Z. Cao, "Nanostructured Superhydrophobic Surfaces," Journal of Materials Science Letters 24, in press.

H.M. Shang, Y. Wang, S.J. Limmer, T.P. Chou, and G.Z. Cao, "Optically Transparent Superhydrophobic Silica-Based Films," Thin Solid Films 472, 37-43 (2005).

Y. Wang, H.M. Shang, T.P. Chou, and G.Z. Cao, "Effects of Thermal Annealing on $\mathrm{Li}^{+}$ Intercalation Properties of $\mathrm{V}_{2} \mathrm{O}_{5} \cdot \mathrm{nH}_{2} \mathrm{O}$ Xerogel Films," Journal of Physical Chemistry B109, 11361-11366 (2005).

Y. Wang, K. Takahashi, H.M. Shang, and G.Z. Cao, "Synthesis and Electrochemical Properties of Vanadium Oxide Nanotube Arrays," Journal of Physical Chemistry B109, 3085-3088 (2005).

Y. Wang, K.H. Lee, H.M. Shang, Y.N. Xia, and G.Z. Cao, “Ag- $\mathrm{Ag}_{0.08} \mathrm{~V}_{2} \mathrm{O}_{5} \cdot \mathrm{nH}_{2} \mathrm{O}$ Composite Films as Host Materials for Lithium-ion Intercalation," Physica Status Solidi 202A, R79-R81 (2005).

Y.J. Kim, H.M. Shang, and G.Z. Cao, "Growth and Characterization of [001] ZnO Nanorod Arrays on ITO Substrates with Electric Potential Assisted Nucleation," submitted to Applied Physics Letters.

H.M. Shang, Y.J. Kim, and G.Z. Cao, "Growth and Characterization of [001] ZnO Nanorod Arrays with Electric Field Assisted Nucleation," Mater. Res. Soc. Symp. Proc. 879E, p.Z4.1Z4.6, 2005. 
H.M. Shang, Ying Wang, B. Milbrath, M. Bliss, and G.Z. Cao, "Effects of Dopants in Cadmium Tungstate Scintillator Films," in Nanophotonic Materials, eds., D.L. Andrews, G.Z. Cao, and Z. Gaburro, Proc. SPIE 5510, p.88-96, 2004.

\section{Presentations:}

Nanostructured Oxide Scintillator Films by Sol-Gel Processing," (Oral), H.M. Shang, M. Bliss, and G.Z. Cao, 2004 SPIE Annual Meeting, Denver, CO, August 2, 2004.

"Development of Nanostructured Oxide Scintillator Films," (Oral), H.M. Shang, M. Bliss, and G.Z. Cao, $56^{\text {th }}$ Pacific Coast Regional Meeting and Basic Science Division Meeting of the American Ceramic Society, Seattle, September 13, 2004.

"Growth of [001] Oriented ZnO Nanorod Arrays with Electric Field Assisted Nucleation," (Oral), H.M. Shang, Y.J. Kim, and G.Z. Cao, 2005 Materials Research Society Spring Meeting, San Francisco, CA, March 30, 2005.

\section{Proposals:}

Nanostructured Polycrystalline Doped $\mathrm{CdWO}_{4}$ Scintillator for Neutron Detection submitted 05/21/04 - NNSA/\$250,000 - not funded

Fabrication of Columnar Microstructure $\mathrm{CdWO}_{4}$ Scintillator for Neutron Detection submitted 10/28/04 - NSF/\$279,597 - not funded

\section{Figures:}
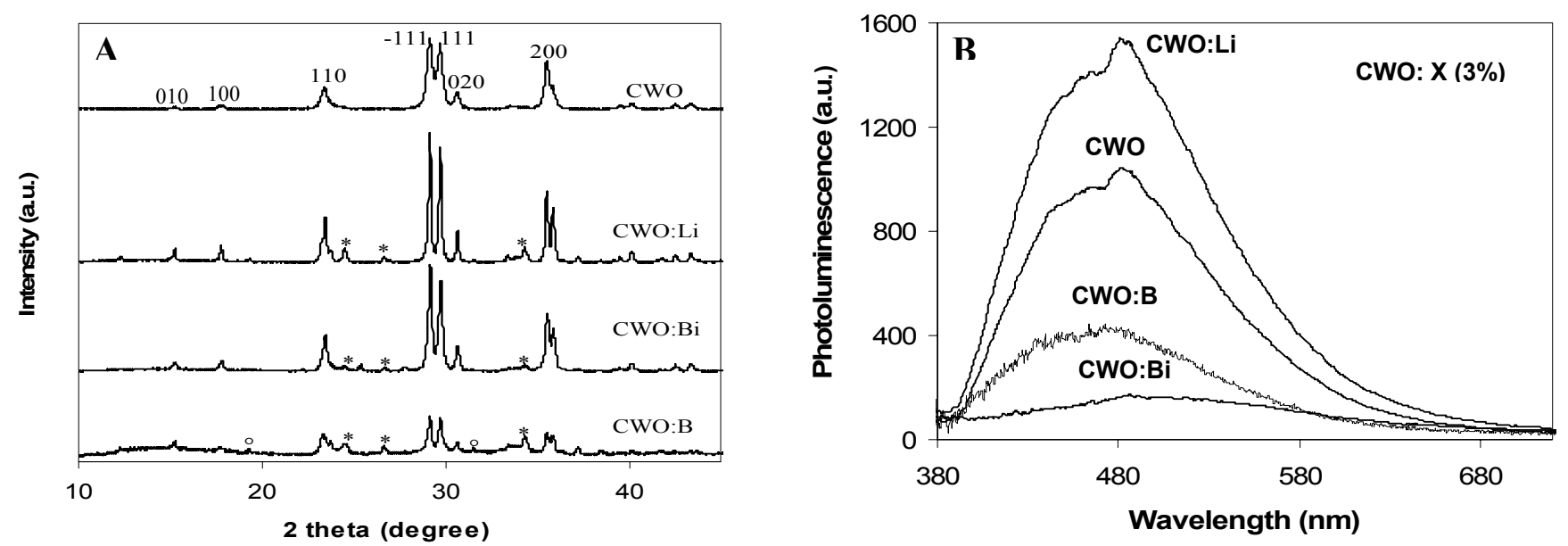

Fig. 1. Sol-gel processing derived CWO films. A is XRD of CWO, CWO: Li, CWO:Bi, and CWO: B powders. Stars represent $\mathrm{WO}_{3}$, and circles represent cadmium borate. $\mathrm{B}$ is the photoluminescence comparison of CWO and doped CWO films 

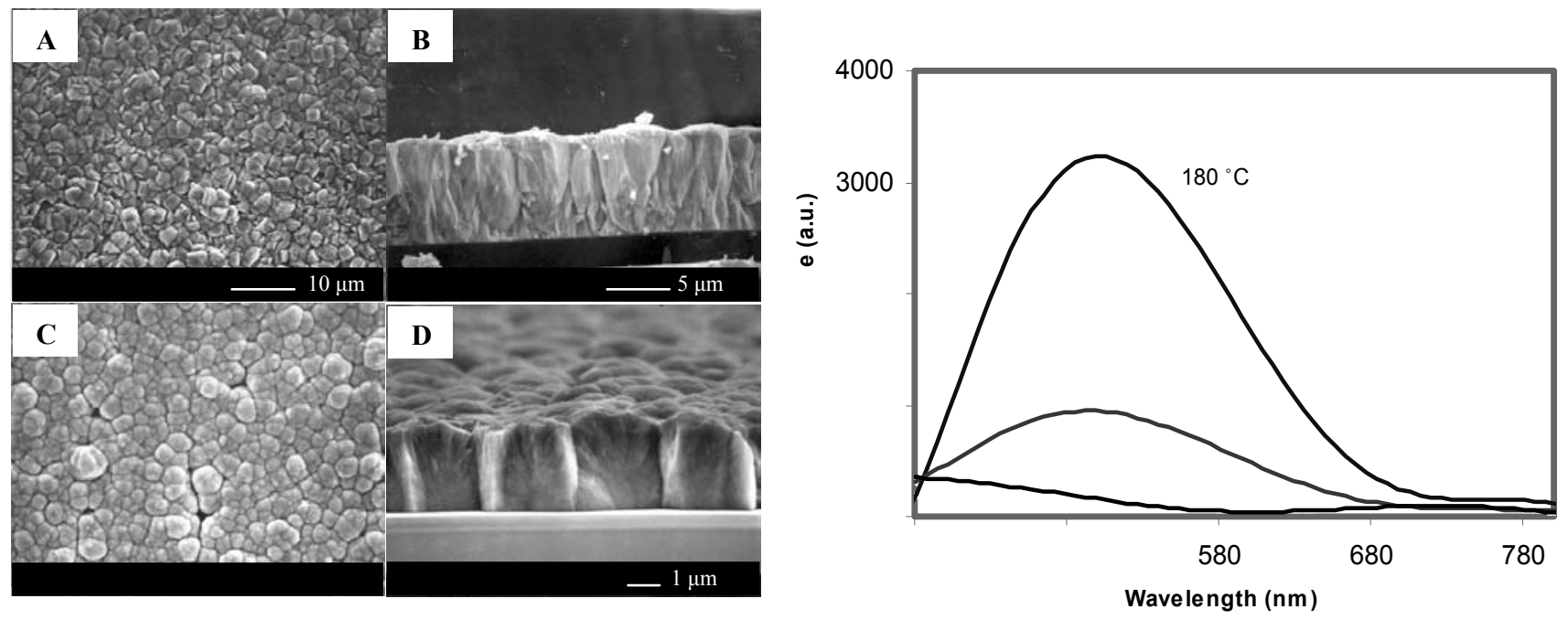

Fig. 2. Hydrothermal synthesized CWO films. A, B, C, and D are the morphologies of films. E is the photoluminescence property of CWO films. A and B were hydrothermal treated at $150^{\circ} \mathrm{C}$. C and D were treated at $180^{\circ} \mathrm{C}$. A and $\mathrm{C}$ were top-view of the films; B and D were side-view of the films. 


\section{Predicting Catalysis at Oxide Nano-Particles}

Awardee: Kiril Tsemekhman

Mentors: Hannes Jonsson - UW, Eric Bylaska - PNNL

\section{Project Summary}

The project involves a joint experimental-theoretical characterization of the structure and reactivity of redox-active oxide surfaces. The theoretical part of the project involves continued methodology development as well as application calculations. We implement improvements to the density functional theory approach in order to achieve proper theoretical description of band gaps and spin states of transition metal oxide surfaces. This methodology is being implemented in the parallel plane-wave based module of NWChem and is being applied to the study of molecular binding and reactions at the iron and titanium oxide surfaces.

None of the commonly used DFT functionals is capable to correctly predict the spin and charge localization both in the bulk and at the surfaces. This problem leads, among other examples, to incorrect band gaps, wrong spin structure of polaron state in hematite and incorrect description of the diffusion of oxygen at the $\mathrm{TiO}_{2}$ rutile (110) surface. These are the problems we work on. A significant progress has been made.

We implemented the Self-Interaction Corrections (SIC) method to complex spin systems such as hematite. We reformulated and implemented this method earlier for spinless systems. Based on our previous results, we expected SIC to solve both the spin localization and band gap problems which is vital for this class of systems. Indeed, we obtained the correct band gap and the localization of additional electron state in hematite. We are currently working on calculating the charge transfer energy barrier which defines the hopping rate of the polaron within Marcus theory. We performed calculations of both the extended system and of model cluster to compare our results with the predictions of the Hartree-Fock calculations of K. Rosso and M. Dupuis. For the first time we implemented Hartree-Fock and hybrid-type PBE0 functional in the planewave framework. This allows us to perform calculations on the extended systems using functionals similar to B3LYP which were previously practically available only to the finite systems.

We showed that PBE0 functional predicts accurate band gaps in most systems. We used this functional to study the diffusion of oxygen molecules on the $\mathrm{TiO}_{2}$ rutile (110) surface which is important for understanding of various catalytic reactions. Because the surface has never been found experimentally to be stoichiometric and is susceptible to formation of bridging oxygen vacancies, it is critical to understand the atomic and electronic structures of such vacancies. All previous calculations have predicted the vacancy level to be at the bottom of the conduction band and, therefore, the system to become metallic in the presence of vacancies. This error also leads to an incorrect atomic displacements around the defect. For the first time, we were able to show the localization of the vacancy state (Fig.1), its energy being inside the band gap, $1.0 \mathrm{eV}$ below the conduction band minimum (vs. $0.8 \mathrm{eV}$ experimentally), and the band gap equal to 3.2 $\mathrm{eV}$ in good agreement with the experimental value. We are working on developing a complete 
picture of vacancy-mediated oxygen diffusion which has now become possible with the PBE0 functional.

\section{Publications, Presentations and Proposals:}

Self-Consistent Implementation of Self-Interaction Corrected Density Functional Theory to Confined and Extended Systems, K. Tsemekhman, E. Bylaska, H. Jonsson, and E. Brown. Submitted to Phys. Rev. Lett., (2004).

Hybrid Functionals in Plane-Wave DFT: Method and Applications, K.Tsemekhman, E. Bylaska, H. Jonsson, in preparation.

ES04: 16th Annual Workshop on Recent Developments in Electronic Structure Methods, Rutgers University, New Brunswick, NJ, May 27-30, 2004. Self-Consistent Self-Interaction Corrected DFT: The Method and Applications to Extended and Confined Systems (Invited Talk).

15th Annual Symposium of the Pacific Northwest Chapter of the AVS The Science and Technology Society, PNNL, Richland, June 15-18, 2004. Self-Consistent Self-Interaction Corrected DFT Studies of Oxides

SRC Meeting, Durham, NC, June 30-July 1, 2004.Activity of Dopants in Silicon and Diffusion of Metal Atoms in Oxides

Nanoscale Science and Technology Workshop 2004, University of Washington, Sept. 15-17, 2004. Small Polaron in Hematite Fe2O3 Predicted by Self-Interaction Corrected DFT.

OEP Workshop, Frie University, Berlin, Germany, March 11-13, 2005. Self-Consistent SIC method and its extension to the exact exchange functionals for extended systems. (Invited talk).

\section{Funding that has resulted from this research:}

None so far. 


\section{Figures:}

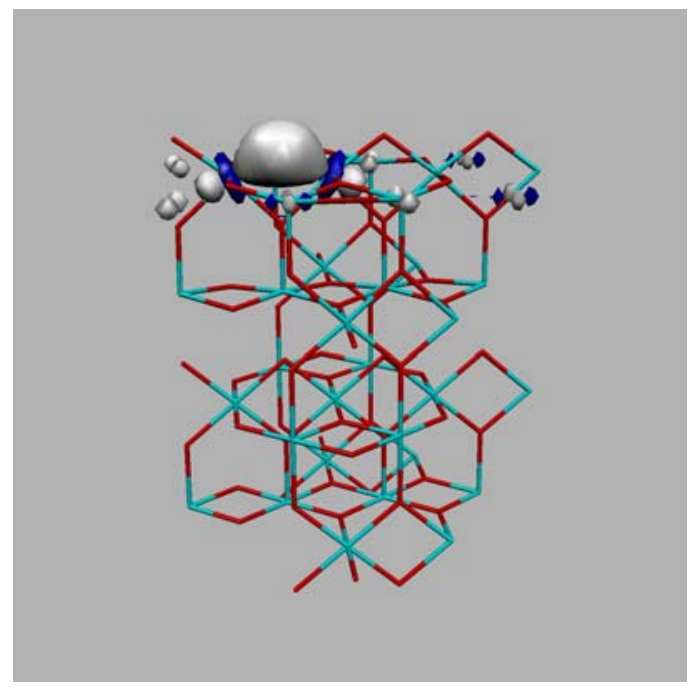

Fig.1. Localized Wannier function corresponding to the vacancy state at $\mathrm{TiO}_{2}$ rutile (110) surface. 


\subsection{Awards Authorized February 2004}

"Smart Superparamagnetic Nanoparticle Imagine Probes for Brain Tumor Research" Awardee: Jonathan Gunn

Mentors: Miqin Zhang - UW, Kevin Minard - PNNL

Page 2.62

"Study of Various Titania Nanostructures for the Exploration of Charge Transport in DyeSensitized Solar Cells"

Awardee: Tammy P Chou

Mentors: Guozhong Cao - UW, Glen E Fryxell - PNNL

Page 2.6

"Fundamental Studies of Monolayer-Protected Nanoparticles by Gas Chromatography" Awardee: Gwen Gross

Mentors: Robert Syncovec - UW, Jay Grate - PNNL

Page 2.13

"Detailed Materials, Magnetic, and Electronic Studies of Doped Transition Metal Oxides for Spintronic Applications"

Awardee: Tiffany Kaspar

Mentors: Kannan Krishnan - UW, Scott A. Chambers - PNNL

Page 2.25

"Epitaxial Growth and Properties of Nanoscale Oxides for Spintronics" Awardee: Diedrich Schmidt

Mentors: Scott A. Chambers - PNNL, Marjorie A. Olmstead - UW

Page 2.22

"Superparamagnetic Nanoparticles for Biomedical Applications"

Awardee: Nathan Kohler

Mentors: Miqin Zhang - UW, Glen Fryxell - PNNL

Page 2.30

"Pd Nanoclusters Supported on MgO(100): Effects of Cluster Size on Chemisorption Properties"

Awardee: Steven Tait

Mentors: Charles Campbell - UW, Bruce Kay - PNNL

Page 2.42 


\title{
Smart Superparamagnetic Imaging Probes for Brain Tumor Research
}

\author{
Awardee: Jonathan Gunn (UW) \\ Mentors: $\quad$ Miqin Zhang (UW) \\ Kevin Minard (PNNL)
}

\section{Project Summary:}

Iron oxide nanoparticles can be used as contrast-enhancement agents for the delineation of tumors through magnetic resonance imaging (MRI) as well as vehicles for directed drug delivery for therapies that can be monitored by MR imaging. In both systems, the nanoparticles require colloidal stability, strong tissue selectivity, and elongated blood circulation time in vivo.

The current state of the art in this area bases protein-particle conjugation on nanoparticles precoated with surfactant, which significantly increases the overall diameter of the targeting/contrast enhancing agent, subsequently limiting its ability to treat selected tumors and tumor metastases that lie across the blood brain barrier. To improve the size characteristics and biocompatibility of the nanoparticle system we have immobilized a heterobifunctional poly (ethylene glycol) (PEG) chain onto the surface of magnetite nanoparticles via a silinization reaction. The unbound end of the PEG molecule bears a trifluoroethylester "handle" that is reacted with ethylene diamine and subsequent linker chemistry for the appropriate biomolecule, fluorophore, or drug.

We first evaluated the attachment mechanism of recombinantly produced annexin $\mathrm{V}$ to iron oxide nanoparticles via an exposed epoxy group of a nanoparticle-bound epoxy-silane chain to which an amino group from the annexin $\mathrm{V}$ protein would bind. The conjugation and purification of these nanoparticles was successfully completed but the specificity to etoposide-treated cells was minimal, indicating the deactivation of protein activity during the conjugation. Weissleder et al. published a paper during the current research cycle indicating that bonding of two amine groups on the annexin $\mathrm{V}$ would deactivate it. To prevent errant PEG termini from deactivating the molecule a two-step bifunctional conjugation between the species was used to attach the protein in a 1:1 ratio of annexin $V$ to nanoparticles. Etoposide-treated cells incubated with annexin V-PEG-nanoparticles showed positive contrast as compared to untreated control cells (Figure 1B), and the contrast varied between the cells treated with differing concentrations of etoposide (Figure 1A). Additionally, the introduction of the PEG linker chain will elongate particle circulation times in vivo versus that of particles based on the epoxy group attachment scheme.

The tumor-targeting molecule PK11195 modified for conjugation was not commercially available and likewise difficult to synthesize in batches large enough for nanoparticle attachment. In order to circumvent these problems, the alternate targeting peptide, chlorotoxin (Cltx), was chosen to replace PK11195 for cell-targeting experiments. The 36 residue peptide was also used as a preliminary targeting molecule used for in vitro MRI and optical confocal microscopy (CM) studies performed with the synergistic microscopy machine developed and 
maintained at PNNL. This nanoparticle system was monolabled with the near-infrared fluorophore, Cy5.5, followed by Cltx attachment by the same conjugation scheme as utilized for the annexin V nanoparticles. Bioactivity of the dual-response probe was verified and the conjugated nanoparticles incubated with brain tumor cells and analyzed by both CM and MRI at PNNL (Figure 2). MR image contrast of the cancer cells showed dramatic changes upon uptake of the nanoparticle conjugates with the shortest MR echo times, while fluorescence microscopy of the same sample showed the presence of fluorescence.

Similar fluorophore studies are underway with the annexin V nanoparticles for further development of particles that can serve as a chemotherapeutic tracker for the quantitation of tumor cell death in vivo. This preliminary particle development will allow us to further understand the fundamentals of nanoparticle uptake by brain tumor tissue through continued UW/PNNL microscopy analysis and help us develop quantitative analysis schemes for personalized drug treatment. 


\section{Figures:}

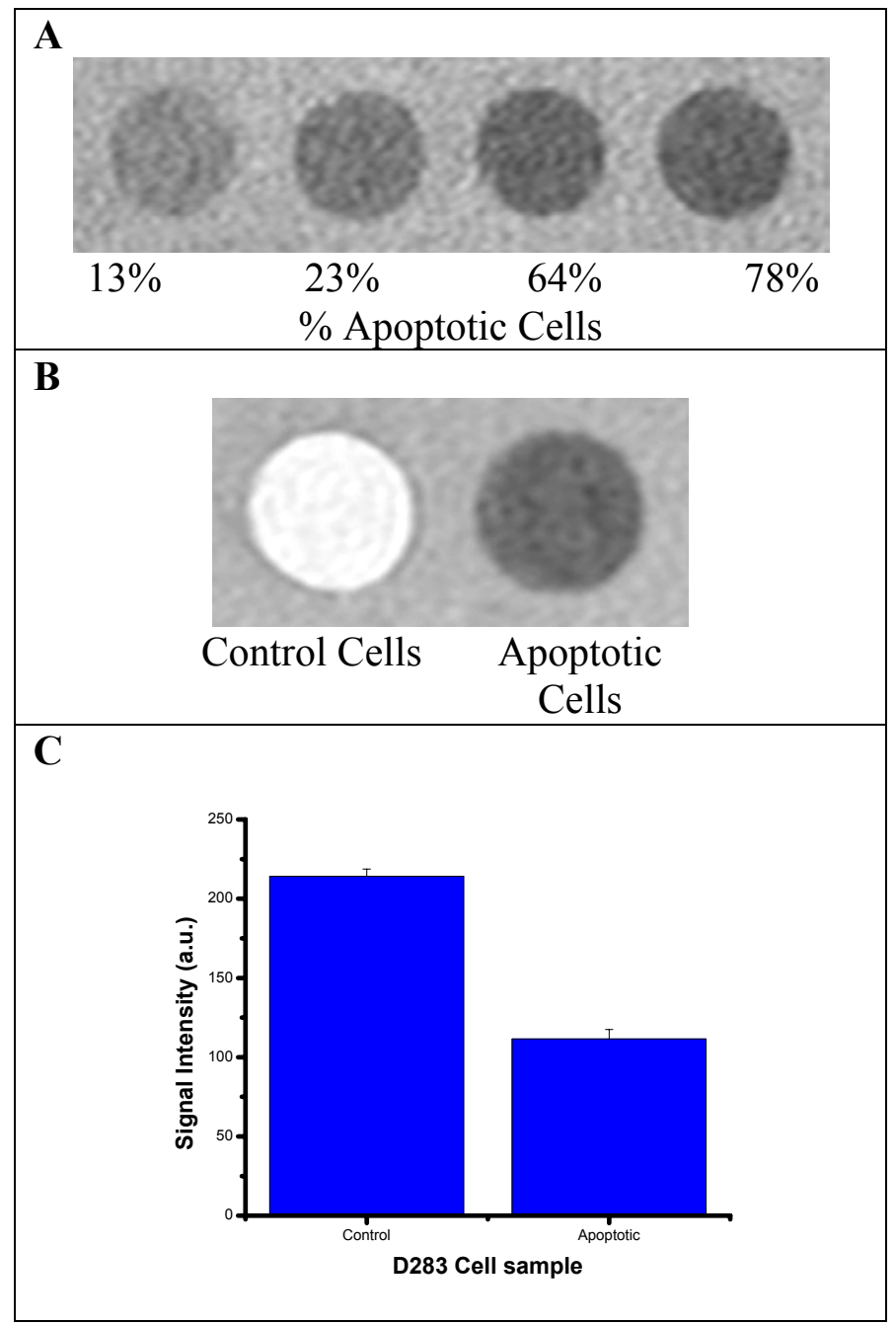

Figure 1 MR phantom images of (A) annexin V nanoparticles incubated with brain tumor cells pretreated with varying concentrations of etoposide to induce cell apoptosis, and (B) untreated versus treated brain tumor cells upon incubation with annexin $\mathrm{V}$ nanoparticles with (C) associated MR signal intensities. 

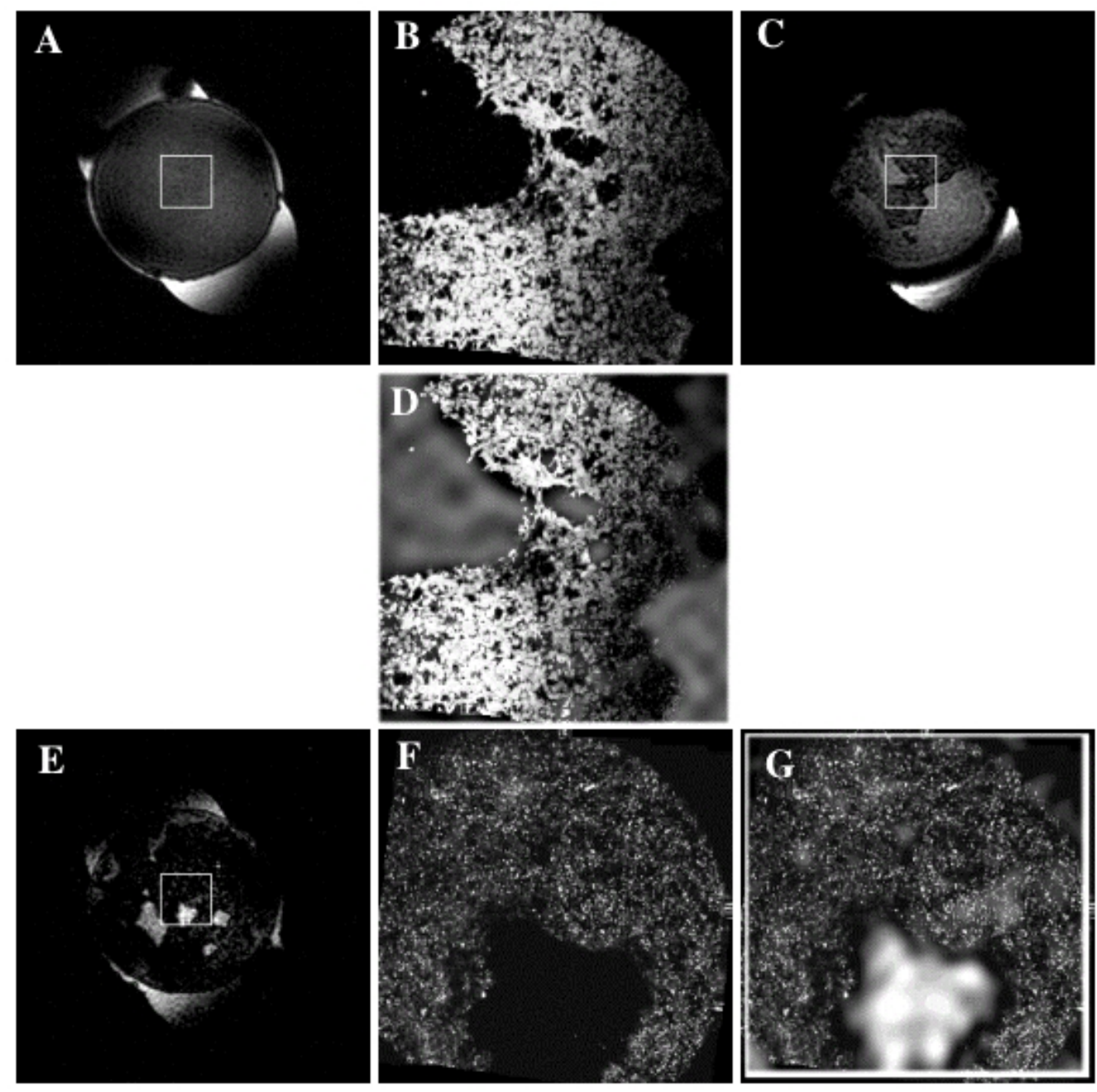

Figure 2 Combined MR and confocal imaging results. (A) Gradient echo MR image of control 9L/Lac Z cells attached to the surface of a 5-millimeter-diameter glass coverslip. (B) Confocal image showing control 9L/Lac Z cells within the white box depicted in A. Cells appear bright and dark regions show where attached cells were intentionally scraped off the glass surface. (C) Gradient echo MR image acquired with a longer echo-time using the same cells as in (A). Under these conditions cells are clearly visible as regions of reduced MR signal intensity. (D) Overlay of B with MR image data within the white box of (C). (E) Gradient echo MR image of 9L/Lac Z cells labeled with nanoparticle-PEG-Cltx-OG conjugates. Acquisition parameters are the same as in (A) but now enhance $\mathrm{T}_{2} *$ relaxation caused by the presence of magnetic nanoparticles destroys the MR signal in regions containing attached cells; thereby, making them visible. (F) Confocal image of nanoparticle-labeled cells within the white box depicted in (E). (G) Overlay of $(F)$ with MR image data within the white box of (E). 


\section{Publications, Presentations and Proposals:}

Refereed archival journal

- O. Veiseh, C. Sun, J. Gunn, N. Kohler, P. Gabikian, D.Lee, R..Ellenbogen, R. Sze, A. Hallahan, Jim Olson, Miqin Zhang*, An optical and MRI multifunctional nanoprobe for targeting gliomas, Nano Letters, in press.

- O. Veiseh, C. Sun, J. Gunn, N. Kohler, N. Bhattarai, D. Lee, R. Sze, A. Hallahan, R..Ellenbogen, J. Olson, M. Zhang ${ }^{*}$, Chlorotoxin-bounded superparamagnetic nanoparticles for brain tumor diagnosis and therapeutics, submitted.

- N. Bhattarai, H. R. Ramay, J. Gunn, F. A. Matsen, and M. Zhang "PEG-grafted chitosan as an injectable thermosensitive hydrogel for sustained protein release", Journal of Controlled Release, 103, 609-624 (2005).

\section{Conference presentations}

- J. Gunn, O. Veiseh, C. Sun, R. Ellenbogen, J. Olson, R. Sze, A. Hallahan and M. Zhang, Superparamagnetic Nanoparticle-bound Chlorotoxin for Brain Tumor Imaging, Oral presentation accepted at the 2005 NSTI Nanotechnology Conference and Trade Show, May 8-12, 2005, Anaheim, California, U.S.A.

- D. Lee, C. Sun, S. Hansen, J. Gunn, A Hallahan, M. Zhang, R.. Sze, and J. M. Olson Magnetic Resonance Target Imaging of Medulloblastoma Cells and Quantitation of Apoptosis, Providence, RI , 2005.

- M. Zhang, Invited talk in CMS2004 The Clay Mineral Society $41^{\text {st }}$ Annual Meeting, Richland, WA, "Iron oxide superparamagnetic nanoparticles for tumor diagnosis and therapeutics," June 2004.

- M. Zhang, Invited talk in Cancer Nanotechnology Symposium: Overcoming Barriers to Collaboration, sponsored by NCI/NIH, Cleveland, Ohio, Oct 2004.

- M. Zhang, Invited talk in Eleventh Annual Neuro-Oncology and Blood-Brain Barrier Consortium Meeting, Portland Oregon, March 2005.

- M. Zhang, Invited talk in $79^{\text {th }}$ ACS Colloid and Surface Sience Symposium, Potsdam, NY, "Superparamagnetic nanoparticle-bound chlorotoxin for brain tumor imaging," June 2005.

- M. Zhang, Invited talk $47^{\text {th }}$ American Association of Physicist in Medicine, Nanotechnology and Cancer, Seattle, July, 2005

\section{Posters}

1. Jonathan Gunn, Omid Veisel, Conroy Sun, Rich Ellenbogen, Jim Olson, Raymond Sze, Andrew Hallohan, Miqin Zhang, Nanoparticle-bound Chlorotoxin for Brain Tumor Imaging, Nanoscale Science and Technology Workshop, September 16-17 Seattle, WA 
2. Jonathan Gunn, Omid Veiseh, Conroy Sun, Patrik Gabikian, Rich.Ellenbogen, KevinMinard, Jim Olson, Raymond Syz, and Andrew Hallahan, Miqin Zhang, Superparamagnetic Nanoparticle-bound Chlorotoxin for Brain Tumor Imaging, Blood Brain Barrier Consortium, March 17-20, Portland, OR

\section{Funding that has resulted from this research:}

Title: Nanoparticle probes for brain painting Sponsoring agency/organization: Children Hospital Role: Co-PI (PI: J. Olson)

Title: Molecular imaging of neurons in brain Sponsoring agency/organization: Dana Foundation Role: Co-PI (PI: J. Olson)

Equipment: High performance Chromatography (HPLC) for protein and nanoparticle separation and analysis (in Zhang's lab) Sponsoring agency/organization: Children's Hospital \& Regional Medical Center Role: Co-PI (Rich Ellenbogen)

Equipment: Nanoparticle analyzer (in Zhang's lab) Sponsoring agency/organization: Children's Hospital \& Regional Medical Center Role: Co-PI (Rich Ellenbogen) 


\subsection{Impacts of the JIN}

\subsection{Summary of Impacts}

\section{Proposal Development Activities benefiting from the JIN}

Collaborations initiated, supported or developed at least in part due to the JIN are playing a significant role in creating new research directions and reshaping existing research programs at both the University of Washington and PNNL. Two pie charts demonstrate the distribution of JIN activities among UW departments and across PNNL Directorate. These activities have inspired a variety of newly-funded research programs or developing funding opportunities and have enabled renewal proposals for a variety of existing programs to be successfully funded at both institutions, through the NSF, DOE, NIH and/or various DOD sources. Although it is hard to quantify exactly what new funding has been produced directly by the JIN, we present data below that suggest that the JIN has been quite successful in this respect. The true impact of JIN is quite broad and may be better evaluated by looking at how different types of JIN activities have become significantly integrated into new and on going programs at both institutions. There is an interesting difference between the natures of the impacts at the two institutions. Many DOE projects are larger and mission related. Because these activities are somewhat focused, it is possible to see how JIN activities have made important contributions to these areas of research as they evolve at PNNL and they are described below. At the university there are many, sometimes smaller, projects where JIN impacts may be a larger portion of the development. Projects ascribed by PIs as evolving from JIN activities are also included.

Catalysis - PNNL has developed an Institute for Interfacial Catalysis. The institute is part of a PNNL laboratory initiative and involves collaborators from many institutions around the country. The institute builds upon northwest research strengths and ultimately seeks to develop a unique catalysis user facility. Activities underway include development and construction of unique experimental tools for catalysis studies. According to Institute for Interfacial Catalysis Deputy Director Charles Peden, the JIN has played and continues to play a significant role in joint UW/PNNL catalysis activities that have been seeds for the new institute. JIN Co-Director Charles Professor of Chemistry Charles Campbell was a key contributor in the formation and development of this institute and is working with PNNL staff and a postdoctoral fellow to design one of the new instruments. In turn, JIN funding has helped UW professors to obtain substantial external funding in the area of catalysis.

Spintrontronics and Diluted Magnetic Semiconductors - Both PNNL and the University of Washington research groups have new programmatic funding in this rapidly moving research area. This area has evolved quickly and PNNL's Dr. Scott Chambers has become one of the world leaders is the oxide based spintronics material. His materials and molecular beam epitaxy expertise complements other expertise in magnetic materials, solution synthesis and interfaces at the University of Washington. Over the past five years a significant funding base has evolved to from a variety of sources (NSF, DOE, DARPA) to create a highly cooperative significant research effort at both institutions. Dr. Chambers and his research team have interacted with many colleagues at the University of Washington. Scott is an unfunded participant in UW NSF research projects and the mentor to several JIN students from the groups of Kannan Krishnan, Daniel Gamelin and Marjorie Olmstead.

Energy Technologies - There is an increasing focus at both institutions on advanced energy research. The possibility of forming a University of Washington Global Energy Initiative is under consideration. Current or past JIN activities involve thermoelectric materials, hydrogen storage, and advanced 
photovoltaic materials that link growing activities at both institutions. As one sign of the impact of these interactions, PNNL recently received three new research programs associated with hydrogen based energy and JIN activities or projects are directly involved with two of these new programs.

Sensor Materials and Security - Several JIN activities have been directly or indirectly related to sensors, sensing materials or transduction processes that are important to chemical, biological and radiation sensors. The outputs of many of these activities have been incorporated in new research proposal and projects that relate to sensors associated with safety, environmental monitoring and security. The ideas and in some cases the people involved are now integrated into research activities or proposals with DOE, Homeland Security or DOD funding. This area also contains one of several examples where a JIN Award student became a postdoctoral fellow and is now a highly valued PNNL staff member.

Bio-nano and Biomedical Technology - There is an increasing level of interaction associated with nanobiology, nano-enhanced medicine and cellular level measurements. Medical, security and fundamental science themes are being developed. Funding options involving NIH, and DoD are being explored. Some of these efforts involve synthesis and clinic activities at the UW and imaging and characterization strengths at PNNL. This is an area where (during FY 2004 and 2005) there is increasing (JIN supported) interactions because of the great potential for interactions with high impact. These interactions have involved seminars at PNNL by UW facility and visits to UW by PNNL staff.

Integration of JIN and UW input into PNNL Core Science Programs - As one sign of the overall impact of the JIN we note that there is now a significant involvement of students, postdoctoral fellow or faculty in PNNL core DOE Office of Science programs related to spintronics (BES-Materials), nanoparticles (BES Geochemistry and BER), catalysis and photocatalysis (BES Chemistry and Materials), hydrogen storage (BES Materials) and chemical physics (BES Chemistry). As one PNNL JIN mentor noted, "work that JIN Graduate Student Steve Tait conducted was included in our BES Chemical Physics and Materials Science renewal proposals."

Nanotechnology Education and Capability Development - UW and PNNL have teamed in several ways to create new opportunities in nanoscience and nanotechnology. The NSF has funded joint UW and PNNL intensive nanoscience courses that now regularly involve cooperative activities among UW, PNNL, Washington State University and the University of Idaho. PNNL through the Environmental Molecular Sciences Laboratory supported the UW portion of the NNIN proposal and efforts are underway to enhance NNIN access to EMSL experimental and computational capabilities. Both the UW and PNNL are working with regional community colleges in a broad Nanotechnology education effort.

Student and Staff Development - A significant indicant of the impact of the JIN relates to the career development of the people involved. Although a systematic study has not been done, success of JIN Awardees attributes to both their talent and the nature of the JIN activities. At least two JIN Awardees are or will soon be PNNL staff members. Another student has started a postdoctoral appointment at the Max Planck Institute for Solid State Physics in Stuttgart and is a finalist for a Humboldt Fellowship. Student Tiffany Kaspar received the Leo Falicov Award for the American Vacuum Society.

It may be important to note that not all JIN activities have been highly successful; however, even unsuccessful projects can be useful. One faculty member notes, "The JIN award for a postdoctoral fellow was very helpful in allowing our group to explore a new direction in our research. Unfortunately, and despite our best efforts, these ideas did not bear fruit and were discontinued after six months, returning the balance of the funds to JIN. No publications or grant proposals have resulted -- only a greater understanding in my group of the challenges of exploring the reaction chemistry of nanoscale objects." 
The pie charts below show the distribution of JIN activities among departments at the UW and among directorates at PNNL.
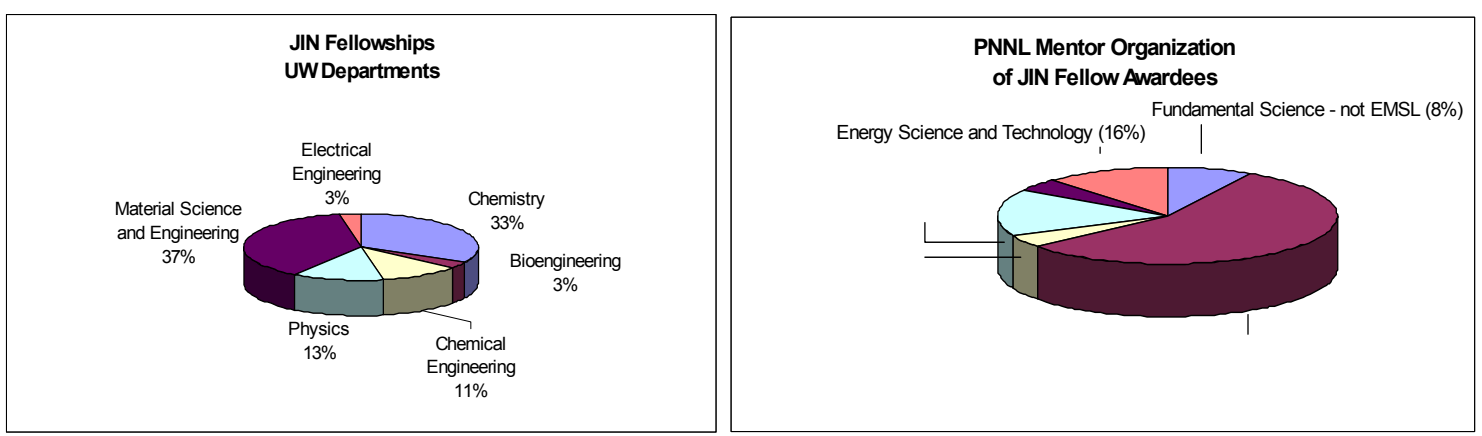

Below follows a list of specific Proposals for which the investigators indicate that JIN activities have played a significant role in the formulation of these proposals.

\section{National Science Foundation:}

Investigators: PI Kannan Krishnan, Co-PI: Daniel R. Gamelin and Marjorie Olmstead Acquisition of a Scanning Probe Microscope System for Research and Education in Nanomagnetism and Spinelectronics,; NSF-IMR grant for $\$ 160 \mathrm{~K}$ awarded for acquisition of the proposed instrumentation

Investigators: Kannan Krishnan, PI; Daniel Gamelin, Marjorie Olmstead, Alec Pakhomov and Scott Chambers, co-PIs;

Magnetic oxide nanostructures in silicon based spintronics; Source of Support: National Science Foundation; List funded total award value. Period Covered: 08/01/05-07/31/08; Location of Research: University of Washington. \$840,251 under review

Investigators: Marjorie Olmstead, PI (Fumio Ohuchi, co-PI);

Chalcogenide Buffer Layers for Oxide Heteroepitaxy on Silicon; Source of Support: National Science Foundation; Period Covered:

06/01/05 - 05/31/08; Location of Research: University of Washington. \$657K Not funded

Investigator: Guozhong Cao

Hierarchical Assemblies of Nanofibers for Photovoltaic Devices (NIRT, PI: Younan Xia)

Submitted 11/12/04, NSF/ $\$ 400,000$, not funded.

Investigator: Guozhong Cao

Fabrication of Columnar Microstructure CdWO4 Scintillator for Neutron Detection submitted 10/28/04 $\mathrm{NSF} / \$ 279,597$ not funded

\section{Department of Energy}

Investigator: C.T. Campbell

Oxide-supported Metal Nanoparticles: Catalytic Properties and Energetics, DOE-BES grant to UW for $\$ 480 \mathrm{~K}$ for the period 3/15/05 to 3/14/08. 
Investigator: Daniel Gamelin

Chemical Manipulation of High Temperature Spin Ordering in Oxide Semiconductors, DOE grant for $\$ 590 \mathrm{~K}$ for period 6/15/05 to 6/14/08. Submitted, under review.

Investigator: D. R. Baer plus team

The Reaction Specificity of Nanoparticles in Solution, \$3,200K for 10/1/2005 to 9/30/2009 DOE BES Chemistry and BER, ongoing program renewal under review

Investigator: Bruce D. Kay and team

"Condensed Phase Chemical Physics: Chemical Kinetics and Dynamics at Interfaces" October 1, 2005 to September 30, 2008. \$10,454K BES Chemical Sciences on going program renewal under review

Investigator: Gregory J. Exarhos (includes Bruce Kay and Scott Chambers)

"Chemistry and Physics of Ceramic Surfaces" October 1, 2005 to September 30, 2008. \$2,000K BES Materials Sciences, on going program, renewal under review.

Investigator: Marjorie Olmstead (co-PI Fumio Ohuchi)

Heteroepitaxy of Intrinsic Vacancy Materials, DOE BES proposal for \$712,650, proposed for 12/01/2004-11/20/2007. Pending.

\section{Department of Defense and National Security}

Investigator: Mehmet Sarikaya (Co-PI Francois Baneyx)

GENETICALLY-ENGINEERED PROTEINS FOR FUNCTIONAL NANOINORGANICS Defense University Research Initiative of NanoTechnology (DURINT)

through ARO; \$5,000,000 (May 1, 2001 - April 30, 2006),

Investigator: Mehmet Sarikaya

DURIP (Defence > University Research Instrumentation Program),

\$180,000 (July 1, 2002 - June 30, 2004).

Investigator: R. E. Synovec

DARPA micro-Gas Chromatograph Proposal (Funded): R.E. Synovec (University of Washington) \$420,000 for 4.5 years starting August 2004 .

Investigator: Chris Aardahl

"CO2 Capture from Submarine Atmospheres" NAVSEA Philadelphia "Signature Collection" Coastal Security, United States Navy- $\$ 600 \mathrm{~K}$ in process

Investigator: Guozhong Cao

Nanostructured Polycrystalline Doped CdWO4 Scintillator for Neutron Detection

submitted 05/21/04 NNSA/\$250,000 not funded

\section{National Institutes of Health and other Medical}

Investigator: Miqing Zhang

Nanoparticle probes for brain painting 
Sponsoring agency/organization: Children Hospital \& Regional Medical Center

Total Funding $\$ 150 \mathrm{~K}$

Role: Co-PI (PI: J. Olson) (Zhang)

Investigator: Miqing Zhang

Molecular imaging of neurons in brain

Sponsoring agency/organization: Dana Foundation

Total Funding: \$120K

Role: Co-PI Miqin Zhang (PI: J. Olson)

Investigator: Miqing Zhang

Equipment: High performance Chromatography (HPLC) for protein and nanoparticle separation and analysis (in Zhang's lab)

Sponsoring agency/organization: Children's Hospital \& Regional Medical Center

Funding: $\$ 54.5 \mathrm{~K}$

Role: Co-PI (Rich Ellenbogen)

Investigator: Miqing Zhang

Equipment: Nanoparticle analyzer (in Zhang's lab)

Sponsoring agency/organization: Children's Hospital \& Regional Medical Center

Amount: \$36K (Analyzer to be located in Prof. Zhang's lab)

Role: Co-PI (Rich Ellenbogen)

Investigator: Miqing Zhang

Molecular imaging diagnosis and treatment of medulloblastoma sponsoring agency/organization:

$\mathrm{NIH} / \mathrm{NCI}$ (Zhang)

Total Amount \$1,693K

Role: Co PI (PI R. Sze)

Investigator: Miqing Zhang

Magnetic nanoparticle-conjugates as contrast agents and drug carriers for cancer diagnostics and therapeutics sponsoring agency/organization: Taiwan-ITRI (Zhang)

Role: PI

Amount to Zhang $\$ 70 \mathrm{~K}$

Duration 7/1/03-6/30/05

\section{Other Foundations}

Investigator: Alex Jen,

Efficient and Low-cost Lighting Technology Based on Organic White Light-emitting Diodes, PI: A. K.Y. Jen, UW TGIF fund for $\$ 50 \mathrm{~K}$ for the period $01 / 01 / 05$ to $12 / 31 / 05$.

Investigator: Daniel R. Gamelin,

An Integrated Laboratory for Physical Property Measurements of Advanced Materials and Novel Devices, Co-PI:- Murdoch Foundation grant for $\$ 499 \mathrm{~K}$ for period 3/01/05 to 2/28/06. Submitted, under review.

Investigators: Kiril Tsemekhman and Hannes Jonsson 
Semiconductor Research Corporation funding initiative currently being reviewed at the level of $\$ 70 \mathrm{~K}$ annually each.

\section{Invention Reports:}

Dietrich Schmidt, Marjorie Olmstead, Epitaxial Growth and Properties of Nanoscale Oxides for Spintronics, As a result of this work the investigators at UW have registered this technology with the UW TechTransfer Office which might result in a future patent application.

G. M. Gross, J. W. Grate, R. E. Synovec; "Monolayer Protected Gold Nanoparticles for use as a Gas Chromatographic Stationary Phase in Capillary and Microfabricated Chromatographic Systems". Date received at OTL: 10/17/2003 (3131-4038DL), 2004.

\section{Other Impacts of JIN on Faculty and Staff}

Two JIN awardees have made a transition form JIN Awardee to postdoc or staff positions. Leo Fifeld was a very successful JIN graduate student, first hired at the laboratory as a postdoc and now hired as a new staff member. Tiffany Kaspar was also a JIN student and now a postdoc. The process of identifying a position in the lab may lead her along the same pathway. Other JIN awardees have finished degrees and have continued as postdocs at other locations, but successful student activities are leading to continued interactions and possibilities of additional JIN awardees being hired by the laboratory.

The joint PNNL/UW nanocourses offer PNNL staff and postdocs options to continue a role in teaching. This option enhances the future employment options for postdoctoral staff who wish to pursue an academic career after their time at the laboratory.

The JIN provides a communication tool facilitating contacts and interactions between the two institutions. One role of the JIN Co-Directors is assisting establishment of contacts of new staff and faculty members at the partner institution. Seminars and visits are arranged and supported through the JIN.

\section{Other Highlights}

Results from JIN Carbon Nanotube work (Leo Fifeld, Chris Aardahl and Larry Dalton has also received media attention:

http://www.voyle.net/Nano\%20Research-05/research-05-0058.htm http://www.eurekalert.org/features/doe/2004-08/dnnl-fcn082404.php http://www.innovations-report.com/html/reports/materials science/report-41985.html

Work by the group of Prof. Miqin Zhang (Materials Science UW), involving student Nathan Kohler and PNNL Staff Member Glen Fryxell [ Nano weapons join fight against cancer] was discussed in the Wall Street Journal in April of 2004 and appeared in the May 192004 Bio Tech News [Magnetic Nanoparticles Target Brain Tumors for Destruction]. 


\subsection{Papers Related to JIN Awards}

The information included in this section has been provided by the research team members as publications linked to JIN Awards and is provided as an indication of JIN activity. The accuracy of each citation has not been fully verified.

\subsubsection{Published in 2002}

1. "Functionalized, Hierarchically-Structured Mesoporous Silica by Sol Electrophoresis and Self-Assembly," T.P. Chou, S.J. Limmer, and G.Z. Cao in Nanoscale Optics and Applications, Proceedings of SPIE 4809, eds. G.Z. Cao and W.P. Kirk, 239-248 (2002).

2. "High-Efficiency Intracellular Uptake of Superparamagnetic Magnetite Nanoparticles for Biomedical Applications in Nanoscience and Nanotechnology in Perspective," Y. Zhang, N. Kohler, and M. Zhang G. Liu, et al. (eds), pp 282, Frontiers of Science and Technology for the 21st Century, Tshinghua University Press (2002).

3. "Growth of Oxide Nanorods using Sol-Gel Electrophoretic Deposition," Limmer, Steven J.; Cao, Guozhong, Electrophoretic Deposition: Fundamentals and Applications Electrochemical Society Proceedings v. 2002-21), 271-278 (2002).

4. "Formation and Optical Properties of Cylindrical Gold Nanoshells on Silica and Titania Nanorods," Limmer, Steven J.; Chou, Tammy P.; Cao, Guozhong. Proceedings of SPIE The International Society for Optical Engineering, v 4809, p 222-230 (2002).

5. "Colloidal Transition-Metal-Doped ZnO Quantum Dots." Radovanovic, Pavle V.; Norberg, Nick S.; McNally, Kathryn E.; Gamelin, Daniel R. Journal of the American Chemical Society 124, 15192, (2002).

6. "Electrophoretic Deposition of Oxide Nanorods inside Pores of Template from Sols," S.J. Limmer and G.Z. Cao, Proceedings of the Electrochemical Society (2002).

7. “Nanoscale Optics and Applications," G.Z. Cao, SPIE Proceedings 4809, Ed. (2002).

8. "Processing and Properties of $\mathrm{Sr}_{2} \mathrm{Nb}_{2-\mathrm{x}} \mathrm{V}_{\mathrm{x}} \mathrm{O}_{7}$ Ferroelectrics," S. Seraji, S.J. Limmer, M.J. Forbess, Y. Wu, T.P. Chou, C. Nguyen, and G.Z. Cao, Materials Science and Engineering B88, 73-38 (2002).

9. "Template-Based Growth of Various Oxide Nanorods by Sol-Gel Electrophoresis," S.J. Limmer, S. Seraji, M.J. Forbess, Y. Wu, T.P. Chou, C. Nguyen, and G.Z. Cao, Advanced Functional Materials 12, 59-64 (2002). 
10. "Influence of Tungsten Doping on Dielectric Properties of Strontium Bismuth Niobate Ferroelectric Ceramics," Y. Wu and G.Z. Cao, Journal of Materials Science Letters 21, 251253 (2002).

11. "Organic-Inorganic Sol-Gel Coating for Corrosion Protection of Stainless Steel," T.P. Chou, C. Chandrasekaran, S. Limmer, C. Nguyen, and G.Z. Cao, Journal of Materials Science Letters 21, 947-949 (2002).

12. "Synthesis and Optical Properties of Nanostructured $\mathrm{CdWO}_{4}$ Films by Sol-Gel Processing," K. Lennstrom, S.J. Limmer, and G.Z. Cao, in Nanoscale Optics and Applications, Proceedings of SPIE 4809, ed. G.Z. Cao and W.P. Kirk, 231-238 (2002).

13. "Nanoscale Optics and Applications," Guozhong Cao and Wiley P. Kirk. Proceeding of SPIE, Vol. 4809, The International Society for Optical Engineering, Bellingham, WA (2002).

\subsubsection{Published in 2003}

1. "Ordered, Dye-Functionalized Titania Nanorods and Their Applications as Sensors," T.P. Chou, C.M. Chung, And G.Z. Cao, In Nanomaterials And Their Optical Applications, SPIE Proceedings 5224, Eds. 53-61, (2003).

2. "Monolayer Protected Gold Nanoparticles as a Stationary Phase for Open Tubular Gas Chromatography," G.M. Gross, D.A. Nelson, J.W. Grate, R.E. Synovec, Analytical Chemistry, 75, 4558-4564 (2003).

3. "Transition from Granular to Dilute Magnetic Semiconducting Multilayers in Iron Beam Deposited Zno/Co," A. Pakhomov, B. Roberts And K.M. Krishnan, Applied Physics Letters 83, 21 (2003).

4. "Electrowetting-Induced Droplet Movement in an Immiscible Medium," Jason S. Kuo, Paolo Spicar-Mihalic, Indalesio Rodriguez, Daniel T. Chiu, Langmuir, 19, 250-255 (2003).

5. "Dynamic Formation of Ring-Shaped Patterns of Colloidal Particles in Microfluidic Systems," D.S.W. Lim, P. Shelby, J.S. Kuo, D.T. Chiu, Applied Physics Letters 83, 1145 $1147,(2003)$.

6. "Selective Electroless and Electrolytic Deposition of Metal for Applicationsin Microfluidics: Fabrication of a Microthermocouple," Peter B. Allen, Indalesio Rodriguez, Christopher L. Kuyper, Robert M. Lorenz, Paolo Spicar-Mihalic, Jason S. Kuo, Daniel T. Chiu, Analytical Chemistry, 75, 1578-1583 (2003).

7. "Molding Techniques for the Rapid Prototyping of Polymeric Microfluidic Devices," G.S. Fiorini, G.D.M. Jeffries, D.S.W. Lim, C.L. Kuyper, D.T. Chiu, Lab Chip 3, 158-163, (2003).

8. "Template-Based Growth of Oxide Nanorods by Sol Electrophoresis," Limmer, Steven J.; 
Cao, Guozhong. Advanced Materials, 15(5), 427-431, (2003).

9. "Nanorods of Various Oxides and Hierarchically Structured Mesoprous Silica by Sol-Gel Electrophoresis," Limmer, Steven J.; Hubler, Timothy L.; Cao, Guozhong. Journal Of SolGel Science And Technology, 26(1/2/3), 577-581, (2003).

10. "Sol Electrophoretic Deposition of Oxide Nanorods," G.Z. Cao And S.J. Limmer, In Nanowire Materials, Ed. Z.L. Wong, Kluwer, Nanowires And Nanobelts: Materials, Properties And Devices V2, 93-110 (2003).

11. "Efficient Green Light-Emitting Diodes from Silole-Containing Copolymers," M. S. Liu, J. Luo, A. K-Y. Jen, Chemical Materials 15, 3496 (2003).

12. "Bright Red-Emitting Electrophosphorescent Device using Osmium Complex as a Triplet Emitter," J.-H. Kim, M. S. Liu, A. K-Y. Jen, B. Carlson, L. R. Dalton, R. Dodda, C. F. Shu, Applied Physics Lettets 83, 776 (2003).

13. "Highly Efficient Blue Light-Emitting Diodes from Polyfluorene Containing Bipolar Pendent Groups," C. F. Shu, R. Dodda, F. I. Wu, M. S. Liu, A. K-Y. Jen, Macromolecules 36, 6698 (2003).

14. A Novel Oxadiazole-Containing Polyfluorene with Efficient Blue Electroluminescence," F-I. Wu, D. S. Reddy, C. F. Shu, M. S. Liu, A. K-Y. Jen, Chemical Materials 15, 269 (2003).

15. "Absorption and Luminescence Properties of Sequentially Random- and Defined Copolymers Based on Poly(Fluorene-Benzothiadiazole)," P. Herguth, J.-H. Kim, X. Z. Jiang, M. S. Liu, A. K.-Y. Jen, MRS Procedings 771 (Organic And Polymeric Materials And Devices), 357 (2003).

16. "Development of Efficient Electron-Transporting Polymers for Light-Emitting Diodes," M. S. Liu, X. Z. Jiang, P. Herguth, S. Liu, A. K.-Y. Jen, Procedings Of SPIE 4800, 130 (2003).

17. "Poly(Fluorene-Co-Benzothiadiazole)S: Effect of Structure, Molecular Weight and Polydispersity on Their Performance in Polymer Light-Emitting Diodes," P. Herguth, X. Z. Jiang, M. S. Liu, A. K.-Y. Jen, Procedings Of SPIE 4800, 138 (2003).

18. "Magnetic Quantum Dots: Synthesis, Spectroscopy, and Magnetism of $\mathrm{Co}^{2+}$ - and $\mathrm{Ni}^{2+}$-Doped Zno Nanocrystals." Schwartz, Dana A.; Norberg, Nick S.; Nguyen, Quyen P.; Parker, Jason M.; Gamelin, Daniel R. Journal Of The American Chemical Society, 125, 13205 (2003).

19. "Band Offsets for the Epitaxial $\mathrm{TiO}_{2} / \mathrm{SrTiO}_{3} / \mathrm{Si}(001)$ System." AC Tuan, TC Kaspar, $\mathrm{T}$ Droubay, JW Rogers, Jr, SA Chambers. Applied Physics Lettets Vol. 83 P. 3734 (2003).

20. "Sol-Gel Derived Hybrid Coatings for Corrosion Protection," T.P. Chou, C. Chandrasekaran, and G.Z. Cao, Journal Of Sol-Gel Science And Technology 26, 321-327 (2003). 
21. "Films, Patterned Structures and Nanorods of Various Oxides and Mesoporous Silica by SolGel Electrophoresis," S.J. Limmer, T. Hubler, And G.Z. Cao, Journal Of Sol-Gel Science And Technology 26, 577-581 (2003).

22. "Adhesion of Sol-Gel-Derived Organic-Inorganic Hybrid Coatings on Polyester" (Invited), T.P. Chou And G.Z. Cao, Journal Of Sol-Gel Science And Technology 27, 31-41 (2003).

23. "The Role of O(1D) in the Oxidation of Si(100)," T.C. Kaspar, A.C. Tuan, R.G. Tonkyn, W.P. Hess, J.W. Rogers, Jr., Y. Ono, Journal Of Vacuum Science And Technology BMicroelectronics And Nanometer Structures 21 (2), 895-899 (2003).

24. "Sol-Gel Electrophoretic Deposition for the Growth of Oxide Nanorods," S.J. Limmer, G. Cao, Advanced Materials, V 15, N 5, P 427-431 (March 4, 2003).

25. "A Novel Oxadiazole-Containing Polyfluorene with Efficient Blue Electroluminescence," Fang-Iy Wu, D. Sahadeva Reddy, Ching-Fong Shu, Michelle S. Liu, Alex K-Y. Journal Of Chemical Materials, 15 (1): 269-274 (Jan. 14, 2003).

26. "Formation and Optical Properties of Gold-Coated Oxide Nanorods," S.J. Limmer, T.P. Chou, G.Z. Cao, Journal Of Physical Chemistry, B107, 13313-13318 (2003).

\subsubsection{Published in 2004}

1. "Metal Nanoparticles Protected with Monolayers; Applications for Chemical Vapor Sensing and Gas Chromatography," J.W. Grate, D.A. Nelson, R. Skaggs, R.E. Synovec, G.M. Gross, Chapter For The Encyclopedia Of Nanoscience And Nanotechnology, Marcel Dekker, Inc., 1859-1867 (2004).

2. "The Development of Novel Gas Chromatographic Stationary Phases Using Monolayer Protected Gold Nanoparticles for Application in High-Speed and Multi-Dimensional Gas Chromatographic Separations," G.M. Gross, J.W. Grate, R.E. Synovec, Journal Of Chromatography A, 1060, 225-236 (2004).

3. "A Bifunctional Poly(Ethylene Glycol) Silane Immobilized on Metallic Oxide-Based Nanoparticales for Conjugation with Cell Targeting Agents,” N. Kohler, G.E. Fryxell, M. Zhang, Journal Of American Chemical Society, 126, 7206-7211 (2004).

4. "High-Speed Gas Chromatography Using a Synchronized Dual-Valve Injector," G.M. Gross, B.J. Prazen, J.W. Grate, R.E. Synovec, Analytical Chemistry, 76, 3517-3524 (2004).

5. "Monolayer-Protected Gold Nanoparticles as an Efficient Stationary Phase for Open Tubular Gas Chromatography Using a Square Capillary: A Model for Chip-Based Gas Chromatography in Square Cornered Microfabricated Channels," G.M. Gross, J.W. Grate, R.E. Synovec, Journal Of Chromatography A, 1029, 185-192 (2004). 
6. "A Study on the Growth of $\mathrm{TiO}_{2}$ Using Sol Electrophoresis," S.J. Limmer, T. P. Chou, G. Z. Cao, Journal Of Materials Science 39, 895-901 (2004).

7. "Development of Titania Nanostructures for the Exploration of Electron Transport in DyeSensitized Solar Cells," T.P. Chou, G.Z. Cao, And G.E. Fryxell, In Nanophotonic Materials, Proceedings Of SPIE 5510, Eds., D.L. Andrews, G.Z. Cao, And Z. Gaburro, P.129-137, 2004.

8. "Noncovalent Functionalization of Carbon Nanotubes with Molecular Anchors Using Supercritical Fluids," Leonard S. Fifield, Larry R. Dalton, R. Shane Addleman, Rosemary A. Galhotra, Mark H. Engelhard, Glen E. Fryxell, And Christopher L. Aardahl. Phys. Chem. B (2004), 108, 8737-8741

9. “Above-Room-Temperature Ferromagnetic $\mathrm{Ni}^{2}+: \mathrm{ZnO}$ Thin Films Prepared from Colloidal Diluted Magnetic Semiconductor Quantum Dots," Schwartz, D.A.; Kittilstved, K.R.; Gamelin, D.R., Appl. Phys. Lett., 2004, 85, 1395-1397.

10. "Synthesis of Colloidal $\mathrm{Mn}^{2}+: \mathrm{ZnO}$ Quantum Dots and High-TC Ferromagnetic Nanocrystalline Thin Films," Norberg, N. S.; Kittilstved, K. R.; Amonette, J. E.; Kukkadapu, R. K.; Schwartz, D. A.; Gamelin, D. R., J. Am. Chem. Soc., 2004, 126, 9387-9398.

11. "Effects of Dopants in Cadmium Tungstate Scintillator Films," H.M. Shang, Ying Wang, B. Milbrath, M. Bliss, And G.Z. Cao, In Nanophotonic Materials, Eds., D.L. Andrews, G.Z. Cao, And Z. Gaburro, Proc. SPIE 5510, P.88-96, 2004.

12. "High-Speed Gas Chromatography Using a Synchronized Dual-Valve Injector," G.M. Gross, B.J. Prazen, J.W. Grate, R.E. Synovec, Anal. Chem., 76, 2004, 3517-3524.

13. "Efficient and Stable Blue Light-Emitting Diodes Based on an Anthracene Derivative Doped Poly(N-Vinylcarbazole)," Y.-H. Niu, B. Q. Chen, T.-D. Kim, M. S. Liu, A. K.-Y. Jen, Appl. Phys. Lett., 85, 2004, 5433-5435.

14. "Experimental Determination of Valence Band Maxima for $\mathrm{SrTiO}_{3}, \mathrm{TiO}_{2}$, and $\mathrm{SrO}$ and the Associated Valence Band Offsets with Si(001)," Chambers SA, Droubay T, Kaspar TC, Gutowski M, Journal Of Vacuum Science \& Technology B, 22 (4): 2205-2215 (Jul-Aug 2004).

15. "Room-Temperature Ferromagnetism in Ion-Implanted Co-Doped $\mathrm{TiO}_{2}(110)$ Rutile," Shutthanandan V, Thevuthasan S, Heald SM, Droubay T, Engelhard MH, Kaspar TC, Mccready DE, Saraf L, Chambers SA, Mun BS, Hamdan N, Nachimuthu P, Taylor B, Sears RP, Sinkovic B, Applied Physics Letters, 84 (22): 4466-4468 (May 31 2004).

16. Accurate Valence Band Maximum Determination for $\mathrm{SrTiO}_{3}(001)$ Chambers $\mathrm{SA}_{2}$ Droubay T, Kaspar TC, Gutowski M, Van Schilfgaarde M, Surface Science, 554 (2-3): 81-89, (April 10, 2004). 
17. "Epitaxial Growth and Properties of Cobalt-Doped $\mathrm{ZnO}$ on Alpha- $\mathrm{Al}_{2} \mathrm{O}_{3}$ Single-Crystal Substrates," Tuan AC, Bryan JD, Pakhomov AB, Shutthanandan V, Thevuthasan S, Mccready DE, Gaspar D, Engelhard MH, Rogers JW, Krishnan K, Gamelin DR, Chambers SA, Physical Review B, 70 (5): Art. No. 054424, (August 2004).

18. "Studies of two and three-Dimensional $\mathrm{ZnO}$ : Co Structures through Different Synthetic Routes," Pakhomov AB, Roberts BK, Tuan A, Shutthanandan V, Mccready D, Thevuthasan S, Chambers SA, Krishnan KM, Journal Of Applied Physics, 95 (11): 7393-7395 Part 2, (June 1, 2004).

19. "Noncovalent Functionalization of Carbon Nanotubes with Molecular Anchors Using Supercritical Fluids," Fifield LS, Dalton LR, Addleman RS, Galhotra RA, Engelhard MH, Fryxell GE, Aardahl CL, Journal Of Physical Chemistry B, 108 (25): 8737-8741 (June 24, 2004).

20. "Reversible $300 \mathrm{~K}$ Ferromagnetic Ordering in a Diluted Magnetic Semiconductor," Schwartz, D. A.; Gamelin, D. R., Advanced Materials, 16, 2115-2118, (2004).

21. "Above-Room-Temperature Ferromagnetic $\mathrm{Ni}^{2}+: \mathrm{ZnO}$ Thin Films Prepared from Colloidal Diluted Magnetic Semiconductor Quantum Dots," Schwartz, D. A.; Kittilstved, K. R.; Gamelin, D. R., Appl. Phys. Lett., 85, 1395-1397, (2004).

22. "Strong Room-Temperature Ferromagnetism in $\mathrm{Co}^{2}+$ Doped $\mathrm{TiO}_{2}$ made from Colloidal Nanocrystals," J. D. Bryan, S. M. Heald, S. A. Chambers, D. R. Gamelin, Journal Of The American Chemical Society, 126, 11640-11647, (2004).

23. "Magnetization Processes in Exchange-Biased Mnpd/Fe Bilayers," Blomqvist P, Krishnan KM, Girt E, Journal Of Applied Physics 95 (12): 8487-8489, (June 15, 2004).

24. “Oxide Nanorods," G.Z. Cao And S.J. Limmer, In Encyclopedia Of Nanomaterials, Ed. H.S. Nalwa, The American Scientific Press, 8, 377-396, (2004).

25. "The Effects of Template and Precursor Chemistry on Structure and Properties of Mesoporous $\mathrm{TiO}_{2}$ Films," X. Shari Li, Glen E. Fryxell, Jerome C. Birnbaum, Chongmin Wang, Langmuir, 20, 9095-9102, (2004).

\subsubsection{Published in $\mathbf{2 0 0 5}$}

1. "Growth and Sintering of Pd Clusters on $\mathrm{Al}_{2} \mathrm{O}_{3}(0001)$," S.L. Tait, L.T. Ngo, Q. Yu, S.C. Fain, Jr., C.T. Campbell, Journal Of Chemical Physics, 122, 064712 (2005).

2. "Template-Based Growth of Oxide Nanorods by Centrifugation," T.L. Wen, J. Zhang, T.P. Chou, S.J. Limmer, And G.Z. Cao, Journal Of Sol-Gel Science And Technology, 33, 193200 (2005). 
3. "PEG-Grafted Chitosan As An Injectable Thermosensitive Hydrogel For Sustained Protein Release," N. Bhattarai, H. R. Ramay, J. Gunn, F. A. Matsen, And M. Zhang, Journal Of Controlled Release, 103, 609-624 (2005).

4. "Evidence of Impurities in Thiolated Single-Stranded DNA Oligomers and Their Effect on DNA Self-Assembly on Gold," Chi-Ying Lee,Heather E. Canavan, Lara J. Gamble, David G. Castner, Langmuir, 21, 5134-5141, (2005).

5. “Optically Transparent Superhydrophobic Silica-Based Films,” H.M. Shang, Y. Wang, S.J. Limmer, T.P. Chou, And G.Z. Cao, Thin Solid Films, 472, 37-43, (2005).

6. "Effects of Thermal Annealing on Li+ Intercalation Properties of $\mathrm{V}_{2} \mathrm{O}_{5} \cdot \mathrm{Nh}_{2} \mathrm{O}$ Xerogel Films," Y. Wang, H.M. Shang, T.P. Chou, And G.Z. Cao, Journal Of Physical Chemistry B, 109, 11361-11366, (2005).

7. "Synthesis and Electrochemical Properties of Vanadium Oxide Nanotube Arrays," Y. Wang, K. Takahashi, H.M. Shang, And G.Z. Cao, Journal Of Physical Chemistry B, 109, 30853088, (2005).

8. "Ag-Ag0.08 $\mathrm{V}_{2} \mathrm{O}_{5} \cdot \mathrm{Nh}_{2} \mathrm{O}$ Composite Films As Host Materials For Lithium-Ion Intercalation," Y. Wang, K.H. Lee, H.M. Shang, Y.N. Xia, And G.Z. Cao, Physica Status Solidi, 202A, R79-R81, (2005).

9. "Growth And Characterization Of [001] ZnO Nanorod Arrays With Electric Field Assisted Nucleation,” H.M. Shang, Y.J. Kim, And G.Z. Cao, Mater. Res. Soc. Symp. Proc., 879E, P.Z4.1-Z4.6, (2005).

10. "N-Alkanes On MgO(100): I. Coverage-Dependent Desorption Kinetics of N-Butane," S. L. Tait, Z. Dohnálek, C. T. Campbell, B. D. Kay, J., Chem. Phys., 122, 164707, (2005).

11. "N-Alkanes On MgO(100): II. Chain Length-Dependence of Kinetic Desorption Parameters For Small N-Alkanes," S. L. Tait, Z. Dohnálek, C. T. Campbell, B. D. Kay, J. Chem. Phys., 122, 164708, (2005).

12. Development of Large Band Gap Host Materials for High-Energy Phosphorescent Emitters, M. S. Liu, Y.-H. Niu, A. K.-Y. Jen, PMSE Preprints 92, 2005, 566-567. (From Old In Press List 2003 Report)

13. "Synthesis of Cadmium Tungstate Films Via Sol-Gel Processing," Lennstrom K, Limmer SJ, Cao GZ, Thin Solid Films, 434 (1-2): 55-61, (June, 23 2005).

14. "Co-Doped Anatase $\mathrm{TiO}_{2}$ Heteroepitaxy on $\mathrm{Si}(001)$," Kaspar TC, Droubay T, Wang CM, Heald SM, Lea AS, Chambers SA, Journal Of Applied Physics, 97 (7): Art. No. 073511, (April 1, 2005). 
15. "Intrinsic Ferromagnetism in Insulating Cobalt Doped Anatase $\mathrm{TiO}_{2}$," Griffin KA, Pakhomov AB, Wang CM, Heald SM, Krishnan KM, Physical Review Letters, 94 (15): Art. No. 157204, (April 22, 2005).

16. "Chemical Manipulation of High-T-C Ferromagnetism in ZnO Diluted Magnetic Semiconductors," Kittilstved KR, Norberg NS, Gamelin DR, Physical Review Letters, 94 (14): Art. No. 147209, (April 15, 2005).

17. "Doped Semiconductor Nanocrystals: Synthesis, Characterization, Physical Properties and Applications,” J. D. Bryan, D.R. Gamelin, Progress In Inorganic Chemistry, (Invited Review), 54, 47-126, (2005).

18. "Cobalt-Doped Anatase $\mathrm{TiO}_{2}$ - A Room Temperature Dilute Magnetic Dielectric Material," K.A. Griffin, A.B. Pakhomov, C.M. Wang, S.M. Heald, And Kannan M. Krishnan, 49th Conference On Magnetism And Magnetic Materials, Jacksonville, FL, J. Appl. Phys., 97, 10D320, (2005).

19. "Growth of Cr-Doped $\mathrm{TiO}_{2}$ Films in the Rutile and Anatase Structure by Oxygen-Plasma Assisted Molecular Beam Epitaxy,” J. Osterwalder, T. Droubay, T. Kaspar, J. Williams, C.M. Wang, S.A. Chambers, Thin Solid Films, 485, 289, (2005).

20. "Epitaxial Growth and Properties of Magnetically Doped $\mathrm{TiO}_{2}$, , S.A. Chambers, T.C. Droubay, T.C. Kaspar, Ch. 7 In Thin Films And Heterostructures For Oxide Electronics, S. Ogale, Ed. Kluwer Academic Publishers, (2005).

\subsubsection{In Press}

1. “An Optical and MRI Multifunctional Nanoprobe for Targeting Gliomas," O. Veiseh, C. Sun, J. Gunn, N. Kohler, P. Gabikian, D.Lee, R..Ellenbogen, R. Sze, A. Hallahan, Jim Olson, Miqin Zhang, Nano Letters, In Press.

2. "The Influence of Dopants on the Nucleation of Semiconductor Nanocrystals from Homogeneous Solution," J. D. Bryan, D.S.Schwartz, D.R. Gamelin, Journal Of Nanoscience And Nanotechnology (Invited), 2005, In Press.

3. "Influences of Processing Parameters on Template-Based Growth of Oxide Nanorod Arrays by Sol Electrophoretic Deposition," S.J. Limmer, T.P. Chou, And G.Z. Cao, Journal Of SolGel Science And Technology, In Press.

4. "Hydrothermal Growth and Photoluminescence of Textured $\mathrm{CdWO}_{4}$ Scintillation Films," H.M. Shang, Y. Wang, M. Bliss And G.Z. Cao, Applied Physics Letters, In Press. 
5. "Development of Nanostructured Oxide Scintillator Films for Neutron Detection," H.M. Shang, Y. Wang, B. Milbrath, M. Bliss, And G.Z. Cao, Nuclear Instruments And Methods In Physics Research A, In Press.

6. "Nanostructured Superhydrophobic Surfaces," H.M. Shang, Y. Wang, D. Li, K. Takahashi, Y.N. Xia, And G.Z. Cao, Journal Of Materials Science Letters 24, In Press.

7. "Methane Adsorption and Dissociation and Oxygen Adsorption and Reaction with CO on Pd Nanoparticles on $\mathrm{MgO}(100)$ and on Pd(111)," S. L. Tait, Z. Dohnálek, C. T. Campbell, B. D. Kay, Surface Sci., In Press.

8. "Material and Interface Engineering for Highly Efficient Polymer Light Emitting Diode," M. S. Liu, Y.-H. Niu, J. D. Luo, B. Q. Chen, T.-D. Kim, A. K.-Y. Jen, J. Macromolecular Chem., In Press.

9. "Nanomagnetism and Spinelectronics: Materials, Microstructure and Novel Properties," Kannan M. Krishnan, Alexandre B. Pakhomov, Yuping Bao, Peter Blomqvist, Yoonsoo Chun, Marcela Gonzales, Kelli Griffin, Xiaosong Ji And Brad Roberts, J., Materials Science, in press 2005 .

13. "Activation of High- $\mathrm{T}_{\mathrm{C}}$ Ferromagnetism in $\mathrm{Mn}^{2+}$ :ZnO Using Amines," K.R. Kittilstved, D.R. Gamelin, J. Am. Chem. Soc., in press 2005.

14. "Non-contact Atomic Force Microscopy Studies of Ultrathin Films of Amorphous Solid Water Deposited on Au (111)," J.M.K. Donev, Q. Yu, B.R. Long, R.K. Bollinger, S.C. Fain, Jr., J. Chem. Phys., 123, in press 2005.

15. "Development of Cellular Absorptive Tracers (CATs) for a Quantitative Characterization of Microbial Mass in Flow Systems," K.P. Saripalli, C.F. Brown, M.J. Lindberg, Res.

Microbiol., in press 2005.

\subsubsection{Submitted (as of January 2005)}

1. "Self-Consistent Implementation of Self-Interaction Corrected Density Functional Theory to Confined and Extended Systems," K. Tsemekhman, E. Bylaska, H. Jonsson, E. Brown, Physics Review Letters.

2. "An Optical and MRI Multifunctional Nanoprobe for Targeting Gliomass," O. Veiseh, C. Sun, J. Gunn, N. Kohler, P. Gabikian, D. Lee, R. Ellenbogen, R. Sze, A. Hallahan, J. Olson, M. Zhang, Journal Of American Chemical Society.

3. "Methotrexate Modified Superparamagnetic Nanoparticles and Their Intracellular Uptake Into Human Cancer Cells,” N. Kohler, C. Sun, J. Wang, M. Zhang, Langmuir.

4. "Methane Dissociation on Mgo-Supported Pd Nanoparticles and on Pd(111)," S.L. Tait, Z. Dohnalek, C.T. Campbell, B.D. Kay, Surface Science. 
5. "Investigation of $\mathrm{Cr}$ as an Alternative Adhesion Layer in $\mathrm{Pt} / \mathrm{Si}$ Electrodes for Ferroelectric Perovskites,” T.C. Kaspar, C.L. Aardahl, D.E. Mccready, A.S. Lea, B.R. Johnson, D.W. Matson, T.S. Dory, J.W. Rogers, Jr., Thin Solid Films.

6. "Activating Ferromagnetism in $\mathrm{Cr}^{3+}: \mathrm{TiO}_{2}$ and $\mathrm{Co}^{2+}: \mathrm{TiO}_{2}$ Nanorods," J. D. Bryan, S.Santangelo, S. Keveren, D. R. Gamelin, 2005, Submitted To Chemistry Of Materials.

7. "Chlorotoxin-Bounded Superparamagnetic Nanoparticles for Brain Tumor Diagnosis and Therapeutics," O. Veiseh, C. Sun, J. Gunn, N. Kohler, N. Bhattarai, D. Lee, R. Sze, A. Hallahan, R. Ellenbogen, J. Olson, M. Zhang.

8. "Porous Organic-Inorganic Hybrids for Removal of Amines Via Donor-Acceptor Interaction," C.M. Chung, T.P. Chou, G.Z. Cao, submitted to Materials Chemistry And Physics.

9. "Multilayer Thermally Crosslinked Hole-Transporting Polymers for Cascade Hole-Injection and Effective Electron-Blocking/Exciton-Confinement in Polymer Hosted Phosphorescent Light-Emitting Diodes”, Y-H. Niu, M.S. Liu, J-W. Ka, A K.-Y. Jen, Appl. Phys. Lett.

10. "Growth and Characterization of [001] ZnO Nanorod Arrays on ITO Substrates with Electric Potential Assisted Nucleation," Y.J. Kim, H.M. Shang, G.Z. Cao, submitted to Applied Physics Letters.

11. "Novel Chalcogenide Buffer Layer for Oxide Heteroepitaxy on Si(001)," D.A. Schmidt, T. Ohta, C. Lu, Q. Yu, F.S. Ohuchi, M.A. Olmstead, submitted to Science.

12. "Perovskite Termination Influence in Oxide Heteroepitaxy," D. A. Schmidt, T. Ohta, Q.M. Yu, M.A. Olmstead, submitted to Physical Review B.

\subsubsection{In Preparation (as of January 2005)}

1. "Hybrid Functionals in Plane-Wave DFT: Method and Applications," K. Tsemekhman, E. Bylaska, H. Jonsson.

2. "Negligible Magnetism In Structurally Excellent $\mathrm{Cr}_{\mathrm{x}} \mathrm{Ti}_{1-\mathrm{x}} \mathrm{O}_{2}$ Anatase Contrasts High-TC Ferromagnetism in Structurally Defective $\mathrm{Cr}_{\mathrm{x}} \mathrm{Ti}_{1-\mathrm{x}} \mathrm{O}_{2}$ " T. C. Kaspar, L. Ye, C. M. Wang, J. D. Bryan, J.E. Jaffe, T. Droubay, V. Shutthandandan, S. Thevuthasan, D.E. Mccready, D.R. Gamelin, A.J. Freeman, S.A. Chambers.

3. "Fabrication and Characterization of ITO-TiO ${ }_{2}$ Core-Shell Nanocable Arrays in DyeSensitized Solar Cells,” T.P. Chou, G. Fryxell, and G.Z. Cao.

4. "Enhanced Transport Properties in Dye-Sensitized Solar Cells with the Incorporation of $\mathrm{TiO}_{2}$ Nanorods," T.P. Chou, G. Fryxell, and G.Z. Cao. 
5. "Direct Fabrication of Porous $\mathrm{TiO}_{2}$ Films Through a Combination of Hydrothermal and Electrophoretic Deposition for Enhanced Light Energy Conversion," T.P. Chou, G. Fryxell, and G.Z. Cao.

6. "Hybrid Functionals in Plane-Wave DFT: Method and Applications," K.Tsemekhman, E. Bylaska, H. Jonsson.

7. "Buffer Layer Enhanced Oxide Heteroepitaxy on Si(001)", D. A. Schmidt, T. Ohta, C. Lu, Q. Yu, F. S. Ohuchi, And M. A. Olmstead

8. "Initial Stages of Anatase $\mathrm{TiO}_{2}$ Heteroepitaxy on Lanthanum Aluminate (001)", D. A. Schmidt, T. Ohta, Q. Yu, And M. A. Olmstead.

9. "Doping Effects on Photoluminescent Properties of Sol-Gel Derived Cadmium Tungstate Films," H.M. Shang, Y. Wang, B. Milbrath, M. Bliss, And G.Z. Cao, To Be Submitted To Applied Physics Letters.

10. "Dependence of Photoluminescent Properties of Sol-Gel Derived Cadmium Tungstate Films On Sintering Conditions," H.M. Shang, Y. Wang, B. Milbrath, M. Bliss, And G.Z. Cao, To Be Submitted To Journal Of Luminescence.

11. "N-Alkanes on $\mathrm{Pt}(111)$ and Graphite(0001):. Chain Length-Dependence of Kinetic Desorption Parameters," S. L. Tait, Z. Dohnálek, C. T. Campbell, B. D. Kay.

12. "Non-Contact Atomic Force Microscopy Studies of Pd Nanoparticles on $\mathrm{Al}_{2} \mathrm{O}_{3}(0001)$," S. L. Tait, L. T. Ngo, C. Polwarth, Q. Yu, S. C. Fain, Jr. And C. T. Campbell.

13. "Development of Cellular Absorptive Tracers (Cats) for a Quantitative Characterization of Microbial Mass in Flow System", Choi, J., Saripalli, K. P., And Meldrum, D.

14. "Negligible Magnetism in Structurally Excellent Cr-Doped $\mathrm{TiO}_{2,}$, T.C. Kaspar, A.J. Freeman, S.A. Chambers.

15. "Quantitative Measurement of Cluster Growth by Non-contact Atomic Force Microscopy on Ultrathin Films of Amorphous Solid Water Deposited on Au (111)," S.C. Fain, Jr., R.K. Bollinger, B.R. Long, J.M.K. Donev, Q. Yu.

The number of JIN publications has grown significantly as the JIN has developed. It is also interesting to observe that there were initially no publications that involved significant contributions from both institutions (there were authors, other than the JIN Awardee, from both PNNL and UW). Although the number of joint publications varies with time and the nature of the projects, there are now a significant true multi-institutional publications resulting from JIN support and other activities. The number and nature of the 2005 publications is preliminary and includes only papers published or accepted for publication as of June 2005. An additional 12 
papers have already been submitted and another 15 are ascribed as in preparation.

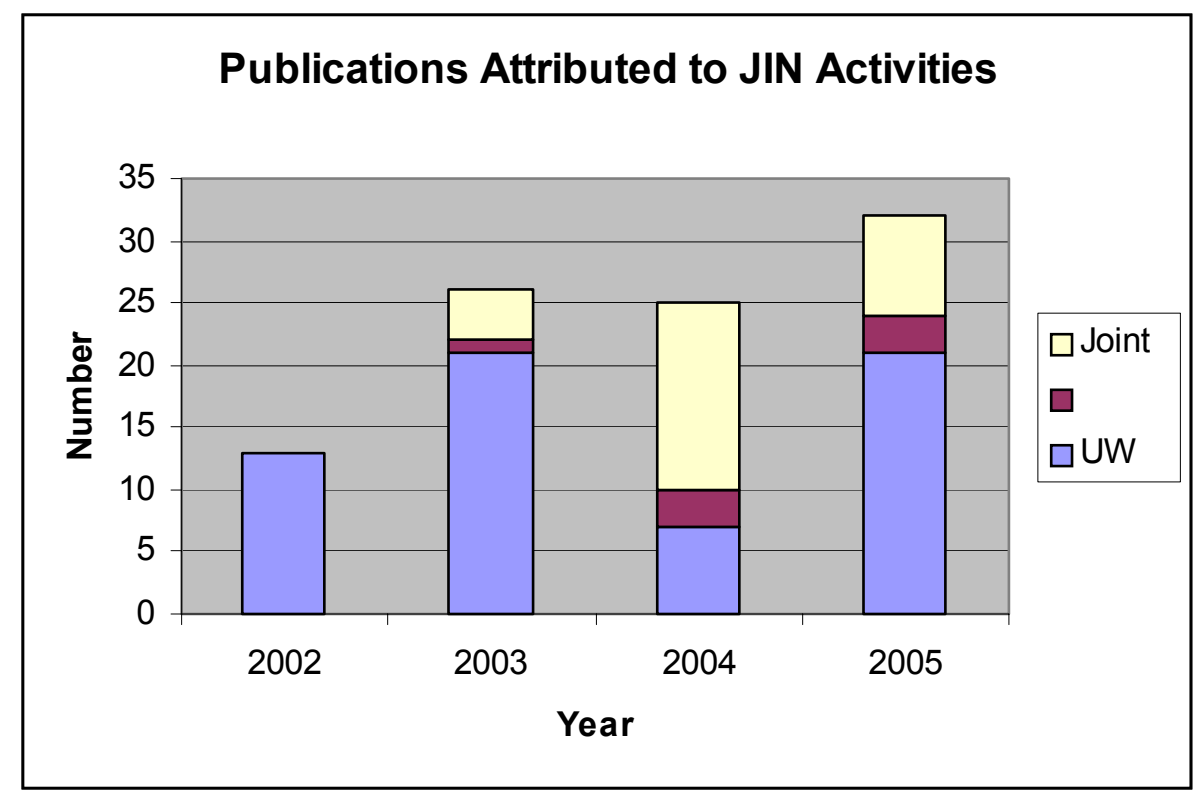

\subsection{JIN Related Presentations in FY04}

1. "Cobalt Doped Anatase $\mathrm{TiO}_{2}$ - a room temperature dilute magnetic dielectric material for spinelectronics," K. A. Griffin, A. B. Pakhomov, C. M. Wang, S. M. Heald, V. Shutthanandan, S. A. Chambers, Kannan M. Krishnan, Nanoscale Science and Technology Workshop, September 2004, Seattle, WA.

2. "Ferromagnetism in Co doped $\mathrm{TiO}_{2}$ films grown by RF magnetron sputtering," K. A. Griffin, A. B. Pakhomov, C. M. Wang, Kannan M. Krishnan, Annual American Physical Society Meeting, March 2004, Montreal, Quebec, Canada.

3. "Magnetism and transport in room-temperature diluted magnetic wide band-gap semiconductors" (invited talk), A.B. Pakhomov, B.K. Roberts, K.A. Griffin and Kannan M. Krishnan, MRS Fall Meeting, Boston, Nov. 29 - Dec. 3, 2004.

4. Development of Titania Nanostructures for the Exploration of Electron Transport in Dye-Sensitized Solar Cells," (Oral), T.P. Chou, G.Z. Cao, and G.E. Fryxell, 2004 SPIE Annual Meeting, Denver, CO, August 2, 2004.

5. "Development of Titania Nanostructures for the Exploration of Electron Transport in Dye-Sensitized Solar Cells," (Oral), T.P. Chou, G.Z. Cao, and G.E. Fryxell, 56 ${ }^{\text {th }}$ Pacific Coast Regional Meeting and Basic Science Division Meeting of the American Ceramic Society, Seattle, WA, September 15, 2004.

6. "Noncovalent Functionalization of Carbon Nanotubes with Molecular Anchors using Supercritical Fluids." Leonard S. Fifield, R. Shane Addleman, Glen E. Fryxell, Christopher L. Aardahl. 2005. American Chemical Society Meeting, San Diego, March 13-17, 2005. 
7. "Homogeneous Catalysts Tethered to Carbon Nanotubes." Leonard S. Fifield, John C. Linehan, R. Shane Addleman, Christopher L. Aardahl, J. David Newell, and Thomas E. Bitterwolf. Materials Research Society Spring 2005, San Francisco, CA

8. "Development of Active Nanomaterials based on Carbon Nanotubes" Leonard S. Fifield, Larry R. Dalton, Rosemary A. Golhotra, R. Shane Addleman, Glen E. Fryxell, and Christopher L. Aardahl. JINN Nano Workshop, University of Washington, Seattle, WA, September, 2003.

9. "Cobalt Doped Anatase $\mathrm{TiO}_{2}$ - a room temperature dilute magnetic dielectric material for spinelectronics," K. A. Griffin, A. B. Pakhomov, C. M. Wang, S. M. Heald, V. Shutthanandan, S. A. Chambers, Kannan M. Krishnan, Nanoscale Science and Technology Workshop, (to be presented September 2004), Seattle, WA.

10. "Ferromagnetism in Co doped $\mathrm{TiO}_{2}$ films grown by RF magnetron sputtering," K. A. Griffin, A. B. Pakhomov, C. M. Wang, Kannan M. Krishnan, Annual American Physical Society Meeting, March 2004, Montreal, Quebec, Canada.

11. "Magnetism and transport in room-temperature diluted magnetic wide band-gap semiconductors" (invited talk), A.B. Pakhomov, B.K. Roberts, K.A. Griffin and Kannan M. Krishnan, MRS Fall Meeting, Boston, Nov. 29 - Dec. 3, 2004.

12. J. Gunn, O. Veiseh, C. Sun, R. Ellenbogen, J. Olson, R. Sze, A. Hallahan and M. Zhang, Superparamagnetic Nanoparticle-bound Chlorotoxin for Brain Tumor Imaging, Oral presentation accepted at the 2005 NSTI Nanotechnology Conference and Trade Show, May 8-12, 2005, Anaheim, California, U.S.A.

13. D. Lee, C. Sun, S. Hansen, J. Gunn, A Hallahan, M. Zhang, R.. Sze, and J. M. Olson Magnetic Resonance Target Imaging of Medulloblastoma Cells and Quantitation of Apoptosis, Providence, RI , 2005 .

14. M. Zhang, Invited talk in CMS2004 The Clay Mineral Society 41st Annual Meeting, Richland, WA, "Iron oxide superparamagnetic nanoparticles for tumor diagnosis and therapeutics," June 2004.

15. M. Zhang, Invited talk in Cancer Nanotechnology Symposium: Overcoming Barriers to Collaboration, sponsored by NCI/NIH, Cleveland, Ohio, Oct 2004.

16. M. Zhang, Invited talk in Eleventh Annual Neuro-Oncology and Blood-Brain Barrier Consortium Meeting, Portland Oregon, March 2005.

17. M. Zhang, Invited talk in 79th ACS Colloid and Surface Sience Symposium, Potsdam, NY, "Superparamagnetic nanoparticle-bound chlorotoxin for brain tumor imaging," June 2005.

18.

19. M. Zhang, Invited talk 47th American Association of Physicist in Medicine, Nanotechnology and Cancer, Seattle, July, 2005

20. Jonathan Gunn, Omid Veisel, Conroy Sun, Rich Ellenbogen, Jim Olson, Raymond Sze, Andrew Hallohan, Miqin Zhang, Nanoparticle-bound Chlorotoxin for Brain Tumor Imaging, Nanoscale Science and Technology Workshop, September 16-17 Seattle, WA 
21. Jonathan Gunn, Omid Veiseh, Conroy Sun, Patrik Gabikian, Rich.Ellenbogen, KevinMinard, Jim Olson, Raymond Syz, and Andrew Hallahan, Miqin Zhang, Superparamagnetic Nanoparticle-bound Chlorotoxin for Brain Tumor Imaging, Blood Brain Barrier Consortium, March 17-20, Portland, OR

22. T.C. Kaspar, T. Droubay, S.M. Heald, C.M. Wang, V. Shutthanandan, S. Thevuthasan, S.A. Chambers. "MBE Growth and Room Temperature Ferromagnetism in Epitaxial Co-doped SrTiO3." AVS 51st International Symposium in Anaheim, California, November 2004.

23. K. Tsemekhman ES04: 16th Annual Workshop on Recent Developments in Electronic Structure Methods, Rutgers University, New Brunswick, NJ, May 27-30, 2004. Self-Consistent Self-Interaction Corrected DFT: The Method and Applications to Extended and Confined Systems (Invited Talk).

24. K. Tsemekhman 15th Annual Symposium of the Pacific Northwest Chapter of the AVS The Science and Technology Society, PNNL, Richland, June 15-18, 2004. Self-Consistent Self-Interaction Corrected DFT Studies of Oxides 5.

25. K. Tsemekhman SRC Meeting, Durham, NC, June 30-July 1, 2004. Activity of Dopants in Silicon and Diffusion of Metal Atoms in Oxides 6.

26. K. Tsemekhman Nanoscale Science and Technology Workshop 2004, University of Washington, Sept. 15-17, 2004. Small Polaron in Hematite Fe2O3 Predicted by Self-Interaction Corrected DFT.

27. K. Tsemekhman OEP Workshop, Frie University, Berlin, Germany, March 11-13, 2005. SelfConsistent SIC method and its extension to the exact exchange functionals for extended systems. (Invited talk).

28. Kittilstved, K.R.; Schwartz, D.A.; Joly, A.G.; Gamelin, D.R. Classical and Dynamic Spectroscopy of $\mathrm{Ni}^{2+}$ in Nanoscale II-VI Semiconductor. Nanoscale Science and Technology Workshop 2003, September 22-23 (Poster).

29. Norberg, N., Kittilstved, K., Amonette, J. E., Kukkadapul, R. K., Schwartz, D. A., and Gamelin, D. R. Colloidal $\mathrm{Mn}^{2+}: \mathrm{ZnO}$ Quantum Dots and High-T $T_{\mathrm{C}}$ Ferromagnetic Thin Film. Nanoscale Science and Technology Workshop 2004, September 16-17 (Poster).

30. "Methotrexate Modified Superparamagnetic Nanoparticles for Cancer Diagnostics and Therapeutics" N. Kohler, C. Sun, D. Gupta, J. Wang, G. Fryxell, and M. Zhang. Magnetic Microcarriers, Lyon, France, May 2004.

31. "Novel functional poly(ethylene glycol) self assembled monolayers for ligand grafting to metal oxide nanoparticles" N. Kohler, G. Fryxell, and M. Zhang. Magnetic Microcarriers, Lyon, France. May 2004.

32. N. Kohler, G. Fryxell and M. Zhang, "Superparamagnetic nanoparticles for imaging," Nanoscale Science and Technology Workshop, Seattle, WA, Sept. 2003.

33. "Buffer Layer Enhanced Heteroepitaxy of TiO2 on Si(001)", D. A. Schmidt, T. Ohta, Q. Yu, F. S. Ohuchi, and M. A. Olmstead. 2004 Nanotech Worskhop, UW, Seattle, WA; 2004 
PNW-AVS/Surface Analysis, Richland, WA; 2004 CDO Networking Day (talk), UW, Seattle, WA; 2004 International Conference on the Physics of Semiconductors, Flagstaff, AZ.

34. "Novel Chalcogenide Buffer Layer for Oxide Heteroepitaxy on Si(001)", D. A. Schmidt, T. Ohta, Q. Yu, F. S. Ohuchi, and M. A. Olmstead. 2005 UW Science and Technology Showcase, Seattle, WA.

35. Nanostructured Oxide Scintillator Films by Sol-Gel Processing," (Oral), H.M. Shang, M. Bliss, and G.Z. Cao, 2004 SPIE Annual Meeting, Denver, CO, August 2, 2004.

36. "Development of Nanostructured Oxide Scintillator Films," (Oral), H.M. Shang, M. Bliss, and G.Z. Cao, $56^{\text {th }}$ Pacific Coast Regional Meeting and Basic Science Division Meeting of the American Ceramic Society, Seattle, September 13, 2004.

37. "Growth of [001] Oriented ZnO Nanorod Arrays with Electric Field Assisted Nucleation," (Oral), H.M. Shang, Y.J. Kim, and G.Z. Cao, 2005 Materials Research Society Spring Meeting, San Francisco, CA, March 30, 2005.

38. S. L. Tait, Z. Dohnálek, C. T. Campbell, B. D. Kay Pd nanoclusters supported on $\mathrm{MgO}(100)$ : Effects of Cluster Size on Chemisorption Properties American Vacuum Society Anaheim CA November 2004.

39. S. L. Tait, Z. Dohnálek, C. T. Campbell, B. D. Kay Pd nanoclusters supported on $\mathrm{MgO}(100)$ : Effects of Cluster Size on Chemisorption Properties American Physical Society (2004).

40. S. L. Tait, Z. Dohnálek, C. T. Campbell, B. D. Kay Pd nanoclusters supported on MgO(100): Effects of Cluster Size on Chemisorption Properties, International Symposium on Non-contact Atomic Force Microscopy, Seattle WA September 2004.

41. C. T. Campbell Invited presentation on Catalysis American Vacuum Society Anaheim CA November 2004.

42. "Ferromagnetism in Co doped Anatase $\mathrm{TiO}_{2}$ - for spintronics applications," K. A. Griffin, A. B. Pakhomov, Kannan M. Krishnan, March 9th, 2005 (oral presentation), Department of Physics \& Astronomy, Solid State Physics Colloquium, University of Glasgow, Glasgow, Scotland, U.K.

43. "Cobalt-Doped Anatase $\mathrm{TiO}_{2}$ - a room temperature dilute magnetic dielectric material," $\mathrm{K}$. A. Griffin, A. B. Pakhomov, C. M. Wang, S. M. Heald, Kannan M. Krishnan, November 10, 2004 (oral presentation), 49th Conference on Magnetism and Magnetic Materials, Jacksonville, FA.

44. "Synthesis of Colloidal $\mathrm{Mn}^{2+}: \mathrm{ZnO}$ Quantum Dots and High- $\mathrm{T}_{\mathrm{C}}$ Ferromagnetic Nanocrystalline Thin Films." Norberg, Nick S.; Kittilstved, Kevin R.; Amonette, James E.; 
Kukkadapu, Ravi K.; Schwartz, Dana A.; and Gamelin, Daniel R. $41^{\text {st }}$ Annual Meeting of The Clay Minerals Society, CMS2004, Richland, Washington, June 2004.

45. "Colloidal $\mathrm{Mn}^{2+}: \mathrm{ZnO}$ Quantum Dots and High $\mathrm{T}_{\mathrm{C}}$ Ferromagnetic Thin Films." Norberg, Nick S.; Kittilstved, Kevin R.; Amonette, James E.; Kukkadapu, Ravi K.; Schwartz, Dana A.; and Gamelin, Daniel R., Fourth Annual Nanoscale Science and Technology Workshop, University of Washington, Seattle, Washington, September 2004 (poster). 


\section{Appendix A}

\section{List of JIN Awards by Award Dates}




\section{Appendix A: List of JIN Awards by Award Dates}

\begin{tabular}{|c|c|c|c|}
\hline January-2002 & Student or PD & UW Mentor & PNNL Mentor \\
\hline $\begin{array}{l}\text { Magneto-Optical Spectroscopy of Nanocrystalline } \\
\text { Ferromagnetic Oxide Semiconductors }\end{array}$ & John Bryan & Daniel Gamelin & Scott Chambers \\
\hline $\begin{array}{l}\text { Growth Characterization of Dye-Functionalized Titania } \\
\text { Nanostructures for Photoelectrochemical Applications }\end{array}$ & Tammy Chou & Guozhong Cao & Glen Fryxell \\
\hline $\begin{array}{l}\text { Fourier Transform Infrared Spectroscopy Studies (FTIR) and } \\
\text { Temperature Programmed Desorption (TPD) of Amorphous } \\
\text { Solid Water (ASW) }\end{array}$ & Jason Donev & Sam Fain & Bruce Kay \\
\hline $\begin{array}{l}\text { Development and Application of Interatomic Potentials for } \\
\text { Heterogeneous Nanostructures }\end{array}$ & Yoon, Joo Chul & Scott Dunham & Anter El-Azab \\
\hline $\begin{array}{l}\text { Advanced Actuator Materials Based on Carbon Nanotube } \\
\text { Composites }\end{array}$ & Leonard Fifield & Larry Dalton & Chris Aardahl \\
\hline $\begin{array}{l}\text { Fundamental Studies of Monolayer-Protected Nanoparticles } \\
\text { by Gas Chromatography - }\end{array}$ & Gwen Gross & Robert Synovec & Jay Grate \\
\hline $\begin{array}{l}\text { Dilute Magnetic Semiconducting Oxide Thin Films and } \\
\text { Nanostructures }\end{array}$ & $\begin{array}{l}\text { Alex Pakhomov/Brad } \\
\text { Roberts }\end{array}$ & Kannan Krishnan & Scott Chambers \\
\hline $\begin{array}{l}\text { Interfacing chip-based nanofluidic-systems to surface- } \\
\text { desorption mass spectrometry }\end{array}$ & Jason Kuo/Gina Fiorini & Daniel Chiu & Cindy Bruckner-Lea \\
\hline $\begin{array}{l}\text { Nanostructure Conjugated Polymers and Hybrid Photovoltaic } \\
\text { Cells }\end{array}$ & Michelle Liu & Alex Jen & Paul Burrows \\
\hline Redox Reactions of Colloidal Metal Oxides & Mira Kanzelberger & James Mayer & Don Camaioni \\
\hline $\begin{array}{l}\text { Epitaxial Growth and Properties of Nanoscale Oxides for } \\
\text { Spintronics }\end{array}$ & Diedrich Schmidt & Marjorie Olmstead & Scott Chambers \\
\hline $\begin{array}{l}\text { Surface Recognition and Incorporation of Additives into } \\
\text { Calcium Oxalate Host Crystals }\end{array}$ & Lara Touryan & Viola Vogel & Allison Campbell \\
\hline $\begin{array}{l}\text { Metalorganic Chemical Vapor Deposition of } \mathrm{Mn}_{\mathrm{x}} \mathrm{Zn}_{1-\mathrm{x}} \mathrm{O} \text { as a } \\
\text { Spintronic Material }\end{array}$ & Allan Tuan & J. W. Rogers & Scott Chambers \\
\hline $\begin{array}{l}\text { Sol-gel electrophoresis for the formation of nanosized } \\
\text { nanostructured materials }\end{array}$ & Steven Limmer & G. Cao & Tim Hubbler \\
\hline
\end{tabular}




\begin{tabular}{|c|c|c|c|}
\hline June-2002 & Student or PD & UW Mentor & PNNL Mentor \\
\hline Superparamagnetic Nanoparticles for Imaging and Therapeutics & Nathan Kohler & Miqin Zhang & Glen Fryxell \\
\hline $\begin{array}{l}\text { Direct Simulation Approach to Multi-Phase Biomaterial Transport } \\
\text { and Nano-Interactions in Microfluidic Systems }\end{array}$ & David Lim & Daniel Chiu & Dave Rector \\
\hline $\begin{array}{l}\text { Nature of Genetically Engineered Protein/Inorganic Interactions: } \\
\text { Novel Molecular Linkers for Nanotechnology }\end{array}$ & Dan Heidel & M. Sarakaya & Wendy Shaw \\
\hline $\begin{array}{l}\text { Transition Metal Doped ZnO Semiconductor Nanoparticles: } \\
\text { Synthesis and Characterization of Electronic Structure }\end{array}$ & Nick Norberg & Dan Gamelin & Jim Amonette \\
\hline $\begin{array}{l}\text { Deposition and Characterization of }(\mathrm{Ba}, \mathrm{Sr}) \mathrm{TiO}_{3} \text { for High- } \\
\text { Permittivity Applications }\end{array}$ & Tiffany Kaspar & J. W. Rogers & Scott Chambers \\
\hline Smart Magnetic Nanoparticle Imaging Probes & Yong Zhang & Miqin Zhang & Kevin Minard \\
\hline $\begin{array}{l}\text { Photochemistry of a Diluted Magnetic Semiconductor Quantum Dot: } \\
\text { A Possible Photocatalyst for Water-Splitting }\end{array}$ & Kevin Kittilstved & Dan Gamelin & Alan Joly \\
\hline $\begin{array}{l}\text { Epitaxial Growth of Co-doped } \mathrm{TiO}_{2} \text { Anatase for Electrical Spin } \\
\text { Injection into Silicon }\end{array}$ & Allan Tuan & J. W. Rogers & $\begin{array}{l}\text { Scott } \\
\text { Chambers }\end{array}$ \\
\hline $\begin{array}{l}\text { Pd nanoclusters supported on } \mathrm{MgO}(100) \text { : effects of cluster size on } \\
\text { chemisorption properties }\end{array}$ & Steve Tait & Charles Campbell & Bruce Kay \\
\hline
\end{tabular}

\begin{tabular}{|c|c|c|c|}
\hline February-2003 & Student or PD & UW Mentor & PNNL Mentor \\
\hline $\begin{array}{l}\text { Renewal-Magneto-Optical Spectroscopy of Nanocrystalline } \\
\text { Ferromagnetic Oxide Semiconductors }\end{array}$ & John Bryan/Dana Swartz & Dan Gamelin & Scott Chambers \\
\hline $\begin{array}{l}\text { Renewal-Synthesis and Characterization of Ordered Dye- } \\
\text { Functionalized Oxide Nanostructures for Photoelectrochemical } \\
\text { Applications }\end{array}$ & Tammy Chou & Guozhong Cao & Glen Fryxell \\
\hline $\begin{array}{l}\text { Renewal-Nondestructive Carbon Nanotube Modification for } \\
\text { Tailored Functionality }\end{array}$ & Leonard Fifield & Larry Dalton & Chris Aardahl \\
\hline $\begin{array}{l}\text { Renewal-Fundamental Studies of Monolayer-Protected } \\
\text { Nanoparticles by Gas Chromatography }\end{array}$ & Gwen Gross & Robert Synovec & Jay Grate \\
\hline Renewal-Redox Reactions of Colloidal Metal Oxides & Mira Kanzelberger & James Mayer & Don Camaioni \\
\hline $\begin{array}{l}\text { Renewal-Electronic Structure of Thin Film Anatase } \mathrm{TiO}_{2} \text { : A } \\
\text { Candidate Spintronics Material }\end{array}$ & Deitrich Schmidt & Marjorie Olmstead & Scott Chambers \\
\hline $\begin{array}{l}\text { Bioaerosol Detection via Nanoparticle Surface Enhanced Raman } \\
\text { Spectroscopy }\end{array}$ & Mary Laucks & E. James Davis & $\begin{array}{l}\text { Feng Zheng } \\
\text { Mark Kingsley }\end{array}$ \\
\hline $\begin{array}{l}\text { Fundamental Studies of Nano-structured Oxides for Energy } \\
\text { Applications }\end{array}$ & Dmitry Kukurznyak & $\begin{array}{l}\text { Fumio Ohuchi } \\
\text { Rajendra Bordia }\end{array}$ & Peter Martin \\
\hline
\end{tabular}




\begin{tabular}{|c|c|c|c|}
\hline June 2003 & Student or PD & UW Mentor & PNNL Mentor \\
\hline $\begin{array}{l}\text { Renewal-Superparamagnetic Nanoparticles for Imaging and } \\
\text { Therapeutics }\end{array}$ & Nathan Kohler & Miqin Zhang & Glen Fryxell \\
\hline $\begin{array}{l}\text { Renewal-Magnetic Nanocrystals: Synthesis and Study ZnO and } \\
\text { GaN Diluted Magnetic Semiconductors }\end{array}$ & Nick Norberg & Dan Gamelin & Jim Amonette \\
\hline $\begin{array}{l}\text { Renewal-Deposition and Characterization of }(\mathrm{Ba}, \mathrm{Sr}) \mathrm{TiO}_{3} \text { for High- } \\
\text { Permittivity Applications }\end{array}$ & Tiffany Kaspar & J. W. Rogers & Scott Chambers \\
\hline $\begin{array}{l}\text { Renewal- Photochemistry of Colloidal Dilute Magnetic } \\
\text { Semiconductor Quantum Dots }\end{array}$ & Kevin Kittilstved & Dan Gamelin & Alan Joly \\
\hline $\begin{array}{l}\text { Renewal-Pd nanoclusters supported on } \mathrm{MgO}(100) \text { : effects of } \\
\text { cluster size on chemisorption properties }\end{array}$ & Steve Tait & Charles Campbell & Bruce Kay \\
\hline $\begin{array}{l}\text { Renewal-Nanostructure Conjugated Polymers and Hybrid } \\
\text { Photovoltaic Cells }\end{array}$ & Michelle Liu & Alex Jen & Paul Burrows \\
\hline
\end{tabular}

\begin{tabular}{|c|c|c|c|}
\hline September 2003 & Student or PD & UW Mentor & PNNL Mentor \\
\hline $\begin{array}{l}\text { Investigation of Macrophage Activation in Response to Nanoscale } \\
\text { Biomaterial Surface Features }\end{array}$ & Allison Golden & Pat Stayton & Wendy Shaw \\
\hline $\begin{array}{l}\text { Growth and optimization of } \mathrm{TM}_{\mathrm{x}}, \mathrm{Ti}_{1-\mathrm{x}}, \mathrm{O}_{2}(\mathrm{TM}=\mathrm{Co}, \mathrm{Mn}, \mathrm{Cr}) \text { films } \\
\text { for silicon based spintronic devices }\end{array}$ & Kelli Griffin & Kannan Krishnan & Scott Chambers \\
\hline $\begin{array}{l}\text { Impurities in Thiolated Single-stranded DNA Oligomers and Their Effect on } \\
\text { DNA Self-assembly on Gold }\end{array}$ & Chi-Ying Lee & Dave Castner & A. Scott Lea \\
\hline $\begin{array}{l}\text { Development of Cellular Absorptive Tracers (CATs) for } \\
\text { Quantitative Characterization of the Complaxity of Nanoscale } \\
\text { Biological Systems }\end{array}$ & Deirdre Meldrum & Deirdre Meldrum & Pradad Saripalli \\
\hline $\begin{array}{l}\text { Nanostructured Cadmium Tungstate Scintillation Films } \\
\text { for Neutron Detection }\end{array}$ & Mary Shang & Guozhong Cao & Mary Bliss \\
\hline Predicting catalysis at oxide nano-particles & Kirik Tsemekhman & Hannes Jonsson & Eric Bylaska \\
\hline
\end{tabular}




\begin{tabular}{|l|l|l|l|}
\hline \multicolumn{1}{|c|}{ January 2004 } & \multicolumn{1}{|c|}{ Student or PD } & \multicolumn{1}{c|}{ UW Mentor } & \multicolumn{1}{c|}{ PNNL Mentor } \\
\hline $\begin{array}{l}\text { Renewal_Study of Various Titania Nanostructures for the } \\
\text { Exploration of Charge Transport in Dye-Sensitized Solar Cells }\end{array}$ & Tammy Chou & Guozhong Cao & Glen Fryxell \\
\hline $\begin{array}{l}\text { Renewal_Fundamental Studies of Monolayer-Protected } \\
\text { Nanoparticles by Gas Chromatograhy }\end{array}$ & Gwen Gross & Robert Synovec & Jay Grate \\
\hline $\begin{array}{l}\text { Renewal_Materials and Magnetic Studies of Sr(CoxTi1-x)O3 } \\
\text { Deposited on Si(001) for Spintronic Applications }\end{array}$ & Tiffany Kaspar & Kannan Krishnan & Scott Chambers \\
\hline $\begin{array}{l}\text { Renewal_Epitaxial Growth and Properties of Nanoscale Oxides for } \\
\text { Spintronics }\end{array}$ & Diedrich Schmidt & Marjorie Olmstead & Scott Chambers \\
\hline $\begin{array}{l}\text { Renewal_Superparamagnetic Nanoparticles for Biomedical } \\
\text { Applications }\end{array}$ & Nathan Kohler & Miqin Zhang & Glen Fryxell \\
\hline $\begin{array}{l}\text { Renewal_Pd Nanoclusters Supported on MgO(100): Effects of } \\
\text { Cluster Size on Chemisorption Properties }\end{array}$ & Steven Tait & Charles Campbell & Bruce Kay \\
\hline $\begin{array}{l}\text { Smart Superparamagnetic Nanoparticle Imaging Probes for Brain } \\
\text { Tumor Research }\end{array}$ & Jonathan Gunn & Miquin Zhang & Kevin Minard \\
\hline
\end{tabular}

\begin{tabular}{|l|l|l|l|}
\hline \multicolumn{1}{|c|}{ October 2004 } & \multicolumn{1}{c|}{ Student or PD } & \multicolumn{1}{c|}{ UW Mentor } & \multicolumn{1}{c|}{ PNNL Mentor } \\
\hline $\begin{array}{l}\text { Reversible Functionalization of Carbon Nanotubes via the Diels- } \\
\text { Alder Reaction }\end{array}$ & Scott Hammond & Larry Dalton & Feng Zheng \\
\hline $\begin{array}{l}\text { Renewal_-Growth and Optimization of TMxTil-xO2 (TM=Co, Mn, } \\
\text { Cr) Films for Silicon-based Spintronic Devices }\end{array}$ & Kelli Griffin & Kannan Krishnan & Scott Chambers \\
\hline $\begin{array}{l}\text { Renewal_- Development of Cellular Absorptive Tracers (CATs) for } \\
\text { Quantitative Characterization of the Complaxity of Nanoscale } \\
\text { Biological Systems }\end{array}$ & Deirdre Meldrum & Mary Lidstrom & Prasad Saripalli \\
\hline Renewal_-Predicting Catalysis at Oxide Nano-Particles & Kiril Tsemekhman & Hannes Jonsson & Eric Bylaska \\
\hline
\end{tabular}

\begin{tabular}{|l|l|l|l|}
\hline \multicolumn{1}{|c|}{ April 2005 } & \multicolumn{1}{c|}{ Student or PD } & \multicolumn{1}{c|}{ UW Mentor } & \multicolumn{1}{c|}{ PNNL Mentor } \\
\hline $\begin{array}{l}\text { Renewal-Materials and Magnetic Studies of Sr(CoxTi1-x)O3 } \\
\text { Deposited on Si(001) for Spintronic Applications }\end{array}$ & Tiffany Kaspar & Kannan Krishnan & Scott Chambers \\
\hline $\begin{array}{l}\text { Renewal-Smart Superparamagnetic Nanoparticle Imaging Probes } \\
\text { for Brain Tumor Research }\end{array}$ & Jonathan Gunn & Miquin Zhang & Kevin Minard \\
\hline Renewal-Development of Nanostructured Scintillator Materials & Mary Shang & Guozhong Cao & Mary Bliss \\
\hline & & & \\
\hline & & & \\
\hline
\end{tabular}




\section{Appendix B}

\section{JIN Related Award Winners}

Pacific Northwest Chapter AVS Best Graduate Student Poster Sept. 2003

Best Student Presentation Awards, Sept. 2003

Leo Falicov Award, November 2003

E.W. Mueller Award 2004

Best Student Presentation Awards, Sept. 2004 


\section{Appendix B: JIN Related Award Winners}

\section{Pacific Northwest Chapter AVS Best Graduate Student Poster}

First Prize in the Graduate Student Poster Presentation Competition at the Symposium of the Pacific Northwest AVS Chapter, Troutdale, Oregon, September 18, 2003 - presented to Steve Tait for "Pd Nanoparticles on MgO(100): Model Catalysts to Probe Particle Size Effects in Alkane Activation," S. L. Tait, Jr., Z. Dohnálek, B. D. Kay, and C. T. Campbell.

\section{Best Student Presentation Awards at $3^{\text {rd }}$ Nanotech Symposium}

Two student Outstanding Presentation Awards, one for an outstanding oral presentation and one for an outstanding poster presentation, were selected from the student participants at the 2003 JIN workshop.

The two award winners were:

Steven L. Tait for the presentation "Pd Nanoparticles on $\mathrm{MgO}(100)$ : Model Catalysts to Probe Particle Size Effects in Alkane Activation."

Robert K. Doot for the Poster "Biomolecular Motors in Hybrid NEMS and MEMS Devices."

These awards consisted of a \$500 cash-prize award and \$500 in travel support for attendance at a scientific meeting.

\section{The Leo M. Falicov Student Award}

Student Tiffany Kaspar was awarded the Leo M. Falicov award by the Magnetic Interfaces and Nanostructures Division of the American Vacuum Society for the presentation "Materials Characterization and Magnetic Studies of Epitaxial $\mathrm{Co}_{\mathrm{x}} \mathrm{Ti}_{1-\mathrm{x}} \mathrm{O}_{2-\mathrm{x}}$ Deposited on $\mathrm{Si}(001)$ by Molecular Beam Epitaxy.” TC Kaspar, T Droubay, AC Tuan, CM Wang, SA Chambers, JW Rogers, Jr., 2003. Tiffany made the presentation at the 50th International American Vacuum Society Symposium, Baltimore MD, Nov. 6, 2003.

\section{E. W. Mueller Award, University of Wisconsin}

Scott Chambers, of the Interfacial Chemistry and Engineering (IC\&E) group at PNNL, a Mentor to several JIN students and leader in the spintronics area, has been awarded the 2004

E.W. Mueller Award to recognize outstanding achievements made to the field of surface science. 


\section{Best Student Presentation Awards at JIN Workshop, September, 2004}

Three student Outstanding Presentation Awards were selected from the student participants at the September, 2004 JIN workshop.

The three award winners were:

First Prize -

D.A. Schmidt, T. Ohta, Q. Yu, F.S. Ohuchi, and M.A. Olmstead for the presentation "Buffer Layer Enhanced Oxide Heteroepitaxy on Si(100)."

Second Prize -

T. Keenan, F. Kosar, G. Boggy, and A. Folch for the presentation 'Nanohole Devices for Chemotaxis Studies."

Third Prize -

N. Norberg, K. Kittilstved, J.E. Amonette, R.K. Kukkadapul, D.A. Schwartz, and D.R. Gamelin for the presentation "Colloidal Mn2+:ZnO Quantum Dots and High-Tc Ferromagnetic Thin Film.” 


\title{
Appendix C
}

\section{Programs from four Nanotech Workshops: Aug. 2001, Feb. 2002, Sept. 2002, Sept. 2003, Sept. 2004}

\author{
Appendix C: Programs from five Nanotech Workshops: \\ Aug. 2001, Feb. 2002, Sept. 2002, Sept. 2003, Sept. 2004
}

JIN Workshop History (Attendance)

First Annual Seattle Nanoscale Science and Technology Workshop (138)

August 16 and 17, 2001, Seattle WA

Richland Nanoscale Science and Technology Workshop: Relating Nanoscience to Problems: Exploiting Opportunities in Nanoscience and Nanotechnology (90)

February 21, 2002, Richland WA

Business Forum Previous to Second Annual Seattle Nanoscale Science and Technology Workshop: Nanotech Meets Business Information Exchange (120)

September 18, 2002, Seattle WA

Second Annual Seattle Nanoscale Science and Technology Workshop (155)

September 19-20, 2002, Seattle WA

Third Annual Seattle Nanoscale Science and Technology Workshop (154)

September 22-23, 2003, Seattle WA

Nanoscale Science and Technology Workshop Sept. 2004

Center for Nanotechnology and UW/PNNL Joint Institute for Nanoscience

September 16-17, 2004, Seattle, WA

Workshop agendas follow. 


\section{First Annual Seattle Nanotechnology Workshop, Aug. 2001}

Sponsored by Center for Nanotechnology/UIF and NSF

UW/PNNL Joint Institute for Nanoscience and Nanotechnology

Co-sponsored by Pacific Northwest National Laboratory/DOE

Henry Art Gallery

August 16 and 17, 2001

University of Washington, Seattle, WA 98195

\section{Nanoscale Science and Technology Workshop 2001 Thursday August 16, 2001 Morning Session}

10:00-12:00 Steering Committee Meeting (Henry Art Gallery conference room)

Afternoon Session

1:00 -1:05 Viola Vogel, UW/BioE

Welcome

1:05-1:20 Bill Rogers, PNNL

Directions of the PNNL Nanoscience and Nanotechnology Initiative

1:20-1:50 Norm Dovichi, UW/Chem

The Chemistry of a Single Enzyme Molecule

1:50-2:20 Peter Lu, PNNL

Single-Molecule Protein Dynamics

2:20-2:35 Daniel Chiu, UW/Chem

Optical Trapping and Microfluidics Approach to Single-Molecule and Single-Cell Manipulations

2:35-2:50 Viola Vogel, UW/BioE

Switching the Functional State of Proteins by Mechanical Force

2:50-3:10 Deidre Meldrum, UW/EE

Integrated Biologically-Active Microsystems

3:10-3:40 Open Forum/Break

Session B: $\quad$ Functional Nanostuctures I (Rogers, Chair)

3:40-4:10 Larry Dalton, UW/Chem

Nanostructured Materials for Novel Photonic and Optoelectronic Applications

4:10-4:25 Alex Jen, UW/MSE

Nanoscale Tailoring of Organic Photonic and Optoelectronic Materials

4:25-4:40 Glen Flyxell, PNNL

Using Self-Assembly to Make Nanostructured Hybrid Materials for environmental Applications

4:40-4:55 Michael Schick, UW/Phys

Self-Assembly of Polymers and Biological Lipids

4:55-5:10 Karl Böhringer, UW/EE

Controlled Part-to-Substrate Micro-Assembly via Electrochemical Surface Modulation

5:10-5:25 Guozong Cao, UW/MSE

Growth of Nanostructured Materials by Sol-Gel Electrophoresis 


\title{
Friday August 17, 2001
}

\section{Morning Session: Functional Nanostructures II (Vogel and Baer, Chairs)}

\author{
8:30-9:20 George M. Whitesides, Harvard University \\ Unconventional Methods of Fabricating Nano- and Microstructures \\ 9:20-9:35 Don Baer, PNNL \\ Oxide Nanostructures: High Surface Area, Quantum Dots, and Spin Structures \\ 9:35-9:55 Charles Campbell, UW/Chem \\ Catalysis on Metal Nanoparticles: Interplay between Structure, Energetics, and \\ Catalytic Activity \\ 9:55-10:10 Paul Burrow, PNNL \\ OLED and Oxide Thin Film Research Oxide \\ 10:10-10:25 Byron Gates, UW/Chem \\ Self-Assembly Approach to 3-D Order Nanostructures \\ 10:25-11:00 Open Forum/Break \\ 11:00-11:15 Eric Ackerman, PNNL \\ Immobilization of Enzymes in Nanoporous Materials at High Efficiency While \\ Retaining Activity \\ 11:15-11:30 Younan Xia, UW/Chem \\ Well-Controlled Nanowires of Semiconductors and Metals through Soft Solution \\ Processing \\ 11:30-11:45 Li-Qiong Wang, PNNL \\ Molecular Assembly in Ordered Nanoporosities \\ 11:45-12:00 S. K. Sundaram, PNNL \\ Synthesis of Semiconductor Nanocrystals Inside a Micelle
}

\section{Poster Session and NUF open house at Fluke Hall (12:00-2:00 p.m.)}

2:00-2:30 Pat Stayton, UW /BioE
Afternoon Session:
Bio-nanomaterials
(Davis, Chair)

Biomaterials That Talk and Listen in Nano-Space

2:30-3:00 Pedro Verdugo, UW/BioE

Dynamics of Marine Biopolymer Assembly: Nano- and Microgels Formation and its Impact on Global Carbon Cyclying

3:30-3:45 Anter El-Azab, PNNL

Computational Modeling of Nano Structures: Challenges and Opportunities

3:45-4:00 Henry Hess, UW/BioE

Molecular Shuttles Based on Motor Proteins

4:00-4:15 Anna Gutowska, PNNL

Stimuli-Responsive Nanogels for Medical Applications

4:15-4:30 Albert Folch, UW/BioE

Designing the Microfluidic Environment of Cells

4:30-4:45 Jim Davis, UW/Office of Research

Adjoin 


\section{Poster Session \\ Friday August 17, 2001 \\ (12:00-2:00 p.m.)}

\section{Lara Touryan/Vogel/BioE}

Surface Recognition and Incorporation of Additives into Calcium Oxalate Host Crystals

John Clemmens/Vogel/BioE

Engineering Surfaces to Direct Microtubule Motion for Motor Protein Based Shuttles Calvin Hu/BioE/Stayton and Hoffman

Control of Cell Adhesion to RGD-Streptavidin using Temperature Sensitive Polymer

Cynthia Buenviaje/Overney/ChemE

Phase Transitions of Confined Polymer Films using Atomic Force Microscopy

Lingyan Li/Jiang/ChemE

Nanoscale Surface Engineering for Protein Adsorption

Nallakkan S. Arvindan/Stuve/ChemE

Nanoparticles for Clean and Efficient Electric Power

Leo Fifield/Dalton/Chem

Investigation of the Mechanism of Molecular Actuators Based on Carbon Nanotubes Jennifer Shumaker-Parry/Campbell/Chem

Micro-array Based Studies of Protein-DNA Interactions Using Surface Plasmon

Resonance Microscopy

Pavle Radovanovic/Gamelin/Chem

Electronic Absorption Studies of Transition Metal Centers in Diluted Magnetic

Semiconductor Quantum Dots

Brian T. Mayers/Xia/Chem

A Solution Phase Approach to Large Scale Synthesis of Uniform Nanowires of

Semiconductors

Byron Gates/Xia/Chem

Fabrication of Micro- and Nanostructures with Monodispersed Colloidal Spheres as the Active Components

Yadong Yin/Xia/Chem

Fabrication of Silicon Nanostructures with Well-Defined Dimensions and Shapes

Steve Limmer/Cao/MSE

Nanosize Effects on the Dielectric Properties of Oxide Materials

Michelle Liu/Jen/MSE

Rod-Coil-Rod Triblock Copolymers for Efficient Photovaltaic Cells

Petra Herguth/Jen/MSE

Electroluminescence of Structurally Defined Copolymer-Block Formation and Phase

Separation

Dan Heidel/Sarikaya/MSE

Nano-Assembly through Engineered Inorganic Recognition Peptides

Jason Donev/Fain/Physics

Morphological Changes in Vapor Deposited Ice on a Au(111)

Milan Diebel/Dunham/EE

Diffusion at the Nanoscale: Quantum Mechanics Meets Fick's Law

Sponsored by the University of Washington and the National Science Foundation IGERT Program

Co-sponsored by DOE's Pacific Northwest National Laboratory 


\title{
Richland Nanotechnology Workshop: Relating Nanoscience to Problems,
} Feb. 2002

\author{
Exploiting Opportunities in Nanoscience and Nanotechnology: Information \\ Exchange and Project Development Workshop, Feb. 21, 2002
}

This workshop will begin the process of revising the focus of the JIN and the PNNL Nanoscience and Nanotechnology Initiative for FY '03.

\author{
February 21, 2002 \\ Hanford House Red Lion \\ Richland, WA
}

The objective of this information sharing and project development workshop is to help identify collaborations and the formation of project teams that will enable novel science and provide a basis for technological advances in DOE mission areas.

Activities planned for the day include a poster session to provide a snapshot of current nanoscience and nanotechnology research at PNNL and the UW, oral presentations on science and technology opportunities in areas important to PNNL, and breakout sessions to help identify specific topics and teams that are interested specific research topics.

Although this meeting is built around current or potential activities of the PNNL Nanoscience and Nanotechnology Initiative (NNI) and the PNNL-University of Washington Joint Institute of Nanoscience (JIN), the participation of other potential collaborators is encouraged.

Poster session - Each program funded as part of the Nanoscience and Nanotechnology Initiative (NNI) will be represented, and other researchers (lab, industry or university) involved in other nano-related projects are encouraged to present a poster summary of their work and interests.

Project Development Workshops - The intent of the workshop is to identify the areas for scientific collaboration and project development. Talks of approximately half an hour will introduce issues in some obvious and less than obvious areas where nanoscience and technology may have a significant impact. One object is to facilitate the difficult job of bridging the gap between basic science and technology applications and to ensure that the NNI (and JIN) focus on seeding top-quality basic science to lay the foundations required to serve DOE missions in the future. Tentative topical areas include Nanoscale Biological Processes and Systems, Nanotechnology in Photonics, Physical and Chemical Sensors, Hydrogen Storage and Energy Systems, and Nanotechnology for Water Resources and Engineering. These are not yet final, and comments and suggestions for session leaders are welcome. We would like to identify at least one PNNL science, PNNL mission, and UW member on each workshop topic.

Exploiting Opportunities in Nanoscience and Nanotechnology

9:00 a.m. Setup of posters

9:45-10:15 am Welcome, Introduction and Schedule updates 
(Don Baer and Paul Burrows)

10:15 - 12:30 p.m. Information Fair - Poster Session

11:30 - 12:30 p.m. Lunch

12:30 - 2:30 p.m. Workshop - Plenary Session (overview talks about workshop areas)

2:40 - 4:40 p.m. Workshop Breakout Sessions

4:40 - 5:10 p.m. Plenary Summaries of Breakout Sessions

Topical Group Leaders for Breakout Sessions and Plenary Speakers

Nanoscale Biological Processes and Systems

Viola Vogel (UW), Steve Colson (FSD) Glen Fryxell

Nanotechnology in Photonics

Greg Exarhos, Paul Burrows, Alex Jen (UW)

Physical and Chemical Sensors

John Hartman, Mike Foley (NSD), Gordon Dudder, Rob Synovec (UW)

Hydrogen Storage and Energy Systems

Jud Virden (ESD), Bruce Kay, Charlie Campbell (UW)

Nanotechnology for Water Resources and Engineering

Joe Devary, Richard Skaggs, Christopher Wend, Loni Peurrung, Don Baer

Objectives of Sessions

The overall objective of the plenary talks and breakout sessions is to identify links between the science that will have been presented in the poster session (and other science that will or can be done around the lab, UW, and at other locations) to some of the laboratory's more applied missions.

Questions to focus and stimulate discussion

1) What are the important and interesting new science opportunities/questions that will provide the fundamental nanoscience basis that can solve some DOE mission-area problems? What is the important science needed to understand or solve a DOE-applied mission problem?

2) Can we form interested, talented teams to create unique opportunities? What teams with the laboratory, involving the University of Washington or other outside people, will help us have a major impact? Clearly related to this identification of needs is a suggestion for important follow on actions. 
3) Are there important technology or science drivers and related funding opportunities? What opportunities do we have to establish programs in the areas identified in 1)? Are there contacts or funding opportunities that we need or can follow up? 


\section{Business Forum Previous to Second Annual Seattle Nanoscale Science and Technology Workshop, Sept. 2002}

\section{Technology Forum: Nanotech Meets Business Information Exchange, September 18, 2002}

Boeing Auditorium

Seafirst Executive Education Center

University of Washington, Seattle, WA 98195

\section{Tentative Program}

1:00-1:30 Viola Vogel, BioE/UW

Nanotechnology - an Overview

1:30-2:30 Avogadro Partners, Seattle

The Emerging Age of Nanobusiness

Panel Discussion (20-minute presentation and 10-minute Q\&A)

\section{2:50-3:20 Amazing Materials}

Walt Mahoney (moderator), Larry Dalton, Chem/UW, Paul Burrows, PNNL, Younan Xia, Chem/UW

\section{3:35-4:05 NanoTechnology and Healthcare}

Viola Vogel, BioE/UW (moderator), Pat Stayton, BioE/UW, Norm Dovichi, Chem/UW, Paul Yager, BioE/UW

4:15-4:45 NanoTechnology for the Environment

Charlie Campbell, Chem/UW (moderator), Don Baer, PNNL, Eric Stuve, ChemE/UW, Jud Virdin, PNNL

7:00-9:00 Steering Committee Meeting for PNNL/UW Joint Institute in Nanotechnology

(Seafirst Executive Education Center Seminar Room) 


\title{
Second Annual Seattle Nanotechnology Workshop, Sept. 2002
}

\author{
Nanoscale Science and Technology Workshop \\ Physics Astronomy A102, University of Washington, Seattle
}

Thursday, September 19, 2002

8:30-8:35 Welcome (Viola Vogel)

Session A: Photonics and NanoMaterials (Burrow, Chair)

8:35-9:15 Liu, J., Sandia National Laboratories

Self-Assembly and Growth of Extended and Oriented Nanostructures

9:15-9:35 Jen, AK-Y, MSE/UW

Nanoscale Tailored Structures for Photonics and Molecular Electronics

9:35-9:55 Dohnálek, Z., Smith, R.S. and Kay, B. D., PNNL

Chemical Activity of Nanoporous Materials

10:10-10:30 Overney, R. M., ChemE/UW

Confinement Effects on Transport Properties in the Interfacial Region

10:30-10:50 Chambers, S. A., Droubay, D., Tuan, A. C., Wang, C.M., Heald, S.M.,

PNNL

Co-doped $\mathrm{TiO}_{2}$ Anatase - A New Material for Spintronics

10:50-11:10 Jiang, S. Y., ChemE/UW

Molecular Engineering of Surfaces for Sensing and Detection

11:10-11:30 Gamelin, D. Chem/UW

Colloidal Transition-Metal-Doped ZnO Quantum Dots

11:30-11:40 Mayers, B. T. and Xia, Y., Chem/UW

Shaped Controlled Synthesis at the Nanoscale

11:40-11:50 Radovanovic, P. and Gamelin, D., Chem/UW

Optical and Magneto-Optical Spectroscopy of Diluted Magnetic Semiconductor

Quantum Dots

11:50-12:00 Donev, J. M. K., Long, B. R., Bollinger, R., Yu, Q., and S. C. Fain, Jr.

Physics/UW

Effects of Molecular Transport at the Nanoscale on the Morphology of Vapor-Deposited Amorphous Solid Water (ASW) at $T<150 K$

12:00-12:10 Schmidt, M., Djalali, R., and Stephan, T. University of Mainz, Germany Nanostructured Cylindrical Brush Polymers: From Molecular Templates to Responsive Macromolecules

Session B: Nanocatalysis (Campbell, chair)

2:00-2:45 Libuda, J. Fritz-Haber-Institute, Berlin

Nanostructured Model Catalysts: Methods - Mechanisms - Kinetics

2:45-3:05 Campbell, C. Chem/UW 
Catalysis by Nanoparticles: State of the Art and Promises for the Future

3:05-3:25 Baer, D. PNNL

Application to the Reaction of Nanoparticulate Iron and Iron-Bimetallic Compounds with Chlorinated Hydrocarbons and Oxyanions

3:25-3:35 Tait, S. L. Jr., Ngo, L. T., Yu, Q., Fain, S. C. Jr., and Campbell C.T. UW

Nano-Scale Sintering Effects on Model Catalysts for Green Chemistry

Session C: NEMS/MEMS

3:50-4:30 Heller, M. University of California San Diego

Challenges and Opportunity for Nanofabrication Process Based on Microelectronic Array Devices

4:30-4:50 Cobden, D. H. Physics, UW

Single-Wall Carbon Nanotube Conducting Probe Tips

4:50-5:10 Hess, H. BioE/UW

Motor Protein Integrated into Nanodevices

5:10-5:20 Zhang, H. F., Wang, C. M., and Wang, L. S., PNNL

Screw Dislocation Driving Formation of Helical Nanowires

5:20-5:30 Tourovskaia, A. and Folch, A. BioE/UW

Micro-Engineered Self-Assembly of Muscle Myotubes

5:45-10:00 Dinner Cruise price included in the registration

Friday, September 20

Session D: Single Cell Analysis

8:30-9:10 Dovichi, N. Chem/UW

The Single Cell Proteome Project

9:10-9:30 Chiu, D. Chem/UW

Initiating the Conformational Transitions of Single DNAs with Optical Trapping

9:30-9:50 Folch, A. Chem/UW

Nanoengineered Cell Culture Devices

\section{Session E: Biological Nanosystems}

10:05-10:45 Guo, P. Purdue University

Construction of Controllable 30nm Viral DNA-Packaging Motor Driven by a RNA Hexamer

10:45-11:05 Vogel, V. BioE/UW

Switching Function by Stretching Molecules

11:05-11:25 Stayton, P. BioE/UW

Smart Materials that Talk and Listen in Nanospace

11:25-11:45 Saripalli, P. and Trease, H. PNNL

Development of Cellular Absorptive Tracers for the Characterization of Nanoscale

Biological Systems

11:45-12:25 Groves, J., University of California, Berkeley 
Molecular Pattern Formation and Cell Signaling at Inter-membrane Junctions

\section{Posters}

Ratna, B. R., Blum, A. S., Soto, C. M., Chatterji, A., Lin, T., and Johnson, J. E., Naval Research Laboratory

Cow Pea Mosaic Virus as a Scaffold for Nanoelectronics

Hampton, C. Y. and Emory, S. R., Chemistry, Western Washington University

Ultra-Sensitive Quantum Dot Based Bioassays

Wenda, T. and Emory, S. R., Chemistry, Western Washington University

Single-Molecule Enzymology Using Surface-Enhanced Raman Spectroscopy

Pugsley, H. R., McMahon, J. M., Wilkinson, F. S., and Emory, S. R., Chemistry, Western

Washington University

Metal Nanoparticle Assemblies for Surface-Enhanced Raman Spectroscopy

McLellan, J.M. and Patrick, D.L., Chemistry, Western Washington University Controlled Growth of Organic Semiconductors Using Liquid Crystal Solvents

Stenkamp, V. S., Bond, L. J., TeGrotenhuis, W. E., Grate, J. W. and Flake, M. D. PNNL Standing Ultrasonic Wave Separator

Ngo, L. T., Grant, A. W., Xu, L, and Campbell, C. T., Chemistry, UW Adsorption and Dehydrogenation of Cyclohexane and Benzene on $\mathrm{ZnO}(0001)-\mathrm{O}$ Supported Pt Nanoparticles

Clemmens, J., Hess, H., Howard, J. and Vogel, V. Bioengineering, UW Engineering Surfaces for Directed Motion of Motor Proteins: Building a Molecular Shuttle System

Lu, Y. and Xia, Y., Chemistry, UW Photonic Crystals Fabricated from Gold-Silica Core-Shell Nanoparticles

Zheng, J. and Jiang, S., Chemical Engineering, UW Molecular Dynamics Simulation of a Protein Adsorption at a Solid Interface

Zheng, J. and Jiang, S., Chemical Engineering, UW Transport Diffusion and Separation of Liquid Mixtures in Carbon Nanotubes: A Molecular Dynamics Simulation Study

Rustad, J. PNNL Molecular Simulation of Water and Hydroxide Exchange on $\mathrm{Al}_{13} \mathrm{O}_{4}(\mathrm{OH})_{24}\left(\mathrm{H}_{2} \mathrm{O}\right)_{127+}$

Gross, G. M., Synovec, R. E., and Grate, J. W., Chemistry, UW and PNNL Fundamental Studies of Monolayer-Protected Nanoparticles by Gas Chromatography

Gutowski, M., Dupuis, M., Bylaska, E., and Rustad, J., PNNL Self-Consistent Charge Density-Functional Based Tight-Binding Method for Predictive Simulations of Nanoscale Materials

Herguth, P., Jiang, X., Liu, M. S., and Jen, K-Y, MSE/UW Energy Transfer in of Random and Structurally Defined Poly(fluorene-

Zhang, 
Surface Modification of Superparamagnetic Magnetite Nanoparticles and Their Intracellular Uptake

Veiseh, M., and Zhang, M. MSE/UW

Guided Natural Cell Growth on Sensor Surfaces Through a Chemically Selective Protein Patterning Technique

Ohta, T., Klust, A., Adams, J. A., Yu, Q., Olmstead, M. A., and Ohuchi, F. S. MSE/UW

First Atomic-Resolution Ultrahigh Vacuum Scanning Tunneling Microscopy Study of GaSe/Si(111) Ultrathin Films,

Anter A. El-Azab, PNNL

Coarse-Grained Atomistic Simulation of Nanoscale Oxides

Gamelin, D. Chemistry, UW

Magnetic Properties of Quantum Dots

Liu, X. and Pollack, G. H., Bioengineering, UW

Stepwise Sliding of Single Actin and Myosin Filaments

Fifield, L. and Dalton, L., Chemistry, UW

Investigation of the Capacitance Minimum of Unannealed Single-Walled Carbon Nanotube Papers in Aqueous Sodium Chloride

Gaither, K. and Goheen, S., PNNL

Designing the Interface between Nanodevices and Biological Systems

Adams, J., Bostwick, A., Ohta, T., Ohuchi, F., Rotenberg, E., Klust, A., and Olmstead, M., Physics, UW, and PNNL Electronic and Structural Properties of AlSe Ultrathin Films on Si(111)

Bostwick, A., Adams, J., Klust, A., Rotenberg, E., and Olmstead, M., Physics, UW and PNNL Low Dimension Metallic States in Heavily Irradiated CaF2 Thin Films on Silicon

Klust, A., Bostwick, A., Ohta, T., Yu, Q., Fumio, O., and Olmstead, M., Physics, UW and PNNL Tip-Sample Interactions during Scanning Probe Microscopy on CaF2/Si(111)

Schimdt, D., Adams, J., Bostwick, A., Chambers, S., and Olmstead, M., Physics, UW and PNNL Electronic Structure of Thin Film Anstase TiO2: A Candidate Spintronics Material

Lay, E., Ohta, T., Klust, A., Yu, Q., Adams, J., Bostwick, A., Ohuchi, F., and Olmstead, M., Physics and MSE/UW Impurity-Stabilized Silicon Island Formation on Si(111) $7 x 7$

Gatuna, I., Nakamura, F., and Ohuchi, F., MSE/UW Study of Kinetics and Energies of DNA Hybridization/Dehybridization Using Surface Plasmon Resonance Spectroscopy (SPR) and Atomic Force Microscopy (AFM)

Yan, M.; Bartlett, M.; Harnish, B, Chem/Portland State University Ultrathin Polymer Films and Arrays by Photochemical Immobilization

Keenan, T., Li, N., Kosar, F., Neils, C., Spilker, M., and Folch, A., BioE/UW Combinatorial Nanofluidic Delivery of Axon Guidance Factors to Embryonic Neurons 


\title{
Third Annual Seattle Nanotechnology Workshop, Sept. 2003
}

\section{Monday Morning, September 22, 2003}

\author{
Kane Hall 110
}

8:30 - 8:45 Welcome (Charles T. Campbell and Don Baer)

\section{Session A: Photonics and Nanomaterials (Scott Chambers, Chair)}

8:45 - 9:30 Jonker, B., Naval Research Laboratory

Semiconductor Spintronics: Promise, Issues, and Prospects

9:30 - 9:50 Gamelin, D., Chem/UW

Magnetic Quantum Dots: Synthesis, Spectroscopy, and Magnetism Nanocrystalline Diluted

Magnetic Semiconductors

9:50 - 10:00 Zhang, H., Wang, C. and Wang, L. S., WSU/PNNL

Synthesis and Characterization of Helical Nanowires

10:00 - 10:10 Fifield, L. and Dalton, L., Chem/UW

Development of Active Nanomaterials Based on Carbon Nanotubes

10:25 - 10:45 Moeck, P., Portland State University

Structural Transitions in Epitaxial and Endotaxial Self-Assembled Semiconductor Quantum

Dots: A Brief Overview

10:45 - 11:05 Xia, Y., Chem/UW

Design and Synthesis of Nanostructured Materials

11:05 - 11:25 Lin, Y., PNNL

Supercritical Fluid Synthesis and Characterization of Catalytic Metal Nanoparticles on Multi-Walled Carbon Nanotubes

11:25 - 11:45 Cobden, D., Physics/UW

Surface Potential Imaging of Single-Walled Carbon Nanotube Devices

11:45 - 11:55 Kopelman, R. and Frank, N., Chem/UW

New Advances in Molecular Bistability: Incorporation of Organic Photochromes into

Magnetic Materials

11:55 - 12:15 Koenenkamp, R., Portland State University

Solar Cells and Transistors Grown in and on Nanometer-Sized Templates

\section{Monday Afternoon, September 22}

Kane Hall 110

\section{Session B: Single Cell Detection (Viola Vogel, Chair)}

\section{1:30 - 2:15 Moerner, W. E., Stanford University}

A Single Molecule as a Nanoscale Probe

2:15 - 2:35 Chiu, D., Chem/UW

Nanoscale Bioanalysis

2:35 - 2:55 Sanchez, E., Portland State University

Pushing the Limits of Near-Field Microscopy

2:55 - 3:15 Rosa, A. L., McCollum, J. and Chandra, R., Portland State University

Fabrication of Near-Field Multiprobe for Rapid Screening of Single Molecules 
3:15 - 3:35 Hu, D. and Lu, P., PNNL

Correlated Topographic and Spectroscopic Imaging Beyond Diffraction Limit by Metallic

Tip-Enhanced Near-Field Fluorescence Lifetime Microscopy

3:35 - 3:55 Lidstrom, M. and Meldrum, D., EE/UW

Life-on-a-Chip: Single Cell Detection for Biological Applications

\section{Session C: NEMS/MEMS (Viola Vogel, Chair)}

4:10 - 4:55 Lee, L., UC Berkeley

Nanogap Biomolecular Junction \& BioPOEMS

4:55 - 5:05 Wang, Y. and Bohringer, K., EE/UW

Protein and Cell Patterning with Programmable Surface Chemistry Chips

5:05 - 5:15 Kosar, T. F. and Folch, A., BioE/UW

Arrays of Microfluidically-Addressable Nanoholes

5:15 - 5:25 Shastry, A. and Lal, R., I. I. T.- Bombay, India

A Low Voltage Electrical Microsystem to Move, Detect and Fractionate DNA

\section{Tuesday Morning, September 23}

\section{Kane Hall 110}

\section{Session D: Nanocatalysis (Don Baer, Chair)}

8:30 - 9:15 Pacchioni, G., Dipartimento di Scienza dei Materiali, Milan

Metal Atoms and Clusters on MgO Thin Films: Theory and Experiment

9:15 - 9:35 Apra, E. and Bylaska, E., PNNL

Use of the NWChem Computational Chemistry Software in Nanotechnology Research

9:35 - 9:55 Campbell, C. T., Chem/UW

Catalysis by Nanoparticles: State of the Art and Promises for the Future

9:55 - 10:15 Baer, D., PNNL

Characterization and Properties of Iron and Iron-Oxide Nanoparticles

10:15 - 11:00 McFarland, E., UC Santa Barbara

Big Reactions on Small Clusters

11:00 - 11:20 Chambers, S., PNNL

$\mathrm{MBE}$ Growth and Properties of Fe- $\mathrm{Cr}$ - and $\mathrm{Mn}$-Doped $\mathrm{TiO}_{2}$

11:20 - 11:30 Kaspar, T. C. and Rogers, B., UW/PNNL

Materials Characterization of Epitaxial $\mathrm{TiO}_{2}$ and $\mathrm{Cox}_{x} \mathrm{Ti}_{1-x} \mathrm{O}_{2-x}$ Deposited on $\mathrm{Si}(001)$ by Molecular Beam Epitaxy

11:30 - 11:40 Tait, S., Dohnalek, Z., Kay, B., and Campbell, C. T., UW/PNNL

Pd Nanoparticles on MgO(100): Model Catalysts to Probe Particle Size Effects in Alkane Activation

11:40 - 12:00 Saraf, L. V., PNNL

Correlation of Oxygen Diffusivity with Grain-Size and Its Impact on Ionic Transport

Properties in Nanocrystalline $\mathrm{CeO}_{2}$

12:00 - 12:20 Thevuthasan, S., PNNL

Influence of Multiple Interfaces on Oxygen Ionic Conductivity in Gadolinia-doped Ceria and Zirconia Nanofilms 


\section{Tuesday Afternoon, September 23}

Kane Hall 110

Session E: Nanotechnology and Biology (Charles T. Campbell, Chair)

2:10 - 2:55 Vogel, V., BioE/UW

Engineering Principles of Biological Nanosystem

2:55 - 3:15 Sarikaya, M., MSE/UW

Molecular Biomimetics: Nanotechnology through Molecular Biology

3:15 - 3:35 Ackerman, E., PNNL

Immobilized Enzymes in Functionalized, Nanoporous Silica

3:35 - 3:55 Hess, H., BioE/UW

Nanodevices Based on Biomolecular Motors: Design and Applications

3:55 - 4:05 Liang, Y. and Palczewski, K., Ophthalmology/UW

Organization of the G Protein-Coupled Receptor Rhodopsin and Opsin in Native Membranes by Atomic Force Microscopy

4:05 - 4:15 Veatch, S. and Kelly, S., Chem and Physics/UW

Immiscibility in Model Lipid Membranes

4:15 - 4:25 Hull, J. and Castner, D., ChemE/UW

Investigation of the Binding Mechanism of the Bacterial Adhesin Scp to Fibronectin

4:25 - 4:45 Stedman, K., Portland State University

Extremophiles and their Viruses in Nanotechnology

4:45 - 4:55 Kohler, N. and Zhang, M., MSE/UW

Superparamagnetic Nanoparticles for Imaging

4:55 - 5:15 Kim, J., PNNL

Single Enzyme Nanoparticles Armored by a Nanoscale Organic/Inorganic Network

\section{Poster Session (12:20 - 2:10 PM, September 23)}

Kane Hall, Walker-Ames Room

Zheng, J. and Jiang, S., ChemE/UW

Non-Fouling Mechanism: A Molecular Simulation Study

Ngo, L. T., Tait, S. L., Yu, Q., Fain, S. and Campbell, C. T., Chem/Physics/UW

Sintering and Reactivity of Pd Nanoparticles on á-Al2O3(0001)-Supported Catalysts for Methane Combustion

Diaz, S., Smedh, M., Shamir, N. and Campbell, C. T., Chem/UW Adsorption Microcalorimetry on Thick Single Crystalline Samples

Schmidt, D. A., Ohta, T., Yu, Q., Chambers, S. A. and Olmstead, M. A., Physics/UW/PNNL Preparation of Lanthanum Aluminate (LaAlO3) Substrates for MBE Growth of TiO2

Ohta, T., Klust, A., Adams, J. A., Yu, Q., Olmstead, M. A. and Ohuchi, F. S., MSE/Physics/UW Heteroepitaxy of III-Se Materials for Their Applications to Nanoelectronics:

Compatibility to Si and Their Growth Studied by in-situ Scanning Probe Microscopy

Mao, D. and Dovichi, N., Chem/UW

Single Copy Detection of Gene Expression in Individual S. Cerevisiae Cells 
Wickes, B. and Castner, D., ChemE/UW

Investigation of Pattern Fidelity and Self-Assembly of DNA-Thiol Patterns by ToF-SIMS Image Analysis

Li, N., Keenan, T. M. and Folch, A., BioE/UW

Neuronal Growth in Micro/Nanofluidic Devices

Chen, C. and Folch, A., BioE/UW

Grayscale Photolithography Using Microfluidic Photomasks

Hsu, C. H., Chen, C. and Folch, A. BioE/UW

"Microcanals" For Micropipette Access to Single Cells in Microfluidic Environments

Stucky, N., Kosar, T. F., Chen, C. and Folch, A., BioE/UW

3D PDMS-Based Arrays of Nanoholes for Cellular Analysis

Boggy, G., Keenan, T. M., Hsu, C. H. and Folch, A., BioE/UW Microvalve Devices for Chemotaxis Studies

Tourovskaia, A. and Folch, A., BioE/UW Synaptogenesis on a Microfludic Chip

Chen, Y. C., Yan, M., Wang, Z. and Prahl, S. A., Oregon Health \& Science University/PSU Fluorescence Anisotropy Study of Molecularly Imprinted Polymers

Roberts, B., Pakhomov, A. B. and Krishnan, K. M., MSE/UW ZnO-Based Diluted Magnetic Semiconductors through Ion Beam and Magnetron Sputtering

Bao, Y., Beerman, M. and Krishnan, K. M., MSE/UW

Controlled Self-Assembly of Colloidal Cobalt Nanocrystals

Chou, T. P and Cao, G., MSE/UW

Ordered, Dye-Functionalized Titania Nanostructures for Photoelectrochemical Applications

Limmer, S. and Cao, G., MSE/UW

Sol Electrophoretic Growth of Oxide Nanostructures

Lin, Y., Liu, J. and Wang, J., PNNL/NMSU

Electrochemical Sensors and Biosensors Based on Conductive Nanomaterials

Liu, S., Jeffryes, C., Rorrer, G. L., Chang, C. and Wang, C., OSU/PNNL

Characterizations of Biogenic Silicon-Germanium Oxide Nanocomposites

Li, D. and Xia, Y., Chem/UW

Fabrication of Ceramic Oxide Nanofibers by Electrospinning

Wang, Y., Jiang, X. and Xia, Y., Chem/UW

Polyol-Mediate Approach to TiO2 and SnO2 Nanofibers under Mild Conditions

Sun, Y. G. and Xia, Y. Chem/UW

Synthesis and Characterization of Metal Nanostructures with Hollow Interiors

Ren, J. and Yan, M., Portland State University

Polymer Thin Films Covalently Immobilized by Thermal and Photochemical Initiation

Harnish, B. and Yan, M., Portland State University

Polymer Ultrathin Films and Multilayers Generated by UV Irradiation

Moeck, P., Portland State University

Endotaxial Growth and Structural Transitions of Quantum Dots in Si Matrix 
Moeck, P. and Pierz, K., Portland State University

Crystallographic Structure and Photoluminescence of Atomically Ordered (Cd,Mn,Zn)Se Quantum Dots in Matrix

Bryan, J. D. and Gamelin, D., Chem/UW

Colloidal Transition Metal Doped TiO2: Precursors to Spintronic Materials

Schwartz, D., Norberg, N., Nguyen, Q., Parker, J. and Gamelin, D., Chem/ UW Synthesis and Spectroscopy of Colloidal ZnO Diluted Magnetic Semiconductor Quantum Dots

Kittilstved, K., Schwartz, D., Joly, A. and Gamelin, D., Chem/UW/PNNL Classical and Dynamic Spectroscopy of Ni2 + in Nanoscale II-VI Semiconductors

Norberg, N., Radovanovic, P. V., Schwartz, D. S., Amonette, J. E. and Gamelin, D., Chem/UW Magneto-optical and Magnetic Studies of Diluted Magnetic Semiconductor Nanocrystals

Radu, I., Hanein, Y. and Cobden, D., Physics/UW

New Techniques for Controlling the Growth of Single-Walled Carbon Nanotubes

Patel, D. G., Benedict, J. B. and Frank, N., Chem/UW

Crystalline State Photoisomerization in a Novel Class of Photochromes

Gable, S. L. and Frank, N., Chem/UW

Role of Magnetic Nanoparticles in Signal Transduction Pathways: Magnetotactic Bacteria

Wang, C. M., Zhang, Y., Shutthanandan, V., Thevuthasan, S., Baer, D. R. and Thomas, L. E., PNNL

Precipitation of Au Nanoclusters in $\mathrm{TiO}_{2}$

Gutowski,1,2 M., Jaffe, J., 1 Yakovkin, I. N. 1,3 and Dupuis, M.1, PNNL

Theoretical Studies of Nanoscale Heterojunctions $\mathrm{Fe}_{2} \mathrm{O}_{3} / \mathrm{Cr}_{2} \mathrm{O}_{3}$ and $\mathrm{Si} / \mathrm{SrTiO}_{3}$

Bachorz, R., Haranczyk, M., Dabkowska, I., Miller, J., Dupuis, M. and Gutowski, M., PNNL Modeling of Damaged DNA at the Density of Functional Level of Theory

Gross, G. M., Synovec, R. E. and Grate, J. W., Chem/UW/PNNL

Fundamental Studies of Monolayer-Protected Nanoparticles by Gas Chromatography

Breneman, W., Advanced Silicon Materials, LLC

Synthesis and Properties of Nanosized Polysilicon

Doot, B., Clemmens, J., Hess, H., Matzke, C.1, Bachand, G.2, Bunker, B.2 and Vogel, V., $\mathrm{BioE} / \mathrm{UW}$

Biomolecular Motors in Hybrid NEMS and MEMS Devices 


\section{Nanoscale Science and Technology Workshop Sept. 2004 Center for Nanotechnology and UW/PNNL Joint Institute for Nanoscience}

\begin{tabular}{|c|c|}
\hline $8: 30-8: 45$ & $\begin{array}{l}\text { Thursday Morning, September } 16 \\
\text { Kane Hall } 210 \\
\text { Welcome (David Castner and Don Baer) }\end{array}$ \\
\hline Session A: & "Nanostructured Materials (Francois Baneyx, Chair) \\
\hline $8: 45-9: 30$ & $\begin{array}{l}\text { Higgins M.. Trinity College Dublin, Ireland } \\
N A\end{array}$ \\
\hline $9: 30-9: 50$ & $\begin{array}{l}\text { Schwartz, D., ChemE/UW } \\
\text { Synthesis and Organization of Non-Equilibrium Inorganic } \\
\text { Nanoparticles }\end{array}$ \\
\hline $9: 50-10: 10$ & $\begin{array}{l}\text { Wiley, B. and Xia, Y., ChemE/Chem/UW } \\
\text { Polyol Synthesis of Silver Nanoparticles: The Formation of Single } \\
\text { Crystal, Truncated Cubes and Tetrahedrons }\end{array}$ \\
\hline $10: 10-10: 30$ & $\begin{array}{l}\text { Bao, Y., Pakhomov, A. B., Krishnan, K. M., MSE/UW } \\
\text { A General Approach to Synthesis Nanoparticles with Controlled } \\
\text { Morphologies and Magnetic Properties }\end{array}$ \\
\hline $10: 30-11: 00$ & Break \\
\hline $11: 00-11: 20$ & $\begin{array}{l}\text { Pecher, K., Baer, D., Engelhard, M., and McCready, D., PNNL } \\
\text { Nano-Magnetite: Spectroscopic Facts and Mystery about an Illusive } \\
\text { Mineral Phase }\end{array}$ \\
\hline $11: 20-11: 40$ & $\begin{array}{l}\text { Bryan, J.D. and Gamelin, D., Chem/UW } \\
\text { Strong Room-Temperature Ferromagnetism in Co2+ - Doped TiO2 } \\
\text { Made from Colloidal Nanocrystals }\end{array}$ \\
\hline $11: 40-12: 00$ & $\begin{array}{l}\text { Ginger, D., and Coffey, D., Physics/Chem/UW } \\
\text { Controlling Phase Separation in Conjugated Polymer Blend Films } \\
\text { with Nanolithographic Templates }\end{array}$ \\
\hline
\end{tabular}

12:00 - 2:00 Luncheon and User Facility Lab Tour 
Thursday Afternoon, September 16

Kane Hall 210

\begin{tabular}{|c|c|}
\hline Session B: & Nanobiotech and Nanomedicine (Dave Castner, Chair) \\
\hline $2: 00-2: 45$ & $\frac{\text { Heath, J., Caltech }}{N A}$ \\
\hline $2: 45-3: 05$ & $\begin{array}{l}\text { Kim, J., Kwak, J. H., Dohnalkova, A., and Grate, J. W. } \\
\text { Nanostructures for Enzyme Stabilization }\end{array}$ \\
\hline $3: 05-3: 25$ & $\begin{array}{l}\text { Kohler, N., Sun, C., Fryxell, G., Wang, J., Gupta, D., and M. Zhang, } \\
\text { MSE/UW } \\
\text { Methotrexate Conjugated Nanoparticles for Cancer } \\
\text { Chemotherapeutics and Diagnostics }\end{array}$ \\
\hline $3: 25-3: 45$ & $\begin{array}{l}\text { Baneyx, F., Thai, C. K., Dai, H., Sastry, M. S. R., Sarikaya, M., and } \\
\text { Schwartz, D. T. ChemE/MSE/UW } \\
\text { Identification and Characterization of Cu2O and ZnO Binding } \\
\text { Polypeptides by Escherichia coli Cell Surface Disaplay }\end{array}$ \\
\hline $3: 45-4: 15$ & Break \\
\hline $4: 15-4: 35$ & $\begin{array}{l}\text { Hess, H., Brunner, C., Clemmens, J., Edwards, J., Ernst, K., Nitta, T., } \\
\text { Phillips, S., Ramachandran, S., Tucker, R., Wang, J., Wu, D., and } \\
\text { Vogel, V., BioE/UW } \\
\text { Moving Forward: Nanodevices Powered by Motor Proteins }\end{array}$ \\
\hline $4: 35-4: 55$ & $\begin{array}{l}\text { Thomas, W., Forero, M., Nilsson, L., Vogel, V., and Sokurenko, E., } \\
\text { BioE/UW } \\
\text { Biological Nano-Adhesive that Strengthens with Tensile Force }\end{array}$ \\
\hline $4: 55-5: 15$ & $\begin{array}{l}\text { Lu, P., Biju, V., Micic, M., and Hu, D., PNNL } \\
\text { Intermittent Single-Molecule Interfacial Electron Transfer Dynamics } \\
\text { in Dye-TiO2 Nanoparticle Systems }\end{array}$ \\
\hline
\end{tabular}

$\begin{array}{ll}\text { 5:45 } & \text { Bus Leaving for Dinner Cruise } \\ \text { 7:00-10:00 } & \text { Focus Session Dinner Cruise }\end{array}$


Friday Morning, September 17

Kane Hall 210

\begin{tabular}{|c|c|}
\hline Session C: & Nanocatalysis and Nanoparticles (Charlie Campbell, Chair) \\
\hline $8: 30-9: 15$ & $\begin{array}{l}\text { Schimdt, L., University of Minnesota } \\
\text { Hydrogen from Fossile and Renewable Fuels in Millisecond Reactors }\end{array}$ \\
\hline $9: 15-9: 35$ & $\begin{array}{l}\text { Vestergaard, E. K., Vang, R. T., Schaub, R., Sahlstrom, E., and } \\
\text { Besenbacher, F., University of Aarhus, Denmark } \\
\text { Scanning Tunneling Microscopy Studies of Reactivity and "Active } \\
\text { Sites" at the Nanoscale }\end{array}$ \\
\hline $9: 35-9: 55$ & $\begin{array}{l}\text { Ohta, T., Schmidt, D. A., Lu, C.-Y., Yu, Q., Olmstead, M. A., and } \\
\text { Ohuchi, F. S., MSE/Physics/UW } \\
\text { Controlled Growth of GaxSey Nanostructures }\end{array}$ \\
\hline $9: 55-10: 00$ & $\begin{array}{l}\text { Castner, D. and Qin, D, CNT/UW } \\
\text { Gift Presentation to CNT Founding co-Director, Professor Charles T. } \\
\text { Campbell }\end{array}$ \\
\hline $10: 00-10: 30$ & Break \\
\hline $10: 30-10: 50$ & $\begin{array}{l}\text { Baer. D., Amonette, J. E., Antony, J., Linehan, J. C., Matson, D. W., } \\
\text { Nurmi, J. T., Pcher, K. H., Penn, R. L., Qiang, Y., and Tratnyek, P. G., } \\
\text { PNNL/Oregon Health and Science University, University of } \\
\text { Minnesota, University of Idaho } \\
\text { Physical and Chemical Properties of Iron and Iron-Oxide } \\
\text { Nanoparticles }\end{array}$ \\
\hline $10: 50-11: 10$ & $\begin{array}{l}\text { Lyubinetsky, I., El-Azab, A., Lea, A. S., Thevuthasan, S., and Baer, } \\
\text { D., PNNL } \\
\text { Novel Stages of Growth of Metal Oxide Nanodots: } \mathrm{Cu}_{2} \mathrm{O} \text { and } \\
\text { SrTiO3(100) }\end{array}$ \\
\hline $11: 10-11: 30$ & $\begin{array}{l}\text { Moeck, P., Seipel, B., Qin, W., and Fraundorf, Portland State } \\
\text { Univeristy } \\
\text { Image-based Nanocrystallography by Means of Transmission Electron } \\
\text { Goniometry }\end{array}$ \\
\hline $11: 30-11: 50$ & $\begin{array}{l}\text { Tsemekhman, K., Bylaska, E. J., and Jonsson, H., Chem/UW } \\
\text { Small Polaron in Hematite Fe2O3Predicted by Self-Interaction } \\
\text { Corrected DFT }\end{array}$ \\
\hline
\end{tabular}

12:00 - 2:00 Poster Session and Luncheon 


\section{Friday Afternoon, September 17}

Kane Hall 210

\section{Session D: $\quad$ Nanotechnology and Environment (Don Baer, Chair)}

\begin{tabular}{ll}
\hline \hline 2:00-2:45 & Hipps. K., Washington State University \\
& $\begin{array}{l}\text { The Use of Weak Intermolecular Interactions in the Design of Self- } \\
\text { Assembling Organic Structures on Surfaces }\end{array}$ \\
2:45-3:05 & Gutowski, M., Autrey, T., and Linehan, J., PNNL \\
Hydrogen Storage in the NHxBHx Materials \\
3:05-3:25 & Autrey, T., Gutowska, A., Li, L., Shin, Y., Wang, C., Li, S., \\
& Linehan, J., Smith, R. S., Kay, B., Schmid, B., Gutowski, M., and \\
& Hess, N., PNNL \\
& Nano-Structural Control of Hydrogen Release from Ammonia \\
& Borane \\
& Saraf, L., Matson, D. W., Shutthanandan, V., Wang, C. M., Marina, \\
O., Dirkes, A., Young, J., Azad, S., Mckingley, M. I., and & Thevuthasan, S., PNNL \\
& $\begin{array}{l}\text { Interface Orientation and Oxygen Transport in Ceria-Zirconia } \\
\text { based Electrolyte Films used in Solid Oxide Fuel Cells }\end{array}$ \\
& Linehan, J. C., Autrey, S. T., Fulton, J. F., and Chen, Y., PNNL \\
& In Situ XAFS/NMR Studies of Transition Metal Catalysis for \\
& Dehydrocoupling of Amino Boranes \\
& Ending
\end{tabular}




\section{Poster Session (12:00 - 2:00 PM, September 17) Kane Hall, $2^{\text {nd }}$ Floor}

Shimogawa, M., Iuliana, R., Wei, J., and Cobden, D., Physics/UW

Nonlinear Transport in Carbon Nanotubes

Mestechkin, M., Zubkov, V., and Tsemekhman, K., Chem/UW

Bandgaps of Zigzag Carbon Single-Wall Nnaotubes: Ground State Degeneracy Predicted by ab initio Calculations

Ahn, C. and Dunham, T., Physics/EE/UW

Stress Effects on Dopant Diffusion and Segregation in Silicon

Deng, R. and Dunham, T., Physics/EE/UW

Understanding and Modeling Limits to Conduction in Nanoscale Interconnects in VLSI

Keenan, T., Kosar, F., Boggy, G., and Folch, A., BioE/UW

Nanohole Devices for Chemotaxis Studies

Chen, C. and Folch, A., BioE/UW

Microfluidically Accessible Nanoholes Molded in PDMS Surface for Cellular Analysis

Choi, J., Saripalli, K. P., and Meldrum, D. EE/UW

Development of Cellular Absorptive Tracers (CATs) for a Quantitative Characterization of Microbial Mass in Flow System

Lorenz, R., Kuyper, C. L., Allen, P. B., Lee, L. P., and Chiu, D. T. Chem/UW and UC Berkeley Direct Laser Writing on Electrolessly Deposited Thin Metal Films for Applications in Microand Nanofluidics

Govindarajan, A. V., Chen, T. C., Wyeth, R. C., Willows, A. O. D., and Bohringer, K, EE/UW Interacellular Neuronal Recording with Flexible Micro-Machined Probe Implants

Haranczyk, M., Bachorz, R., Dabkowska, I., Dupuis, M., Miller, J. H., and Gutowski, M. Tools and Methods for Computational Characterization of Damaged Sites in DNA

Tucker, R., Vogel, V., and Hess, H., BioE/UW/ETH

Light Controlled Localized Fuel Delivery for Molecular Shuttles

Nitta, T., and Hess, H., BioE/UW

Fluctuation in Velocity and Direction of Movement of Molecular Shuttles

Wu, D., Tucker, R., and Hess, H., BioE/UW 
Caged ATP, Smart Fuel for Biomolecular Motors

Cooksey, G. A., Chang, A. H., Little, W. C., Mourad, P. D. and Vogel, V., BioE/UW/ETH Thin Cells are Fast: Fibroblast Speed is Modulated by Cell Width, Substratum Adhesivity, and Age within the Cell Cycle

Dai, H., Schwartz, D. T., Choe, W., Nguyen, C., and Baneyx, F. ChemE/UW Synthesis and Assembly of Nanostructured Materials using Genetically Engineered Proteins

Li, L., Chen, S., Zheng, J., Ratner, B. D., and Jiang, S. ChemE/BioE/UW

Protein Adsorption on Oligo(ethlylene glycol) Terminated Alkanethiol Self Assembly

Monolayers: Non-foulding Mechanism on the Molecular Basis

Lee, C.-Y., Gamble, L. J., and Castner, D. G., ChemE/BioE/UW

XPS and ToF-SIMS Characterization of Thiolated Single-Stranded DNA Oligomers SelfAssembled onto Gold Surfaces

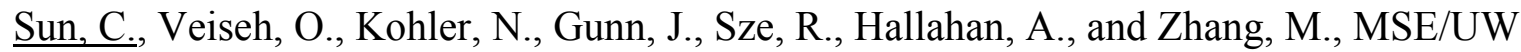
Intracelluar Uptake of Folate Receptor Targeted Superparamagnetic Nanoparticles for Enhanced Tumor Detection by MRI

Gunn, J., Veiseh, O., Sun, C., Ellenbogen, R., Olson, J., Syz, R., Hallahan, A., and Zhang, M., MSE/UW

Superparamagnetic Nanoparticle-bound Chlorotoxin for Brain Tumor Imaging

Sengupta, A., Laucks, M. L., and Davis, E. J., Chem/ChemE/UW

Detection of Biological Species/Bioaerosols by Surface Enhanced Raman Scattering using Nanometallic Surfaces

Tait, S. L., Ngo, L. T., Dohnalek, Z., Yu, Q., Fain, S., Kay, B. and Campbell, C. T., Chem/Physics/UW/PNNL Pd Nanoparticles for Hydrocarbon Catalysis: Particle Sintering by AFM and Particle Size Dependent Methane Dissociation by Molecular Beams

Zhu, J., Diaz, S., Heeb, L. R. and Campbell, C. T., Chem/UW

Calorimetric Adsorption Energies on Thicker Single Crystals: Pb on NiAl(110)

Schmidt, D. A., Ohta, T., Yu, Q., Ohuchi, F. S., and Olmstead, M. A., Physics/MSE/UW Buffer Layer Enhanced Oxide Heteroepitaxy on Si(100)

Polwarth, C., Tait, S. L., Fain, S. C., Physics/UW

Optimizing Non-Contact Atomic Force Microscopy for Model Catalysis Studies 
Wang, Y., Takahashi, K., and Cao, G. Z., MSE/UW

$\mathrm{Ni}_{-} \mathrm{V}_{2} \mathrm{O}_{5} \bullet \mathrm{nH}_{2} \mathrm{O}$ Core-Shell Nanocable Arrays for Electrochemical Pseudocapacitors

Shang, H., Wang, Y., Milbrath, B., Bliss, M. and Cao, G. Z., MSE/UW/PNNL

Doping Effects on Microstructure and Scintillation Properties of Cadmium Tungstate Films

Feaver, A. and Cao, G. Z., MSE/UW

Poros Carbon Materials for Gas Storage

Prowse, M. S., Yamamoto, A., Kukuruznyak, D. A., Lippmaa, M., Chickyow, T., and Ohuchi, S. A., MSE/UW

Advantages Thermoelectric Behavior in Compositionally Graded Co-Doped TiO2 Rutile

Nguyen, N, Chen, W., Prowse, M., Speaks, D. T.and Ohuchi, S. A., MSE/UW

Thermoelectric Transport of the Mn-Cu-Co-Ni Spinel Oxides Process and Nano-Structure

Dependence

$\underline{\text { Suzuki, N., Sarikaya, M., and Ohuchi, S. A., MSE/UW }}$

Interactions of Selected Amino-Acids with Inorganic Substrates Studies by X-Ray Photoelectron Spectroscopy

Yip, H., Ma, H., and Jen, K.-Y. MSE/UW

Controlled Self-Assembly of Aromatic Organophosphoic Acid Monolayer on $\mathrm{SiO}_{2} / \mathrm{Si}$

Zin, M., Xu, Q. Ma, H., and Jen, K.-Y. MSE/UW

Patterned Array of Single-Walled Carbon Nanotubes on Rigid Self-Assembled Monolayers

Kim, T.-D., Luo, J., Haller, M., Kang, J.-W., Tian, Y., and Jen, K.-Y. MSE/UW

New Paradigm to Realize the Full Potential of Organic Electro-Optic Materials

Chen, C., Tian, Y., Haller, M., Tucker, N. M., Luo, J., and Jen, K.-Y. MSE/UW

Novel Nanostructured Functional Electro-optic Block Copolymers

Dong, J., Ma, H., Yip, H., Jen, K.-Y., and Parviz, B, EE/MSE/UW

Fabrication and Characterization of Nano-Junctions Made via Molecular Self-Assembly of Anthryl Phosphonic Acid

Gray, T. and Overney, R., ChemE/UW

Stabilizationof Optoelectronic and Photonic Polymer Materials via Nanorheological

Engineering

McLellan, J., Geissler, M., and Xia, Y., Chem/UW

Edge Spreading Lithography: A New Technique for Nanoscale Fabrication 
Chen, J., Herricks, T., Geissler, M., and Xia, Y., Chem/UW

Synthesis of Single Crystal Platinum Nanowires by Controlling Reaction Rate of a Polyol Process

Babel, A., Zhu, Y., Li, D., Xia, Y., and Jenekhe, S. A., ChemE/Chem/UW Conjugated Polymer Nanowires

Hancock, J., Zhu, Y., and Jenekhe S. A., Chem/ChemE/UW

Studies of Single-Molecule Nanostructures Formed by Conjugated Polymer Bollebrushes

Munro, A. and Ginger, D., Chem/UW

Electrical and Optical Properties of Single Quantum Dots

Chen, Y. and Ginger, D., Chem/UW

Surface Assembly of DNA-Functionalized Gold Nanoparticles

Liu, W. and Gamelin, D. Chem/UW

Photovoltaic Cells Based On Transition Metal Doped Quantum Dots

Norberg, N., Kittilstved, K., Amonette, J. E., Kukkadapul, R. K., Schwartz, D. A., and Gamelin, D. R., Chem/UW/PNNL Colloidal Mn ${ }^{2+}: Z n O$ Quantum Dots and High-Tc Ferromagnetic Thin Film

Griffin, K. A., Pakhomov, A. B., Wang, C. M., Heald, S. M., Shutthanandan, V., Chambers, S. A., and Krishnan, K. M., MES/UW/PNNL Cobalt Doped Anatase $\mathrm{TiO}_{2}$ - A Room Temperature Dilute Magnetic Dielectric Material for Spin-Electronics

Ramachandran, S., Kumar, G. L., Blick, R. H., Weide, D. W., CSE/University of Wisconsin, Madison

Colloidal Quantum Dots Initiate Current Bursts in Lipid Bilayers

Moeck, P., Kapilashrami, M., Rao, A., Browning, N. D., McCann, P. J., Physics/Portland State University

Nominal PbSe Nano-islands on PbTe: Grown by MBE, analyzed by AFM and TEM 


\section{Appendix D}

\section{Syllabi for the Three Intensive Nanoscience Courses}

D1 Nanoclusters, Nanomaterials, and Nanotechnology

Two week introductory course

May 2003

May 2004

D2 Fabrication and Characterization of Nanomaterials January 2004

January 2005

D3 Theory and Modeling of Nanoscale Materials Systems September 2003 


\title{
Appendix D: Syllabi for the Three Intensive Nanoscience Courses
}

\section{D.1 Nanoclusters, Nanomaterials, and Nanotechnologies - May 2003}

\author{
May 19 - 30, 2003 \\ Richland, WA
}

First week: Lai-Sheng Wang (unless otherwise noted)

May 19 13:00 - 13:30 General Introduction and Remarks (Don Baer, Lai-Sheng Wang, Fumio Ohuchi)

Monday $\quad$ 13:40 - 14:30 Introduction to Nanotechnology (Paul Barrows)

May $20 \quad$ 09:00 - 09:50 Introduction to Clusters

Tuesday $\quad 10: 00-10: 50$ Nanocluster generation in the gas phase: molecular beam methods 11:00 - 11:50 Gas aggregation and laser vaporization 13:00 - 13:50 Mass spectrometry study of clusters: size distribution and magic numbers

14:00 - 14:50 Lab: laser vaporization, time-of-flight mass spectrometry, and photoelectron spectroscopy

May $21 \quad$ 09:00 - 09:50 Magic numbers in alkali clusters: the electron shell model

Wednesday 10:00-11:00 Photoionization of metal clusters: the metallic droplet model 11:00 - 11:50 Photoelectron spectroscopy and electronic structure of clusters 13:00 - 13:50 Photoelectron techniques and time-of-flight photoelectron analyzer 14:00 - 14:50 Molecular to bulk transition, nonmetal to metal transitions

May $22 \quad$ 09:00 - 09:50 Transition metal clusters and aluminum clusters

Thursday 10:00 $\quad 10: 50$ Oxide clusters

11:00 - 11:50 Novel clusters and molecules: from clusters to materials

13:00 - 13:50 Chemical reactivity of clusters and cluster surface analogy 14:00 - 14:50 Gold clusters, nano-particles, and special catalytic properties

May 23 09:00 - 09:50 Discovery of Buckyballs, and Properties of fullerenes and fullerites

Friday $\quad 10: 00-10: 50$ Carbon Nanotubes

11:00 - 11:50 Race to Catch a Buckyball: NOVA TV program on $\mathrm{C}_{60}$

13:00 - 13:50 Synthesis and Properties of Nanowires (David McIlroy, U.I.)

14:00 - 14:50 Helical nanosprings (David McIlroy, U.I.)

\section{Second week:}

May $26 \quad$ 09:00 - 10:50 Magnetic nano-films and nanoparticles for use in information storage

Monday (Y. K. Hong, U. of Idaho)

11:00 - 11:50 Nanolithography and nanodevice transport (Chris Berven, U. I.)

D. 1 
13:00 - 14:50 Nanocluster-Assembled Materials: Synthesis, Magnetic Properties Applications (Y. Qiang, U. of Idaho)

15:20 - 17:00 Synthesis of Carbon Nanotubes and Nanowires (Lab: Hai-Feng Zhang)

$\begin{array}{ll}\text { May 27 } & \text { 09:00 }- \text { 09:50 Scanning electron mircoscopy (Jim Young) } \\ \text { Tuesday } & \text { 10:00 - 11:50 SEM of Nanotube samples (Jim Young) } \\ & \text { 13:00 - 13:50 Transmission electron microscopy (Chongmin Wang) } \\ & \text { 14:00 - 17:00 TEM of Nanotube samples (Chongmin Wang) }\end{array}$

May $28 \quad$ 09:00-09:50 Molecular beam epitaxy (Scott Chambers)

Wednesday 10:00-10:50 MBE Lab (Scott Chamber)

11:00 - 11:50 X-ray photoelectron spectroscopy and application to materials (Don Baer)

13:00 - 13:50 XPS Lab (Don Baer)

14:00 - 14:50 Optical Imaging (Holtom)

15:00 - 15:50 Single Molecule/imaging Lab (Holtom)

May $29 \quad$ 09:00-09:50 Unique optical properties of metallic nanoparticles (Peter

$\begin{array}{lll} & & \mathrm{Lu} \text { ) } \\ \text { Thursday } & 10: 00-10: 50 & \text { Scanning tunneling microscopy (Scott Lea) } \\ & 11: 00-11: 50 & \text { STM Lab (Scott Lea) } \\ & 13: 00-13: 50 & \text { Nano-ice films (Jim Cowin) } \\ 14: 00-14: 50 & \text { Nano-ice film Lab (Jim Cowin) }\end{array}$

May $30 \quad$ 09:00 - 09:50 Laser-Surface Interaction (Wayne Hess)

Friday $\quad 10: 00-10: 50 \quad$ Laser Surface Lab (Wayne Hess)

Class ends

\section{Grading:}

1. Assigned reading materials

2. Selected home works

3. A term paper to be turned in by end of summer: propose an experiment or idea relevant to nanomaterials and nanotechnology. Give background information, motivation, experimental design and proposed procedures, and expected outcomes. The paper can be an improvement or refinement of an existing idea or experiment from the literature. Total Length: 10-15 pages (12 point font, double space, 1-inch margin) for text, tables, figures/illustrations, and references.

Format:

1. Title, name

4. Background information

2. Abstract

5. experimental design and procedures

3. Objectives

6. expected outcomes and conclusions 


\section{Nanoclusters, Nanomaterials, and Nanotechnologies - May 2004}

\section{May 17-28, 2004 \\ Richland, WA}

Lecture Locations: EMSL 1075

\section{First week: Lai-Sheng Wang}

$\begin{array}{ll}\text { May 17 } & 08: 30-09: 30 \text { Badging } \\ \text { Mon } & \text { 09:30 - 10:00 General introduction (Don, Fumio, Lai-Sheng) } \\ & \text { 10:00 - 10:50 Introduction to Nanoscience (Don Baer) } \\ & \text { 11:00 - 11:50 Gas phase clusters and the molecular beam methods } \\ & \text { 12:00 - 13:00 Lunch } \\ & 13: 00-13: 50 \text { Gas aggregation and laser vaporization } \\ & 14: 00-14: 50 \text { Mass spectrometry study of clusters: size distribution and magic } \\ \text { numbers } & \end{array}$

15:00 - 17:00 Discussion of lab projects and term papers

May $18 \quad 09: 00-09: 50$ Magic numbers in alkali clusters: the electron shell model

Tue 10:00 - 10:50 Photoelectron spectroscopy and electronic structure of clusters 11:00 - 11:50 Clusters as novel molecules: aromaticity and antiaromaticity

12:00 - 13:00 Lunch

13:00 - 17:00 Lab projects

May 19 09:00 - 09:50 Building larger clusters: molecular to bulk transition

Wed $\quad 10: 00-10: 50$ Clusters of transition metals, Al, and Si

11:00 - 11:50 Oxide clusters: models for bulk surfaces and defect sites

12:00 - 13:00 Lunch

13:00 - 13:50 Boron clusters - small is different

14:00 - 14:50 Gold clusters, nano-particles, and special catalytic properties

15:00 - 17:00 Lab projects

May $20 \quad$ 09:00 - 09:50 Novel clusters and molecules: from clusters to materials

Thu 10:00 - 10:50 Nanocluster assembled materials (You Qiang) 11:00 - 11:50 Nanocluster assembled materials (You Qiang) 
12:00 - 13:00 Lunch

13:00 - 17:00 Lab projects

May $21 \quad$ 09:00 - 09:50 Discovery of Buckyballs, and Properties of fullerenes and fullerites

Fri

10:00 - 10:50 Carbon Nanotubes

11:00 - 11:50 Race to Catch a Buckyball: NOVA TV program on the discovery

of $\mathrm{C}_{60}$

12:00 - 13:00 Lunch

13:00 - 13:50 Semiconducting junction properties (Fumio Ohuchi)

14:00 - 15:50 MOS and MOSFET device structures (Fumio Ohuchi)

15:00 - 17:00 Lab projects

May 22 Saturday, Barbecue

Second week

May $24 \quad$ 09:00 - 09:50 Scanning electron microscopy (Jim Young)

Mon $\quad 10: 00-10: 50$ Nanolithography and nanodevice transport (Chris Berven)

11:00 - 11:50 Nanolithography and nanodevice transport (Chris Berven)

12:00 - 13:00 Lunch

13:00 - 17:00 Lab projects

19:00 - 19:50 X-ray photoelectron spectroscopy (Don Baer)

20:00 - 20:50 X-ray photoelectron spectroscopy (Don Baer)

May $25 \quad$ 09:00 - 09:50 Transmission electron microscopy (Chongmin Wang)

Tue $\quad 10: 00-10: 50$ Synthesis and Properties of Nanowires (David Mcllroy)

11:00 - 11:50 Helical nanosprings (David McIlroy)

12:00 - 13:00 Lunch

13:00 - 17:00 Lab projects

19:30 - 20:30 Informal discussion of lab projects

May $26 \quad$ 09:00 - 09:50 Scanning probe microscopy (Scott Lea)

Wed 10:00 - 10:50 Scanning probe microscopy (Scott Lea)

11:00 - 11:50 Molecular beam epitaxy (Scott Chamber) 


$$
\begin{aligned}
& \text { 12:00 - 13:00 Lunch } \\
& \text { 13:00 - 13:50 Molecular beam epitaxy (Scott Chamber) } \\
& \text { 14:00 - 14:50 Nanobio (Cindy Bruckner-Lea) } \\
& \text { 15:00 - 17:00 Lab projects }
\end{aligned}
$$

May $27 \quad$ 09:00 - 09:50 Nanosensors (Yuehe Lin)

Thu 10:00 - 10:50 Nano Ice films (Jim Cowin)

11:00 - 11:50 Nano Ice films (Jim Cowin)

12:00 - 13:00 Lunch

13:00 - 13:50 Single molecule spectroscopy and near-field scanning optical microscopy (Peter Lu)

14:00 - 14:50 Single molecule spectroscopy and near-field scanning optical microscopy (Peter Lu)

15:00 - 17:00 Small projects

May $28 \quad$ 09:00 - 09:50 MBE and oxide thin films (Zdenek Dohnalek)

Fri 10:00 - 10:50 MBE and oxide thin films (Zdenek Dohnalek) 11:00 - 11:50 Laser surface interactions (Wayne Hess)

12:00 - 13:00 Lunch

13:00 - 17:00 Discussion and presentation of projects and term papers

17:00 Class ends

\section{Grading:}

1. Assigned reading materials

2. Selected quizzes

3. Small team projects (three members/team) and a term paper and presentation. 


\section{D.2 Fabrication and Characterization of Nanomaterials - January 2004}

\section{January 5-23, 2004}

Richland, Washington

Coordinators: $\quad$ Prof. F. S. Ohuchi -UW, Dr. D. R. Baer -PNNL, Prof. L-S. Wang -WSU

Small projects for January nano-synthesis and characterization course. During week 1 of the course, three types of specimens will be synthesized. These will involve a nanofilm formed by MBE, and oxide nanostructure, and a nanostructured solgel film. Each course participant will be directly involved with one of these synthesis activities. These activities will be lead by:

1) Nanofilm - Tim Droubay, Josh Williams

2) Oxide nanostructures - Theva Thevuthasan, Igor Lyubinetsky

3) SolGel Film, Lax Saraf.

The end of week 1 and week 2 will focus on characterization of the three nanostructures by five different methods. Each course participant will see each of the methods, but will focus on one. These teams will be led as follows:

1) Electron Spectroscopy - Mark Engelhard, Scott Lea, and Don Baer

2) Ion Beam methods - Theva Thevuthasan and Shutta Shutthanandan

3) X-ray Methods - Josh Williams and Dave McCready

4) TEM/SEM - Chongmin Wang and Jim Young

5) SPM Scott Lea and Igor Lyubinetsky.

The small project activity in week three will involve integration of the characterization methods to understand the nature of the synthesized materials. A series of synthesis or process questions will be posed at the start of the study as the objectives of the analyses. The students will prepare a report summarizing the results and make a short presentation on the final day of the course. 


\begin{tabular}{|c|c|}
\hline $1 \mathrm{pm}$ to $1: 50 \mathrm{pm}$ & $\begin{array}{l}\text { Day } 1 \text { January } 5 \text { (Monday) } \\
\text { Course introduction (Don Baer) }\end{array}$ \\
\hline $2 \mathrm{pm}$ to $2: 50 \mathrm{pm}$ & $\begin{array}{l}\text { Approaches, limitations \& Challenges to nanosystem formation (Don Baer and/or } \\
\text { Paul Burrows) }\end{array}$ \\
\hline $3 \mathrm{pm}$ to $4: 30 \mathrm{pm}$ & $\begin{array}{l}\text { Small-Project Descriptions and initial Reading Assignments } \\
\text { Synthesis Task leads: 1) Nanofilm - Tim Droubay, Josh Williams 2) Oxide } \\
\text { nanostructures - Theva Thevuthasan, Igor Lyubinetsky, 3) SolGel, Lax Saraf }\end{array}$ \\
\hline 7:pm to $8 \mathrm{pm}$ & $\begin{array}{l}\text { Nano Clusters Lecture I (L-S Wang) } \\
\text { Day } 2 \text { January } 6 \text { (Tuesday) }\end{array}$ \\
\hline 9:00 to $9: 30$ am & Quiz 1 \\
\hline $9: 40$ am to $10: 40 \mathrm{am}$ & Nano Clusters Lecture II (L-S Wang) \\
\hline 10:50 am 11:50 am & Lab visit - Nano Clusters \\
\hline $1 \mathrm{pm}$ to $1: 50 \mathrm{pm}$ & MBE Lecture I Films Chambers/Droubay \\
\hline $2 \mathrm{pm}$ to $2: 50 \mathrm{pm}$ & MBE lab tours \\
\hline $\begin{array}{l}3 \mathrm{pm} \text { to } 5: 00 \mathrm{pm} \\
7: \mathrm{pm} \text { to } 8 \mathrm{pm}\end{array}$ & $\begin{array}{l}\text { Film growth for small projects } \\
\text { MBE Nano-Films, MBE nanostructures, SolGel } \\
\text { MBE Lecture II - Nanostructures Thevuthasan/Lyubinetsky } \\
\text { Day } 3 \text { January } 7 \text { (Wednesday) }\end{array}$ \\
\hline 9:00 to $9: 30$ am & Quiz 2 \\
\hline $9: 40$ am to $10: 40 \mathrm{am}$ & Supramolecular Chemistry I Rafail Khairoutdinov \\
\hline 10:50 am 11:50 am & Supramolecular Chemistry II Rafail Khairoutdinov \\
\hline $1 \mathrm{pm}$ to $1: 50 \mathrm{pm}$ & XRD Lecture Josh Williams \\
\hline $2 \mathrm{pm}$ to $2: 50 \mathrm{pm}$ & XRD lab tour Dave McCready \\
\hline $3 \mathrm{pm}$ to $5: 00 \mathrm{pm}$ & $\begin{array}{l}\text { Synthesis activities and/or XRD analysis } \\
\text { Day } 4 \text { January } 8 \text { (Thursday) }\end{array}$ \\
\hline $\begin{array}{l}9: 00 \text { to } 9: 30 \text { am } \\
9: 40 \text { am to } 10: 40 \text { am }\end{array}$ & $\begin{array}{l}\text { quiz } 3 \\
\text { SEM Lecture Jim Young }\end{array}$ \\
\hline 10:50 am 11:50 am & TEM Lecture I Chongmin Wang \\
\hline $1 \mathrm{pm}$ to $1: 50 \mathrm{pm}$ & TEM Lecture II Chongmin Wang \\
\hline $2 \mathrm{pm}$ to $2: 50 \mathrm{pm}$ & Tour of SEM/TEM labs \\
\hline $3 \mathrm{pm}$ to $5: 00 \mathrm{pm}$ & XRD/Synthesis/Start TEM Cross section \\
\hline 7:pm to $8 \mathrm{pm}$ & $\begin{array}{l}\text { Scanning Probe Lecture } 1 \text { STM Lyubinetsky } \\
\text { Day } 5 \text { January } 9 \text { (Friday) }\end{array}$ \\
\hline 9:00 to $9: 30$ am & Quiz 4 \\
\hline $9: 40$ am to $10: 40$ am & Scanning Probe Lecture II Atomic Force Microscopy - Lea \\
\hline 10:50 am 11:50 am & SPM lab tours \\
\hline $1 \mathrm{pm}$ to $1: 50 \mathrm{pm}$ & Ion Beams I cluster formation - Thevusthasan and team \\
\hline $2 \mathrm{pm}$ to $2: 50 \mathrm{pm}$ & Ion Beam Analysis Shutta or Theva \\
\hline $3: 00 \mathrm{pm}$ to $4: 00 \mathrm{pm}$ & Accelerator Tour \\
\hline $4: 00 \mathrm{pm}$ & $\begin{array}{l}\text { Odds and ends - Sample prep/synthesis/XRD/TEM } \\
\text { Day } 6 \text { January } 12 \text { (Monday) }\end{array}$ \\
\hline $9: 00$ to $9: 30$ am & Quiz 5 \\
\hline $9: 40 \mathrm{am}$ to $10: 40 \mathrm{am}$ & XPS Don Baer and Mark Engelhard \\
\hline 10:50 am 11:50 am & AES - A. Scott Lea \\
\hline $1 \mathrm{pm}$ to $1: 50 \mathrm{pm}$ & XPS AES and SIMS lab tour \\
\hline & $\begin{array}{l}\text { Characterization Task/Project Activities Task Leads 1) XPS Mark and Don, 2) } \\
\text { RBS - Theva and Shutta, 3) XRD - Josh and Dave, 4) TEM/SEM - Chongmin and }\end{array}$ \\
\hline $2 \mathrm{pm}$ to $5: 00 \mathrm{pm}$ & Jim, 5) SPM Scott and Igor \\
\hline 7:pm to $8 \mathrm{pm}$ & AFM and SERS H. Peter Lu \\
\hline & Day 7 January 13 (Tuesday) \\
\hline $9: 00$ to $9: 30$ am & Quiz 6 \\
\hline $9: 40$ am to $10: 40 \mathrm{am}$ & CVD - Saraf or Aardahl \\
\hline
\end{tabular}




\begin{tabular}{|c|c|}
\hline 10:50 am 11:50 am & Carbon Nanotubes - Feng (Richard) Zheng \\
\hline $1 \mathrm{pm}$ to $1: 50 \mathrm{pm}$ & Self Assembly - SAMS Glen Fryxell \\
\hline $2 \mathrm{pm}$ to $2: 50 \mathrm{pm}$ & SAMMS Glen Fryxell and/colleagues \\
\hline $3 \mathrm{pm}$ to $5: 00 \mathrm{pm}$ & Characterization Activities \\
\hline 7:pm to $8 \mathrm{pm}$ & $\begin{array}{l}\text { Filaments, Nanosprings and Ribbons - Haifeng Zhang } \\
\text { Day } 8 \text { January } 14 \text { (Wednesday) }\end{array}$ \\
\hline 9:00 to $9: 30$ am & Quiz \\
\hline $9: 40$ am to $10: 40 \mathrm{am}$ & Single Enzyme Nanoparticles I JB KIM \\
\hline 10:50 am 11:50 am & Single Enzyme Nanoparticles II \\
\hline $1 \mathrm{pm}$ to $1: 50 \mathrm{pm}$ & Characterization Tasks - Coordinate with team leads \\
\hline & Day 9 January 15 (Thursday) \\
\hline 9:00 to $9: 30 \mathrm{am}$ & Quiz 7 \\
\hline $9: 40$ am to $10: 40 \mathrm{am}$ & Ballistic Deposition I - Kay or Dohnalak \\
\hline 10:50 am 11:50 am & Ballistic Deposition II \\
\hline $1 \mathrm{pm}$ to $1: 50 \mathrm{pm}$ & Ballistic Deposition Lab tour and Characterization Activities \\
\hline 7:pm to $8 \mathrm{pm}$ & Special Lecture? \\
\hline & Day 10 January 16 (Friday) \\
\hline $1 \mathrm{pm}$ to $1: 50 \mathrm{pm}$ & Visit UW nanotech center \\
\hline & Day 11 January 19 (Monday) \\
\hline $9: 00$ to $9: 30 \mathrm{am}$ & Quiz \\
\hline $9: 40$ am to $10: 40 \mathrm{am}$ & XAS measurements Pecher and Droubay \\
\hline 10:50 am 11:50 am & XAS II \\
\hline $1 \mathrm{pm}$ to $1: 50 \mathrm{pm}$ & Nano/Films Organic I Burrows \\
\hline $2 \mathrm{pm}$ to $2: 50 \mathrm{pm}$ & Nano Films Organic II \\
\hline $3 \mathrm{pm}$ to $4: 30 \mathrm{pm}$ & Particle Sizing and Counting - Pecher \\
\hline 7:pm to $8 \mathrm{pm}$ & Report preparation \\
\hline & Day 12 January 20 (Tuesday) \\
\hline $9: 40$ am to $10: 40 \mathrm{am}$ & Sol gel (Cao) \\
\hline 10:50 am 11:50 am & Electrochemical Etching - Lax Saraf \\
\hline $1 \mathrm{pm}$ to $1: 50 \mathrm{pm}$ & Sol gel $(\mathrm{Cao})$ \\
\hline $2 \mathrm{pm}$ to $2: 50 \mathrm{pm}$ & Clean Room Visit? \\
\hline $3 \mathrm{pm}$ to $5: 00 \mathrm{pm}$ & Report and Presentation work \\
\hline 7:pm to $8 \mathrm{pm}$ & Report prep help session \\
\hline & Day 13 January 21 (Wednesday) \\
\hline $9: 00$ to $9: 30 \mathrm{am}$ & Quiz \\
\hline $9: 40$ am to $10: 40 \mathrm{am}$ & Particle Synthesis - Linehan \\
\hline 10:50 am 11:50 am & Nanoparticle Formation II \\
\hline $1 \mathrm{pm}$ to $1: 50 \mathrm{pm}$ & Project time \\
\hline & Day 14 January 22 (Thursday) \\
\hline $9: 40$ am to $10: 40 \mathrm{am}$ & NMR TBD \\
\hline 10:50 am 11:50 am & Magnetic Measurements Tim Droubay \\
\hline $1 \mathrm{pm}$ to $1: 50 \mathrm{pm}$ & Interface Defects, F. S. Ohuchi \\
\hline $2 \mathrm{pm}$ to $2: 50 \mathrm{pm}$ & Magnetic Nanoparticles I - You Qiang \\
\hline $3 \mathrm{pm}$ to $4: 30 \mathrm{pm}$ & Magnetic Nanoparticles II - You Qiang \\
\hline 7:pm to $8 \mathrm{pm}$ & Ohuchi's lecture (Interface Defects) discussion \\
\hline & Day 15 January 23 (Friday) \\
\hline $9: 00$ to $9: 30$ am & Final Report and Prep Preparation \\
\hline 10:00 to noon & Presentations on synthesis and characterization of three $\mathrm{m}$ \\
\hline
\end{tabular}




\section{Fabrication and Characterization of Nanomaterials}

January 4-21, 2005

Richland, Washington

\begin{tabular}{|c|c|}
\hline & Day 1 January 4 (Tuesday) \\
\hline 9:40 am to $10: 40$ am & check in and badging \\
\hline 10:50 am 11:50 am & \\
\hline Lunch & \\
\hline $1 \mathrm{pm}$ to $1: 50 \mathrm{pm}$ & Course introduction (Don Baer) \\
\hline $2 \mathrm{pm}$ to $2: 50 \mathrm{pm}$ & Approaches, limitations \& Challenges to nanosystem formation (Paul Burrows) \\
\hline & Small-Project Descriptions and initial Reading Assignments \\
\hline & Synthesis Task leads: 1) Nanofilm - Tim Droubay, 2) CeO2 nanostructures - Lax \\
\hline & Saraf, Theva Thevuthasan, and Don Baer, 3) Co on Si and silicide layers - \\
\hline $3 \mathrm{pm}$ to $4: 30 \mathrm{pm}$ & Yanwen Zhang and Lax Saraf \\
\hline 7:00 7:45 pm & Get acquainted time \\
\hline $7: 45 \mathrm{pm}$ to $8: 45 \mathrm{pm}$ & Nano Clusters Lecture I (L-S Wang) \\
\hline & Day 2 January 5 (Wednesday) \\
\hline 9:00 to $9: 30$ am & Quiz 1 \\
\hline $9: 40$ am to $10: 40 \mathrm{am}$ & Nano Clusters Lecture II (L-S Wang) \\
\hline 10:50 am 11:50 am & Lab visit - Nano Clusters \\
\hline Lunch & \\
\hline $1 \mathrm{pm}$ to $1: 50 \mathrm{pm}$ & Nanoparticle Synthesis I - You Qiang \\
\hline $2 \mathrm{pm}$ to $2: 50 \mathrm{pm}$ & Nanoparticle Synthesis II - You Qiang \\
\hline $3 \mathrm{pm}$ to $5: 00 \mathrm{pm}$ & Small Project Growth Studies \\
\hline & Day 3 January 6 (Thursday) \\
\hline 9:00 to $10: 00$ am & Nanofabrication and Characterization at WSU (Prof. KW Hipps WSU) \\
\hline $10: 10$ am to $11: 10 \mathrm{am}$ & Self organized layered nanostructures (Prof. KW Hipps WSU) \\
\hline $11: 20$ am 11:50 am & Quiz 2 and update \\
\hline Lunch & \\
\hline $1 \mathrm{pm}$ to $1: 50 \mathrm{pm}$ & Introduction to XPS (Don Baer) \\
\hline $2 \mathrm{pm}$ to $2: 50 \mathrm{pm}$ & Small Project Time \\
\hline $3 \mathrm{pm}$ to $5: 00 \mathrm{pm}$ & Small Project Time \\
\hline $7: 30 \mathrm{pm}$ to $8: 30 \mathrm{pm}$ & XPS/Multi-Techniques - nanostructure challenges (Don Baer) \\
\hline & Day 4 January 7 (Friday) \\
\hline 9:00 to $9: 50$ am & SEM Lecture (Bruce Arey) \\
\hline $10: 00$ to $10: 50 \mathrm{am}$ & Introduction to AES - (Scott Lea $)$ \\
\hline 11:00 am 11:50 am & TEM Lecture I (Chongmin Wang) \\
\hline Lunch & \\
\hline $1 \mathrm{pm}$ to $1: 50 \mathrm{pm}$ & TEM Lecture II (Chongmin Wang) \\
\hline $2 \mathrm{pm}$ to $3: 30 \mathrm{pm}$ & Tour of SEM/TEM/AES/XPS labs \\
\hline $3: 30 \mathrm{pm}$ to $5: 00 \mathrm{pm}$ & Small project time \\
\hline 7:pm to $8 \mathrm{pm}$ & Open \\
\hline
\end{tabular}




\begin{tabular}{|c|c|}
\hline & Day 5 January 10 (Monday) \\
\hline 9:00 to $9: 30 \mathrm{am}$ & Quiz 3 and update \\
\hline $9: 40$ am to $10: 40$ am & Scanning Probe Lecture I Scanning Tunneling Microscopy - (Igor Lyubinetsky) \\
\hline $\begin{array}{l}\text { 10:50 am 11:50 am } \\
\text { Lunch }\end{array}$ & Scanning Probe Lecture II Atomic Force Microscopy - (Scott Lea) \\
\hline $1: 00$ to $1: 50$ & SPM lab tour (Scott Lea and Igor Lyubinetsky) \\
\hline $2 \mathrm{pm}$ to $2: 50 \mathrm{pm}$ & $\begin{array}{l}\text { Small Project Characterization status and planning Characterization Task/Project } \\
\text { Activities Task Leads 1) XPS Mark and Don, 2) RBS Yanwen, 3) XRD -Dave, } \\
\text { 4) TEM/SEM - Chongmin and Bruce, 5) SPM Scott and Igor }\end{array}$ \\
\hline $\begin{array}{l}3 \mathrm{pm} \text { to } 5: 00 \mathrm{pm} \\
7: 30-8: 30 \mathrm{pm}\end{array}$ & $\begin{array}{l}\text { Small projects } \\
\text { Single molecule spectroscopy and } \\
\text { near-field scanning optical microscopy (Peter Lu) }\end{array}$ \\
\hline & Day 6 January 11 (Tuesday) \\
\hline 9:00 to $9: 50$ am & Ion Beams I cluster formation - Thevusthasan and/or Zhang \\
\hline $10: 00$ am to $10: 50 \mathrm{am}$ & Ion Beam Analysis (Yanwen Zhang) \\
\hline $\begin{array}{l}\text { 11:00 am 11:50 am } \\
\text { Lunch }\end{array}$ & Accelerator Tour (Yanwen Zhang) \\
\hline $1 \mathrm{pm}$ to $1: 50 \mathrm{pm}$ & XRD Lecture (Josh Williams) \\
\hline $2: 00$ to $2: 50 \mathrm{pm}$ & XRD lab tour (Dave McCready) \\
\hline $3 \mathrm{pm}$ to $5: 00 \mathrm{pm}$ & Characterization Task/Project Activities \\
\hline $7: 30 \mathrm{pm}$ to $8: 30 \mathrm{pm}$ & Open \\
\hline & Day 7 January 12 (Wednesday) \\
\hline 9:00 to $9: 30 \mathrm{am}$ & Quiz 4 \\
\hline 9:40 am to $10: 40$ am & Molecular beam epitaxy I (Scott Chambers) \\
\hline $\begin{array}{l}\text { 10:50 am 11:50 am } \\
\text { Lunch }\end{array}$ & Molecular beam epitaxy II (Scott Chambers) \\
\hline $1 \mathrm{pm}$ to $1: 50 \mathrm{pm}$ & NMR of Nanosystems - (Herman Cho) \\
\hline 2:00 to $5: 00$ & Projects \\
\hline 7:pm to $8 \mathrm{pm}$ & Oxide Nanostructures (Igor Lyubinetsky) \\
\hline & Day 8 January 13 (Thursday) \\
\hline $9: 00$ to $9: 50 \mathrm{am}$ & Bucky Ball and nanotubes I (Leo Fifeld/Richard Zheng) \\
\hline $9: 40$ am to $10: 40$ am & Functionalized Nanotubes - (Leo Fifeld) \\
\hline $\begin{array}{l}\text { 10:50 am 11:50 am } \\
\text { Lunch }\end{array}$ & Electrochemical Etching for Nanostructaures (Lax. Saraf) \\
\hline $1 \mathrm{pm}$ to $1: 50 \mathrm{pm}$ & Molecular Electronics (Babak Parviz) \\
\hline $2 \mathrm{pm}$ to $5: 00 \mathrm{pm}$ & Small Projects \\
\hline & Day 9 January 14 (Friday) \\
\hline 9:00 to $9: 50 \mathrm{am}$ & Chemical Vapor Deposition (Lax Saraf) \\
\hline 9:40 am to $10: 40 \mathrm{am}$ & UW Characterization and Synthesis (Lara Touryan) \\
\hline $\begin{array}{l}\text { 10:50 am 11:50 am } \\
\text { Lunch }\end{array}$ & UW Characterization and Synthesis (Lara Touryan) \\
\hline $1 \mathrm{pm}$ to $1: 50 \mathrm{pm}$ & Interfaces and Defects I (Fumio Ohuchi) \\
\hline $2 \mathrm{pm}$ to $2: 50 \mathrm{pm}$ & Interfaces and Defects II (Fumio Ohuchi) \\
\hline $3 \mathrm{pm}$ to $5: 00 \mathrm{pm}$ & Projects \\
\hline
\end{tabular}


Day 10 January 17 (Monday)

Self Assembly and SAMS (Glen Fryxell)

10:00 am to 10:50 am SAMMS (Glen Fryxell)

11:50 am 11:50 am Single Enzyme Nanoparticles I JB KIM

Lunch

$1 \mathrm{pm}$ to $1: 50 \mathrm{pm} \quad$ Single Enzyme Nanoparticles II

$2 \mathrm{pm}$ to $5: 00 \mathrm{pm} \quad$ Small Projects

7:30 pm to 8:30 pm Materials for Sensors (Yuehe Lin)

Day 11 January 18 (Tuesday)

9:00 to 9:50 am X-ray Adsorption Spectroscopy (K Pecher and T Droubay)

9:40 am to 10:40 am X-ray Adsorption Spectroscopy (K Pecher and T Droubay)

10:50 am 11:50 am Buckey Balls and Carbon Nanotubes (Leo Fifield)

Lunch

$1 \mathrm{pm}$ to $1: 50 \mathrm{pm}$

Buckey Balls and Carbon Nanotubes (Leo Fifield)

$2 \mathrm{pm}$ to $5: 00 \mathrm{pm}$

$7: 30 \mathrm{pm}$ to $8 \mathrm{pm}$

Project Status (Don Baer)

9:00 to 9:30 am Quiz5

Day 12 January 19 (Wednesday)

10:50 am 11:50 am

Particle Solution Synthesis - (John Linehan)

Lunch

$1 \mathrm{pm}$ to $1: 50 \mathrm{pm} \quad$ Magnetic Properties (Tim Droubay)

$2 \mathrm{pm}$ to $5: 00 \mathrm{pm} \quad$ Small Projects

7:pm to $8 \mathrm{pm} \quad$ Report prep help session

Day 13 January 20 (Thursday)

9:00 to 9:50 am Catalysis - Nanochemistry I (Cathy Chin)

9:40 am to 10:40 am Catalysis - Nanochemistry II (Cathy Chin)

10:50 am 11:50 am Ballistic Deposition I (Zdenek Dohnalek)

Lunch

$1 \mathrm{pm}$ to $1: 50 \mathrm{pm} \quad$ Ballistic Deposition II (Zdenek Dohnalek)

$2 \mathrm{pm}$ to $2: 50 \mathrm{pm} \quad$ Project time

$3 \mathrm{pm}$ to $4: 30 \mathrm{pm}$

$: 30 \mathrm{pm}$ to $8: 30 \mathrm{pm} \quad$ Presentation Help?

9:30 am to Noon Project Presentations - conducted like a group meeting 


\title{
D.3 Theory and Modeling of Nanoscale Material Systems - Sept. 2003
}

\author{
University of Washington-Pacific Northwest National \\ Laboratory-NSF Intensive Course in Nanoscience \\ September 16-20 Seattle WA
}

Course Objective: To offer a theory perspective in areas related to the structure, stability, and functional characteristics of nanoscale materials, and the connection of this theory to physically based models and multiple scales (atomic, mesoscale, continuum). Primary emphasis will be on solid-state nanoscale materials such as quantum dots, self-assembled mono-layers, and thin films. The course will consist of lecture-type presentations on theoretical developments in the areas of synthesis, structure, and properties followed by guided hands-on investigation of specific application examples, culminating with an extensive individual project in one of the course topic areas.

Prerequisites: $\quad$ Exposure to basic statistical thermodynamics (e.g., PHYS 224, PHYS 328, PHYS 524, MSE 321, MSE 525, EE 539, Chem E 326, Chem E 525, ME 521, or CHEM 456) and introductory quantum mechanics (e.g., PHYS 225, Phys 315, PHYS 324, MSE 351, EE 482, MSE 565, EE 531, ME 522, or CHEM 455).

Instructor(s): $\quad$ Anter El-Azab (PNNL) \& Scott Dunham (UW)

Listing: UW EE 539N (Electrical Engineering, Topics in Solid State)

Location: UW campus, EE/CSE Building Room EE1 042

Time: 8:30am-5:30pm, Sept.16-20, plus follow-on project consultations, seminars.

Readings: Course packet with papers from literature plus course notes.

Student Evaluation: 4 short quizzes covering reading material and course content (20\%), 5 lab reports $(30 \%)$, project $(50 \%)$.

Registration: $\quad 3$ quarter credits, 2 semester credits ( 20 hours of lecture, 20 hours of lab/discussion plus consultations on project).

Lecture Content

- Important nanoscale systems and their novel properties (clusters, dots, films) (2 hours).

- Nucleation and growth: diffusion of atoms, nucleation theory, crystal growth (4 hours).

- Elastic (epitaxial and compositional) stresses and their distribution in model nanoscale systems; effects of stress on structure and properties of quantum dots and films (2 hours)

- Self-organization: morphological and compositional nanoscale pattern formation (2 hours).

- Atomic-scale theory of nanostructures (2hours).

- Computational modeling: structure and stability (molecular dynamics, multiscale approaches) (2 hours).

- Mechanical, lattice dynamics, cluster properties (2 hours)

- Electronic/optical/magnetic properties of nanostructures (quantum effects) (4 hours)

Lab projects:

D. 12 
Lab \#1: Classical (continuum) nucleation and growth

Lab \#2: Formation of self-assembled arrays of III-V semiconductor quantum dots.

Lab \#3: Pattern formation in self-assembled alloy monolayers.

Lab \#4: Molecular dynamics simulations of material structure and properties.

Lab \#5: Quantum dots and Coulomb blockade devices.

Up to date and additional information can be found at

www.nano.washington.edu/pnnl/courses.html while the registration site is

http://www.engr.washington.edu/epp/nano/.

D.13 


\section{Appendix E}

\section{Joint Institute for Nanoscience Steering Committee and \\ Joint Institues Council of Fellows and Advisory Board}




\section{Appendix E: JIN Organization}

Joint Institute for Nanoscience Steering Committee:

\begin{tabular}{|l|l|}
\hline From the University of Washington: & $\begin{array}{l}\text { From Pacific Northwest National } \\
\text { Laboratory }\end{array}$ \\
$\begin{array}{l}\text { Charles Campbell (Co-Director) } \\
\text { Professor, Chemistry }\end{array}$ & $\begin{array}{l}\text { Donald Baer (Co-Director) Fellow } \\
\text { Interfacial Chemistry and Engineering }\end{array}$ \\
$\begin{array}{l}\text { Karl Bohringer (2001 - 2004) } \\
\text { Associate Professor, Electrical Engineering }\end{array}$ & $\begin{array}{l}\text { Eric Ackerman, Staff Scientist } \\
\text { Protein Function }\end{array}$ \\
$\begin{array}{l}\text { Dan Gamelin (starting 2004) } \\
\text { Assistant Professor, Chemistry }\end{array}$ & $\begin{array}{l}\text { Paul Burrows, Fellow } \\
\text { Materials Chemistry and Surface Research }\end{array}$ \\
$\begin{array}{l}\text { Samson Jenekhe } \\
\text { Professor, Chemical Engineering }\end{array}$ & $\begin{array}{l}\text { Bruce Kay, Fellow } \\
\text { Chemical Structure and Dynamics }\end{array}$ \\
Shaoji Jiang (2001- 2003) & H. Peter Lu, Senior Research Scientist \\
Associate Professor, Chemical Engineering & Chemical Structure and Dynamics \\
Marjorie Olmstead (starting 2004) & \\
Professor, Physics & \\
Younan Xia (2001 - 2004) & \\
Associate Professor, Chemistry & \\
Miqin Zhang (starting 2003) & \\
Engineering & \\
\hline
\end{tabular}


Joint Institutes Advisory Board Members (2001-2004)

\begin{tabular}{|l|l|}
\hline University of Washington: & PNNL: \\
$\begin{array}{l}\text { Albert Berger } \\
\text { Associate Dean, Office of Research and } \\
\text { Graduate Education } \\
\text { Professor, Physiology and Biophysics }\end{array}$ & $\begin{array}{l}\text { Walter Apley } \\
\text { Associate Laboratory Directory, } \\
\text { Environmental Technology } \\
\text { Interim Laboratory Director (deceased) }\end{array}$ \\
$\begin{array}{l}\text { Denice Dee Denton } \\
\text { Dean, College of Engineering } \\
\text { Professor, Electrical Engineering }\end{array}$ & John Bagley \\
Craig Hogan & Director of External Relations \\
Vice Provost for Research, Office of the & Jean Futrell \\
Provost & Battelle Fellows, Chair PNNL Council of \\
Professor, Physics and Astronomy & Fellows \\
Alvin Kwiram & Michael Kluse \\
Professor, Chemistry & Associate Laboratory Director for National \\
Vice Provost for Research Emeritus & Security \\
Marsha Landolt & J.W. Rogers \\
Dean of Graduate School (deceased) & Chief Research Officer \\
& \\
\hline
\end{tabular}

